\title{
Functional properties of the plasma membrane of human glioma initiating cells
}

\author{
PhD Thesis \\ in partial fulfillment of the requirements \\ for the degree "Doktor rerum naturalium (Dr. rer. nat.)" \\ in the Neuroscience Program at \\ the Georg August University Göttingen, Faculty of Biology \\ Submitted by \\ Alonso Barrantes-Freer \\ Born in \\ San José, Costa Rica
}

Göttingen

March 52012 
Supervisor, thesis committee member: Prof. Dr. Walter Stühmer

Thesis committee member: Prof. Dr. Tobias Moser

Thesis committee member: Dr. Till Marquardt 
I hereby declare that I prepared this doctoral thesis, entitled "Functional properties of the plasma membrane of human glioma initiating cells", on my own and with no other sources and aids than those cited.

Alonso Barrantes-Freer

March $5^{\text {th }}$ 2012, Göttingen 


\section{Table of Contents}

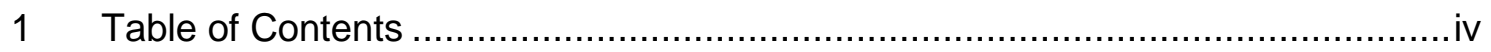

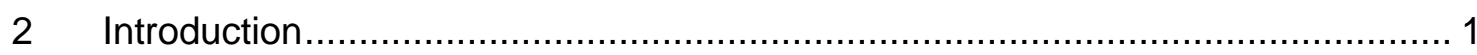

2.1 Primary Brain Tumors: Definition ........................................................... 1

2.2 Incidence and Prognosis ……….......................................................... 1

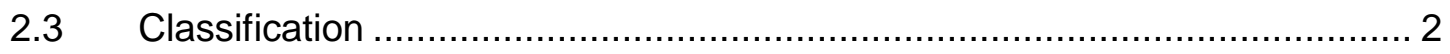

2.4 Cellular heterogeneity: origin and progression of gliomas ........................... 4

2.4.1 The cell of origin of gliomas ................................................................ 5

2.4.2 Animal models of glioma: A look into early tumorigenic events................. 6

2.4.3 Lineage markers in human gliomas ...................................................... 8

2.4.4 Brain tumor initiating cells and the cancer stem cell hypothesis ................ 9

2.4.5 Nestin and NG2: Lineage markers in pathological states? ..................... 12

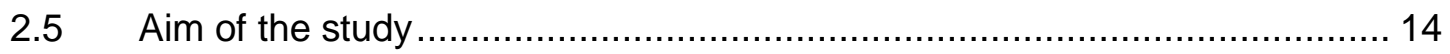

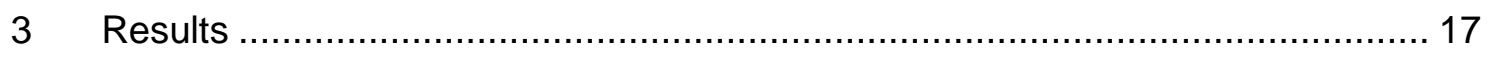

3.1 BTICS express NG2, Nestin and GFAP ............................................. 17

3.2 BTICs have a restricted differentiation potential.......................................... 22

3.3 Membrane Properties of BTICs: Electrophysiology …………………...... 26

3.3.1 BTICs have a moderate membrane resistance ..................................... 26

3.3.2 BTICS express voltage dependent $\mathrm{Na}^{+}$currents and regenerative voltage transients 27

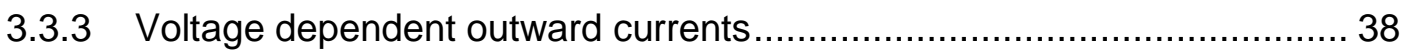

3.3.4 BTICs express functional glutamate receptors ..................................... 45

3.3.5 No detectable dye-coupling in cultured BTICs ..................................... 47

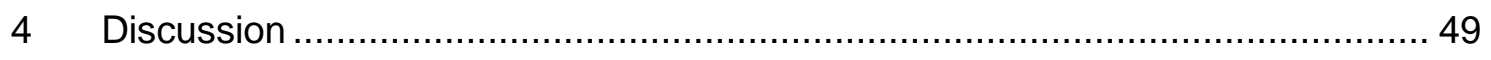

4.1 Isolation of BTICs: Conceptual and technical considerations ...................... 49 
4.2 Molecular characterization and differentiation potential of BTICs .............. 51

4.3 Functional membrane phenotype of BTICs .......................................... 54

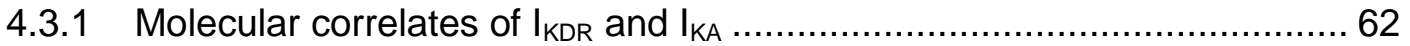

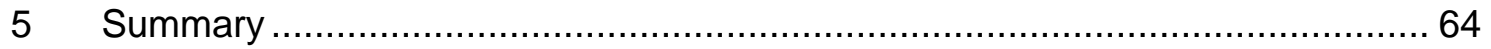

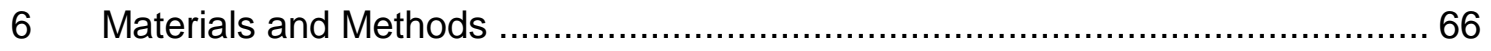

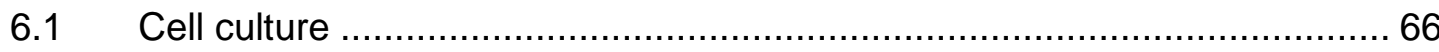

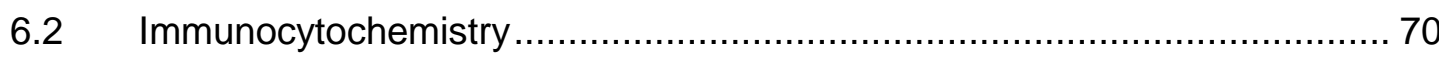

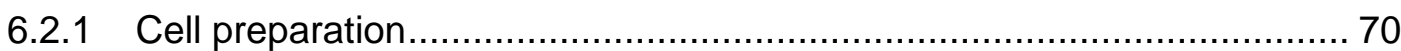

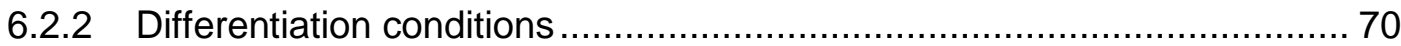

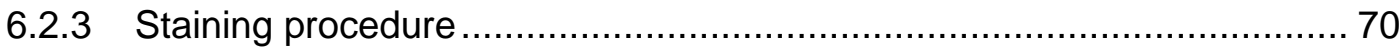

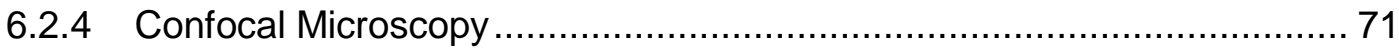

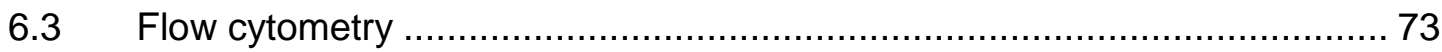

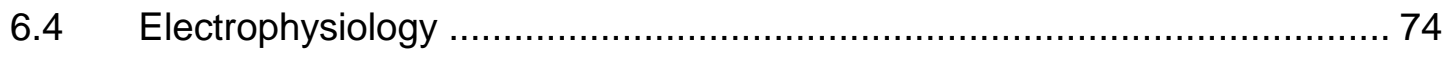

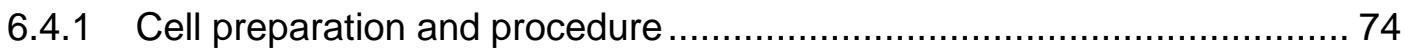

6.4.2 Voltage/Current Protocols .......................................................... 74

6.4.3 Analysis of electrophysiology data ............................................... 78

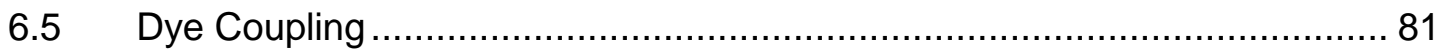

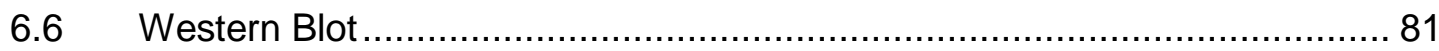

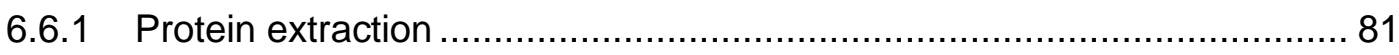

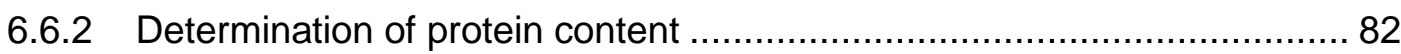

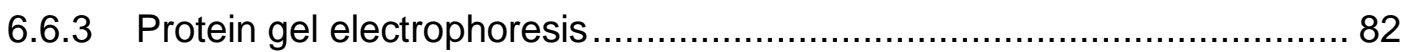

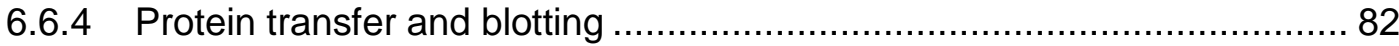

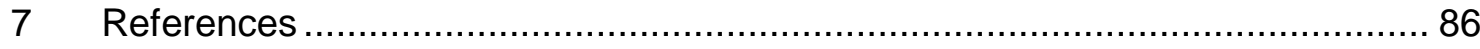

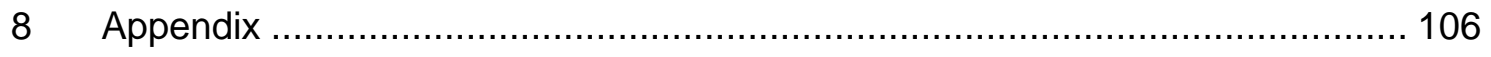

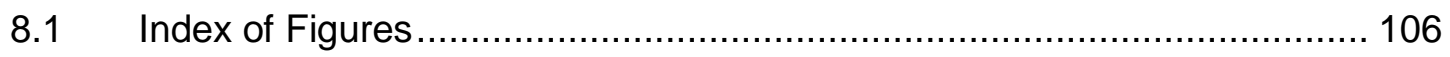

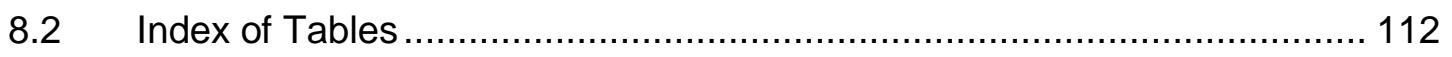




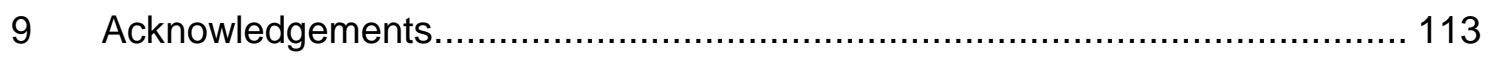

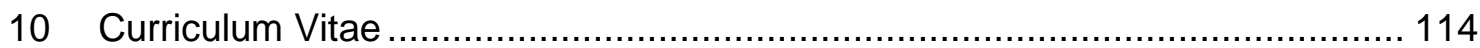




\section{Abbreviations}

\begin{tabular}{|c|c|}
\hline 4-AP & 4-Aminopyridine \\
\hline AHP & Afterhyperpolarization \\
\hline AMPA & a-amino-3-hydroxy-5-methyl-4-isoxazolepropionic acid \\
\hline ANOVA & Analysis of variance \\
\hline bFGF (FGF2) & Basic fibroblast growth factor \\
\hline BTIC & Brain tumor initiating cells \\
\hline CD & Cluster differentiation \\
\hline CNS & Central nervous system \\
\hline CNTF & Ciliary neurotrophic factor \\
\hline CSC & Cancer stem cell \\
\hline CTZ & Cyclothiazide \\
\hline Cx43 & Connexin 43 \\
\hline EFGR & Epidermal growth factor receptor \\
\hline EGF & Epidermal growth factor \\
\hline EP & Electrophysiology \\
\hline FCS & Fetal calf serum \\
\hline FORS & Forskolin \\
\hline GBM & Glioblastoma multiforme \\
\hline GFAP & Glial fibrillary acidic protein \\
\hline GluR & AMPA receptor subunit \\
\hline I & Current \\
\hline ICC & Immunocytochemistry \\
\hline $\mathrm{KA}$ & Potassium A-type \\
\hline KDR & Potassium delayed rectifier \\
\hline LY & Lucifer Yellow \\
\hline MBP & Myelin basic protein \\
\hline MRF & Maximum rate of fall \\
\hline MRR & Maximum rate of rise \\
\hline NB & Neurobasal \\
\hline NeuN & Neuronal nuclei \\
\hline NF1 & Neurofibromatosis type1 \\
\hline NG2 & Chondroitin sulfate proteoglycan \\
\hline NSA & Neurosphere assay \\
\hline NSC & Neural stem cells \\
\hline OPC & Oligodendrocyte progenitor cells \\
\hline PDGFR & Platelet derived growth factor \\
\hline PE & Phycoerythrin \\
\hline PTB & Post transient baseline \\
\hline
\end{tabular}




$\begin{array}{ll}\text { PTX } & \text { Phrixotoxin } \\ \mathrm{R}_{\mathrm{m}} & \text { Membrane resistance } \\ \text { shRNA } & \text { Short hairpin ribonucleic acid } \\ \text { SVZ } & \text { Subventricular zone } \\ \tau & \text { Time constant } \\ \text { T3 } & \text { Tri-iodothyronine } \\ \text { TEA } & \text { Tetraethyl ammonium } \\ \text { TP3 } & \text { TO-PRO-3 } \\ \text { TTX } & \text { Tetrodotoxin }\end{array}$

viii 


\section{Introduction}

\subsection{Primary Brain Tumors: Definition}

Brain tumors are a heterogeneous family of intracranial neoplasms that differ in their clinical manifestation, prognosis, treatment and biology (Deangelis, 2001). Brain tumors can be classified into primary or metastatic, depending on the tissue where the neoplasm originates. Primary brain tumors arise from cells of the central nervous system (CNS), whereas metastatic brain tumors arise from tissues outside the CNS and spread, later on, to the brain. CNS lymphomas are also considered primary brain tumors. The metastatic type is about ten times more frequent than the primary and represents a common complication of extracranial malignancies (Fox et al., 2011) . Metastatic brain tumors lie outside of the scope of this work and are reviewed elsewhere (Fox et al., 2011; Patchell, 2003).

Based on their behavior, tumors have been traditionally termed as benign or malignant, which implies a prognostic correlate. Benign tumors are non-invasive and once resected, do not recur. Malignant tumors, on the other hand, are tumors with fast growth, increased infiltrative potential and often recur after resection. However, it should be kept in mind, that due to their anatomical location, the so-called benign brain tumors can also be lethal, moreover they tend to undergo malignant transformation over time and infiltrate neighboring tissue (Behin et al., 2003).

\subsection{Incidence and Prognosis}

In Germany, 6861 new cases of primary brain tumors were diagnosed in 2008, with a combined age standardized rate of incidence of 8.3 per 100000 persons (Ferlay et al., 2010). The incidence is comparable with that of Western Europe, 5.1 per 100000 and higher than the global incidence of 3.5 per 100000 (Ferlay et al., 2010). 
Although the combined age incidence is low, there is a clear difference according to age group. In Germany, from a total of 426800 newly diagnosed cancer cases in 2006, $1.7 \%$ represented brain tumors of all types in adults, whereas for children, brain tumors represented almost 20\% (Koch-Institut and Deutschland, 2010).

Brain tumors are the most frequent solid neoplasms and the main cancer-related mortality in the pediatric population (Pollack, 1994). Despite this fact, the two more common types of tumors, medulloblastoma and low grade glioma (Section 2.3 Classification; page 2), have a fairly good prognosis with a mean five year survival of $\sim 87 \%$ and $97 \%$ respectively (Packer et al., 2006; Wisoff et al., 2011).

The scenario for the adult population is less optimistic. The most frequent primary brain tumors in adults are gliomas and primary CNS lymphoma (Behin et al., 2003). The most common gliomas are the malignant astrocytomas: anaplastic astrocytoma and glioblastoma (Section 2.3 Classification, page 2), with an incidence of 3 to 4 per 100000 persons (Deangelis, 2001). Unlike the case of pediatric tumors, with current therapeutic approaches the two year survival rate for glioblastoma is only $26.5 \%$ (Stupp et al., 2005).

Given their high incidence, mortality and lack of effective treatment, malignant gliomas will be at the center of this work. Other primary malignancies will be referred to when pertinent and are reviewed in detail elsewhere: low grade gliomas (Sanai et al., 2011), CNS lymphomas (Gerstner and Batchelor, 2010) and pediatric brain tumors (Pollack and Jakacki, 2011).

\subsection{Classification}

The most widely used classification of gliomas, the "Classification of Tumours of the Nervous System" of the World Health Organization (WHO), relies mainly on histological criteria to group brain tumors based on their similarity to non-neoplastic cellular components of the CNS (Louis et al., 2007b).

Accordingly, tumors can be first divided into tumors of neuroepithelial tissue, meningeal tumors, germ cell tumors and tumors of the sellar region as well as lymphomas and hematopoietic neoplasms. The neuroepithelial group includes the two most frequent types of primary brain tumor in adults, the astrocytic and the 
oligodendroglial tumors, which can be further subclassified in seven and two subgroups, respectively (Table 1). Nevertheless, the actual origin of brain tumors remains unclear (Section 2.4 Cellular heterogeneity: page 4). However, the first microscopical descriptions of brain tumors already proposed that neoplasms arise from glial or neuronal precursors, implying the existence of a cell of origin (Bailey and Cushing, 1926).

Table 1. Classification of astrocytic tumors and their correspondent WHO grading. Adapted from the 2007 WHO Classification of Tumours of the Central Nervous System (Louis et al., 2007b)

\begin{tabular}{cc}
\hline Astrocytic tumors & WHO Grade \\
\hline \hline Pilocytic astrocytoma & $\mathrm{I}$ \\
Pilomyxoid astrocytoma & $\mathrm{II}$ \\
Subependymal giant cell astrocytoma & $\mathrm{I}$ \\
Pleomorphic xanthoastrocytoma & $\mathrm{II}$ \\
Diffuse astrocytoma & $\mathrm{II}$ \\
Fibrillary astrocytoma & $\mathrm{II}$ \\
Gemistocytic astrocytoma & $\mathrm{II}$ \\
Protoplasmic astrocytoma & $\mathrm{II}$ \\
Anaplastic astrocytoma & $\mathrm{III}$ \\
Glioblastoma & $\mathrm{IV}$ \\
Giant cell Glioblastoma & $\mathrm{IV}$ \\
Gliosarcoma & $\mathrm{IV}$ \\
Gliomatosis cerebri & $\mathrm{IV}$ \\
\hline
\end{tabular}

Although this study deals mainly with astrocytic malignancies, to better illustrate the complexity of brain tumors it is worth mentioning that seven other types of neuroepithelial neoplasms exist, namely the oligoastrocytic mixed gliomas, ependymal, choroid plexus, pineal region, embryonal, neuronal and mixed neuronal-glial tumors, each with its own specific subtypes (Louis et al., 2007b).

The histopathological characteristics allow not only the classification, but can also aid to predict a tumor's biological behavior (Louis et al., 2007a). The WHO uses a fourtiered grading system to stratify the tumors from low (grades I-II) to high grade (grades III-IV). The grade correlates directly with malignancy (Section 2.1 Primary Brain 
Tumors: Definition, page 1) and is determined by the area within a tumor with the highest grade identified.

Grade I neoplasms show restricted proliferation and low recurrence after complete surgical resection. Grade II tumors can recur despite low proliferation and tend to progress to higher grades. Astrocytomas can be graded as WHO II if cytological atypia and diffuse infiltration are found. The presence of anaplasia and mitotic activity in astrocytoma are criteria for WHO III, which in the clinical setting often translates to treatment modalities with adjuvant radio- and/or chemotherapy. Finally, grade IV astrocytomas, the most malignant and frequent primary brain tumors in adults (Section 2.2 Incidence, page 1), present micro vascular proliferation and/or necrosis and course with fast disease progression and poor prognosis (Louis et al., 2007b). A tumor can also be termed as secondary, when a high grade tumor arises from a lower grade tumor (Louis et al., 2007b).

The other grading systems available, namely the St Anne-Mayo (Daumas-Duport et al., 1988; Kim et al., 1991) and the Kernohan (Kernohan et al., 1949) schemes, also rely on similar morphological premises as the WHO system.

\subsection{Cellular heterogeneity: origin and progression of gliomas}

Tumors in general and brain tumors in particular exhibit a marked inter- and intratumor heterogeneity in their cellular morphology, marker expression and genetic lesions. This represents a major hurdle for the understanding of tumor biology and the consequent rational drug development since the identity, significance and interactions of different subpopulations are poorly understood (Visvader, 2011).

It has been argued that the identification of the cell of origin of glioma might help to understand the importance of different cellular subpopulations by providing insight into the complex cellular interactions in the tumor microenvironment. This question has been addressed using animal models of induced gliomagenesis in specific cell types (Section 2.4.2, page 6). However, the exact cytogenesis of gliomas is still a matter of extensive debate (Huse and Holland, 2010).

Alternatively, based on the premise that distinct cellular subpopulations differ in their ability to maintain and propagate a tumor, several studies have tried to elucidate the contribution of individual malignant cell types to tumor progression. A widely used 
method has consisted in the establishment of primary cell lines from tumor biopsies. By culturing in selective media, it is possible to isolate cells with the intrinsic ability to initiate lesions that recapitulate the hallmarks of the original tumor upon implantation in immunodeficient mice and have therefore been called brain tumor initiating cells (BTICs) (Singh et al., 2004) (Section 2.4.4, page 9). As with the cell of origin, the exact lineage, source, functional properties and significance of BTICs are also controversial (Clarke et al., 2006).

Finally, the molecular, genetic and histopathological analysis of tumor biopsies and their prognostic correlate has constituted another approach to try to determine the relative contribution of distinct cellular subpopulations to patient outcome (Section 2.4.3 Lineage markers in human gliomas, page 8).

Therefore, to gain a better insight into the complexity of tumor heterogeneity, in the following sections we will analyze the controversies, experimental results and methods regarding cell of origin and BTICs.

\subsubsection{The cell of origin of gliomas}

Traditionally, gliomas have been thought to originate from dedifferentiated mature glia (Huse and Holland, 2010; Vick et al., 1977). Although widely accepted, the socalled dysembriogenetic theory fails to explain the origin of mixed gliomas and it is also not clear why the origin of a tumor should relate to its most frequent cell type, as brain tumors of similar histological characteristics often exhibit very different behaviors (Sanai et al., 2005).

Mature glia seemed the most plausible target of malignant transformation since it was the only known cycling cell population in the postnatal brain, yet other cell types that undergo mitosis, such as glial progenitors and neural stem cells have later been described (Dawson et al., 2003).

Besides their proliferative potential, neural stem cells (NSCs) and astrocyte- and oligodendrocyte-progenitor cells (OPCs) share other characteristics with glioma cells that make them an attractive tumorigenic substrate. For instance they 1) self-renew, 2) produce heterogeneous progeny, 3) are motile; 4) associate with blood vessels and 5) NSCs are regulated by pathways often functional in brain tumors (Sanai et al., 2005). 
Interestingly, already in 1926, the Bailey's and Cushing's classification of gliomas proposed that these tumors originate from primitive neuroectoderm. For glioblastoma multiforme, a term also coined in that work, the postulated origin was a primitive precursor of the stromal population or glioblasts (Bailey and Cushing, 1926).

The idea that brain tumors could arise from immature cells was again brought forward by Globus and Kuhlenbeck in the 1940's, when they stated that the "subependymal plate" was a site where "immature embryonal residue" could serve as the substrate for the formation of neuroectodermal neoplasms (Globus and Kuhlenbeck, 1942, 1944).

The first empirical support for this hypothesis came from experiments where chemically induced gliomas in rats showed increased susceptibility to arise from the subventricular zone (SVZ) (Hopewell, 1975; Lantos and Cox, 1976). A similar predisposition was found in zones sheltering proliferative populations in models of virally induced gliomagenesis in dogs (Vick et al., 1977).

Since then, the better understanding of the mechanisms of normal neurogenesis and the identification of more defined pools of progenitor cells and their respective markers led to the development of more sophisticated models. Transgenic mice and gene transfer technologies have been implemented to specifically target oncogenic mutations to restricted cellular subpopulations in the brain. These tools have proven valuable to gain insight into the initial events of gliomagenesis.

\subsubsection{Animal models of glioma: A look into early tumorigenic events}

To faithfully model early gliomagenesis, the ideal transgene strategy should match the relevant cellular subpopulation with its appropriate oncogenic mutation. However, both variables are unknown. Therefore different CNS subpopulations have been targeted by common mutations found in clinical glioma specimens. Unfortunately, the genetic background of malignant astrocytomas is so heterogeneous that even distinct tumor types might reflect a collection of genetically overlapping entities (Furnari et al., 2007). This complexity suggests that oncogenic mutations can hardly be represented by a single transgenic model (Huse and Holland, 2009); hence, different approaches have been followed. 
For instance, the activation of pathways involving Ras and Akt is frequently found in human astrocytomas (Feldkamp et al., 1997). Based on this observation, Holland and co-workers used a retroviral delivery system to transfer genes encoding mutant activated Ras and/or Akt specifically to astrocytes or neural progenitors in the mouse. They found that GBM-like tumors appeared when both Ras and Akt were delivered to progenitors, but not to astrocytes (Holland et al., 2000).

Using conditional transgenic animals it was observed that when a mutant form of Tpr53 was expressed in NSCs, nearly $90 \%$ of the mice developed high-grade tumors (Wang et al., 2009).

Similarly, the induction of malignant gliomas was achieved through the activation of a nestin-cre (Nes-Cre) transgene or Cre virus injection in the SVZ in a mouse with floxed alleles for the tumor suppressor genes Nf1, Trp53 and Pten. When the same strategy was directed to the cortex or striatum, no tumor induction was observed (Alcantara Llaguno et al., 2009) highlighting once more the involvement of NSCs/progenitor cell compartment in gliomagenesis.

Similar studies have provided evidence that NSC-progeny, particularly astrocyte and oligodendrocyte progenitor cells (OPCs), rather than NSCs, might serve as the cell of origin for malignant glioma. For example, brain tumors were successfully induced by specifically overexpressing platelet derived growth factor $\beta$ in NG2 cells (Lindberg et al., 2009) and a hyperactive form of the epidermal growth factor receptor (EGFR) in OPCs could reproduce tumors reminiscent of oligodendroglioma (Persson et al., 2010).

Also, in a lineage-tracing study using mosaic mouse models, sporadic mutations in Trp53/Nf1 restricted to NSCs or OPCs led to gliomagenesis, where the OPC served as the cell of origin, even when the mutations were induced in NSCs (Liu et al., 2011).

Alternatively, it has been suggested that the genetic pathway disturbed, rather than cell type is determinant for gliomagenesis. In their experiments, Bachoo and coworkers transferred the commonly in GBM overexpressed EGFR (Ekstrand et al., 1991; Von Deimling et al., 1992) into astrocytes or NSCs of mice lacking the cell cycle and apoptosis related genes Ink4a and Arf. Upon implantation, both the transfected NSCs and astrocytes could induce tumors with a high-grade glioma phenotype (Bachoo et al., 2002). 
Although the studies using glioma induced models do not definitely resolve the issue of the cell of origin in glioma, they do underscore at least two major aspects: 1) the crucial significance of cellular and genetic heterogeneity of gliomas and 2) to a variable degree, the involvement of NSCs and OPCs in tumor origin and progression.

\subsubsection{Lineage markers in human gliomas}

The results obtained from induced gliomagenesis in transgenic mouse models can only provide clues about the biology of human brain tumors. Additionally in the human context the study is restricted to late-stage tumors which can offer limited information about cell of origin (Visvader, 2011). Nevertheless, tumor biopsies represent the best possible preparation to gain insight into the cellular populations that contribute to disease progression in the human. Therefore a common approach to study the intratumoral heterogeneity has consisted in correlating lineage marker expression with clinical or other histopathological criteria.

The glial fibrillary acidic protein (GFAP) is a widely used marker for astroglial cells and is frequently expressed in GBM in a heterogeneous fashion (Oh and Prayson, 1999). In immunohistochemical studies of 131 and 85 brain tumors, the percentage of positive cells and the intensity of the GFAP staining correlated inversely with malignancy (Tascos et al., 1982; Velasco et al., 1980). It has been proposed that the reduction of GFAP in higher grade astrocytic tumors reflects a less differentiated status of the tumor cells rather than a step in tumor progression (Wilhelmsson et al., 2003).

Interestingly, the expression of specific markers of immature cell types like NSCs and OPCs has been successfully demonstrated in several brain tumors.

Nestin, a specific marker of NSCs (Lendahl et al., 1990) was found by immunohistochemistry in 67 out of 78 brain tumors including astrocytomas and correlated with tumor grade (Dahlstrand et al., 1992). Similarly, nestin expression has also been reported in other series of human brain tumors, both in tumor cells as well as in vascular endothelial cells (Almqvist et al., 2002; Sugawara et al., 2002; Toyama et al., 1992).

Recently, using tissue microarrays and immunohistochemistry in a series of 40,70 and 283 astrocytic gliomas, three independent groups have observed a correlation 
between the levels of nestin expression and tumor grade (Ehrmann et al., 2005; Rushing et al., 2010; Wan et al., 2011). Other stem cell specific markers like mushashi1 have also been found in human tumor specimens (Uchida et al., 2004).

The chondroitin sulfate proteoglycan (NG2) and the platelet derived growth factor receptor a (PDGFRa), are specific markers of the so-called NG2 glia or oligodendrocyte progenitor cells (OPCs) (Nishiyama et al., 1999; Nishiyama et al., 1996). Like its name suggests, OPCs are a progenitor population that differentiates mainly into oligodendrocytes in vivo (Komitova et al., 2011), yet they can also give rise to astrocytes (Zhu et al., 2008; Zhu et al., 2011).

Similar to nestin, NG2 had a greater expression in high- than in low-grade gliomas and was found to co-localize with PDGFRa (Chekenya et al., 1999). Also, NG2 could be detected by immunohistochemistry in seven out of seven oligodendrogliomas and one of five glioblastomas (Shoshan et al., 1999). Recently, in a larger screening of 74 GBM biopsies, the levels of NG2 had an inverse correlation with survival. Furthermore, $\mathrm{NG}^{+}$GBM cells showed increased resistance to ionizing radiation (Svendsen et al., 2011).

Although the correlation of lineage markers with prognosis highlights, once again, the importance of tumor heterogeneity, it should be kept in mind that the relative abundance of cells expressing a particular marker is not necessarily indicative of its relevance regarding tumor progression.

\subsubsection{Brain tumor initiating cells and the cancer stem cell hypothesis}

Pure immunohistochemical studies show that late-stage human astrocytomas contain subpopulations of cells that express lineage markers of astrocytes, NSCs and OPCs and have a prognostic correlate (Section 2.4.3 Lineage markers in human gliomas, page 8). Although these findings suggest that nestin ${ }^{+}$and/or $\mathrm{NG}^{+}$ subpopulations play a role in glioma, this approach cannot provide information about the functional properties of these subpopulations and their relative contribution to tumor progression.

The expression of NSC markers led to the idea that nestin ${ }^{+}$cells in tumors might share other functional properties of normal NSCs. In the normal mouse CNS, sphere 
forming stem- and progenitor cells can be isolated by means of the neurosphere assay (NSA). The NSA consists in culturing dissociated tissues under conditions that do not support the long-term viability of the majority of cells, leading to its consequent death. Additionally, the medium is supplemented with epidermal growth factor (EGF), basic fibroblast growth factor (bFGF) or both, promoting the survival and expansion of cell populations that are responsive to these factors (Reynolds and Rietze, 2005; Reynolds and Weiss, 1992).

Therefore, Ignatova and co-workers used the NSA to isolate sphere-forming subpopulations from human GBM and anaplastic astrocytoma samples. Besides exhibiting spheroid growth, this tumor stem-like subpopulation exhibited characteristics reminiscent of normal NSCs, like 1) expression of the developmental markers nestin and tenascin and 2) when grown in serum containing medium, the cells expressed markers of more differentiated progeny such as GFAP and $\beta$-III tubulin (Ignatova et al., 2002).

This method has further been used to isolate stem-like populations from other human brain malignancies such as medulloblastoma, pilocytic and anaplastic astrocytoma (Hemmati et al., 2003; Singh et al., 2003) and GBM (Galli et al., 2004; Yuan et al., 2004).

Furthermore, after orthotopic implantation in immunodeficient mice, stem-like populations were able to produce a tumor reminiscent of the patient's original neoplasm and have been therefore called cancer stem cells (CSCs) or brain tumor initiating cells (BTICs) (Singh et al., 2004; Vescovi et al., 2006).

The tumor propagation ability of BTICs has made this subpopulation the focus of extensive research and consequently the center of great controversy regarding its identity, origin, characteristics and significance in the in vivo context.

To explain the possible role of stem-like cell subpopulations in tumors, three nonexclusive mechanisms have been postulated 1) normal stem cells and cancer cells share similar mechanisms of self-renewal, 2) tumors cells arise from normal stem cells and 3) tumors contain a special subpopulation of "cancer stem cells" (CSCs) that can proliferate indefinitely and drive the growth and formation of a hierarchically organized tumor (Reya et al., 2001). 
Despite its utility, the NSA only allows the a posteriori identification of BTICs, limiting the approach to several experimental questions especially in the in vivo situation. Although several strategies for prospective identification have been proposed, no reliable method is currently available.

Still, given its abundance in the literature, it is worth to briefly mention the discussion around the CD133 molecule, a proposed prospective marker for BTICs. The normal neural stem cell marker CD133 was used to isolate tumor cells from pediatric medulloblastomas and adult glioblastomas. When implanted in the brains of immunodeficient mice, $\mathrm{CD}_{133^{+}}$, but not $\mathrm{CD} 133^{-}$cells, were able to recapitulate the patients' original tumor (Singh et al., 2004).

The notion that a rare population of BTICs could be identified by means of a single marker (CD133) found echo outside the field of neuro-oncology. Shortly after, CD133 became a global marker for stem cells and CSCs, with which stem-like populations were successfully isolated from liver (Rountree et al., 2008), prostate (Collins et al., 2005; Richardson et al., 2004), lung (Eramo et al., 2007) and pancreas (Hermann et al., 2007).

However, in the field of gliomas the validity of CD133 as a universal marker for BTICs was confronted with the observation that CD133 spheroids and CD133adherent cells isolated from primary GBMs, were also able to give rise to tumors upon implantation in immunodeficient animals (Beier et al., 2007; Ogden et al., 2008; Wang et al., 2007). Moreover, after serial in vivo passaging, tumors originated from CD133cells increased their expression of CD133 (Wang et al., 2007). Since CD133 is no longer considered as a reliable marker for the a priori identification of BTICs, the NSA remains the most widely accepted approach for the isolation of stem-like sub populations from brain tumors.

Nevertheless, the significance of stem-like subpopulations in brain tumors and even the definition of CSCs is still a matter of great controversy. In 2006, the American Association of Cancer Research (AACR) organized a workshop on CSCs "to evaluate data suggesting that cancers develop from a small subset of cells with self-renewal properties analogous to organ stem cells" (Clarke et al., 2006). Here, a CSC was defined as "a cell within a tumor that possess the capacity to self-renew and to cause the heterogeneous lineages of cancer cells that comprise the tumor" (Clarke et al., 2006). 
In a similar fashion, a definition for brain tumor stem cells has been proposed as a cell that reproduces the original tumor upon implantation, and has extensive selfrenewal ability, karyotypic or genetic alterations, aberrant differentiation properties, the ability to generate non tumorigenic end cells and multilineage differentiation capacity (Vescovi et al., 2006).

Others have challenged the notion of a single, rare cancer stem cell population and have instead, proposed that there might even be several populations with varying degrees of "stemness", which might depend on the environment (Hill, 2006). Even further, it has been suggested that the tumor forming potential is a characteristic of all tumor cells to a variable degree and not necessarily a special feature of a subpopulation (Kern and Shibata, 2007).

Regardless of the controversies, it is important to note that all of the above mentioned studies show a similar, reproducible set of observations namely:

1) by using the NSA a subpopulation of cells can be isolated from brain tumors,

2) the isolated subpopulation exhibits spheroid growth and expresses markers of normal NSCs and/or differentiated progeny,

3) variations in the expression of lineage specific markers ("differentiation") can be induced by changing the growth factor composition of the culture medium, and

4) upon implantation in immunodeficient mice, the cells give rise to a tumor with a similar phenotype to that of the patients original neoplasm (Beier et al., 2007; Galli et al., 2004; Ignatova et al., 2002; Singh et al., 2003; Singh et al., 2004; Wang et al., 2007).

\subsubsection{Nestin and NG2: Lineage markers in pathological states?}

While it seems plausible that BTICs contribute to tumor propagation, their lineage identity is much less understood. Traditionally, the expression of NSC/progenitor markers and their ability to "differentiate" has caused BTICs to be described as "stemlike cells". However, whereas CNS subpopulations can be readily identified by their marker expression under physiological conditions, care should be taken when using this method to determine lineage in the diseased brain. 
For example, it has been shown that reactive astrocytes can express nestin and mushashi1 during regeneration after CNS lesion (Clarke et al., 1994; Frisén et al., 1995; Lin et al., 1995; Oki et al., 2010; Tamagno and Schiffer, 2006). In a similar context, it has been suggested that reactive astrocytes might also transiently express NG2 (Komitova et al., 2011).

Further, the NG2 protein is not detectable in multipotent stem-cells or terminally differentiated cells (Komitova et al., 2009), but is upregulated in response to commitment to a particular lineage or in injury, where proliferation and motility are required (Stallcup and Beasley, 1987). This fact has led to the interpretation that NG2 is more a marker of cell status (quiescent vs. activated) than a marker for a specific cell type (Stallcup and Huang, 2008). Similar expression patterns in other tissues support this argument. For example, in the development of the rat limb, stem cells show no expression of NG2, then it is upregulated in immature chondroblasts and downregulated in mature chondroblasts (Fukushi et al., 2003). Analogous phenomena can be observed in the skin, hair follicle and vasculature (Ghali et al., 2004; Legg et al., 2003; Stallcup and Huang, 2008).

Furthermore, while it seems very clear that $\mathrm{NG}^{+}$cells correspond to OPCs during development, the identity of the cycling PDGFRa ${ }^{+} / \mathrm{NG}^{+}$cells in the adult brain remains unresolved. It has been proposed that this population might be heterogeneous and might consist of 1) a reserve pool of oligodendrocyte progenitors and 2) a distinct class of glial cell called a polydendrocyte of yet unknown function (Dawson et al., 2000; Horner et al., 2002; Karram et al., 2005; Nishiyama et al., 2002; Peters, 2004; Stallcup and Huang, 2008; Trotter et al., 2010).

Also, regarding its function, it has been shown that the NG2 protein can regulate cell motility in glioma (Burg et al., 1997; Makagiansar et al., 2004) and melanoma cells (Burg et al., 1998; Burg et al., 1997; Eisenmann et al., 1999) and can influence cell proliferation of OPCs, glioma cells and pericytes (Makagiansar et al., 2004; Nishiyama et al., 1996; Ozerdem and Stallcup, 2004). Moreover, transfection of NG2 in NG2glioma cells lead to an increased tumor growth and vascularization in orthotopic xenograft models (Wang et al., 2011).

Likewise, nestin has been implicated in proliferation, migration and survival of brain tumor cells (Chou et al., 2003; Wei et al., 2008). For example, glioma cells with high nestin expression formed larger tumors in vivo and blocking nestin expression with 
shRNA reduced the volume and growth of tumors (Lu et al., 2011). Additionally the expression of high levels of nestin has been reported in pancreas (Jimeno et al., 2009), thyroid (Yamada et al., 2009), breast (Li et al., 2007) and gastrointestinal (Tsujimura et al., 2001) cancer as well as melanoma (Brychtova et al., 2007).

The role of nestin and NG2 in invasion and proliferation could represent a selective advantage for cells in the tumor microenvironment, implying that their expression in glioma cells and other malignancies might be distinctive of a cell's proliferative capacitive and not a marker of its lineage (Al-Mayhani et al., 2011; Ishiwata et al., 2011). Therefore, a complementary approach should be implemented to reliably establish the identity BTICs.

Most of the cellular components of the CNS exhibit a well characterized robust electrophysiological signature, including astrocytes (Parkerson and Sontheimer, 2003; Sontheimer et al., 1992; Stacey Nee and Harald, 2000), oligodendrocytes (Sontheimer and Kettenmann, 1988; Tripathi et al., 2011), microglia (Ducharme et al., 2007; Newell and Schlichter, 2005; Pannasch et al., 2006), neural progenitor cells of the SVZ (Lai et al., 2010; Wang et al., 2003) and NG2 cells (Bergles et al., 2000; Chittajallu et al., 2004; Káradóttir et al., 2008; Lin and Bergles, 2002).

It seems plausible that the electrophysiological membrane properties could complement traditional cell culture and antibody-based schemes to obtain further quantitative evidence about the identity of BTICs. Yet, to our knowledge, this approach has never been tested.

\subsection{Aim of the study}

Brain tumors are heterogeneous regarding cell morphology, marker expression and genetic lesions (Visvader, 2011). The relative contribution to tumor maintenance and progression of distinct neoplastic cellular subpopulations might aid in the development of rational treatments, however it remains poorly understood.

A widely used approach to gain insight into tumor heterogeneity consists in using the neurosphere assay (NSA) to isolate tumor cells from human brain malignancies. The cells obtained through this method have been called brain tumor initiating cells (BTICs) since they might contribute to tumor progression (Clarke et al., 2006). Although the ability of BTICs to propagate tumors is widely accepted, their identity is still under debate. BTICs exhibit many properties of normal neural stem cells and progenitor cells 
like self-renewal, multipotential differentiation and lineage marker expression (Galli et al., 2004; Persson et al., 2010; Singh et al., 2004). However it has been argued that the expression of markers of $\mathrm{NSC} /$ progenitor cells might confer selective advantage to neoplastic cells in the tumor microenvironment, casting doubts about their utility as lineage markers in a pathological context (Al-Mayhani et al., 2011). Besides differentiation and self-renewal potential, little is known about the functional properties of BTICs.

Distinct normal CNS subpopulations exhibit a well-defined electrophysiological signature. The robustness of this fingerprint relies on the high resolution of the patch clamp technique, since it allows the simultaneous measurement of several membrane parameters at a functional level in real time (Hamill et al., 1981). Hence we propose that electrophysiological membrane properties can complement traditional cell culture and marker based approaches to gain insight into the identity and functional aspects of BTICs, a strategy that has not been reported so far.

In the present study, we will characterize a panel of five primary BTICs derived from human GBM specimens at three levels of description: antigen expression, differentiation potential and membrane physiology.

The panel of BTICs used in this study has been established by the neurosurgery department (Universitätsmedizin, Göttingen) and has been derived from intraoperative samples confirmed as GBM by a certified neuropathologist (Universitätsmedizin, Göttingen). Further, the cells have been isolated using the NSA and the tumor forming ability of each cell line has been tested by implantation in immunodeficient mice, where they gave rise to tumors with hallmarks of GBM.

For the antigen-based lineage analysis, we will describe the expression of markers of NSCs and OPCs as well as terminal differentiated cells (astrocytes, neurons and oligodendrocytes) using antibody-based techniques. Second, we will test the differentiation potential of BTICs in response to diverse growth factors and finally, we will measure the electrophysiological properties of BTICs and see whether they are reminiscent of immature cells (NSCs/OPCs), a rather mature phenotype (astrocytes) or neither.

The antigen based characterization of human primary GBMs and their differentiation potential has been described in numerous reports. In this work we 
present, for the first time, a detailed characterization of the electrophysiological membrane properties of BTICs as a complement to cell culture and marker based strategies. This novel approach might prove useful to shed light into BTIC identity, therefore contributing to the debate about tumor-heterogeneity and providing information about a neglected aspect of BTICs, namely their functional properties. 


\section{Results}

\subsection{BTICS express NG2, Nestin and GFAP}

The expression of NG2 protein, a marker for glial progenitors, was determined by western blot analysis using a rabbit-polyclonal NG2 antibody (Chemicon). In five out of seven lines tested we detected a band at $\sim 280 \mathrm{kDa}$ compatible with NG2. The relative intensity of the band was variable between cell lines, where \#10 and \#1034 showed a higher expression than \#1063, \#1095 and \#1051. No band was detected in cell lines $\# 1075$ and \#1080 (Figure 1).

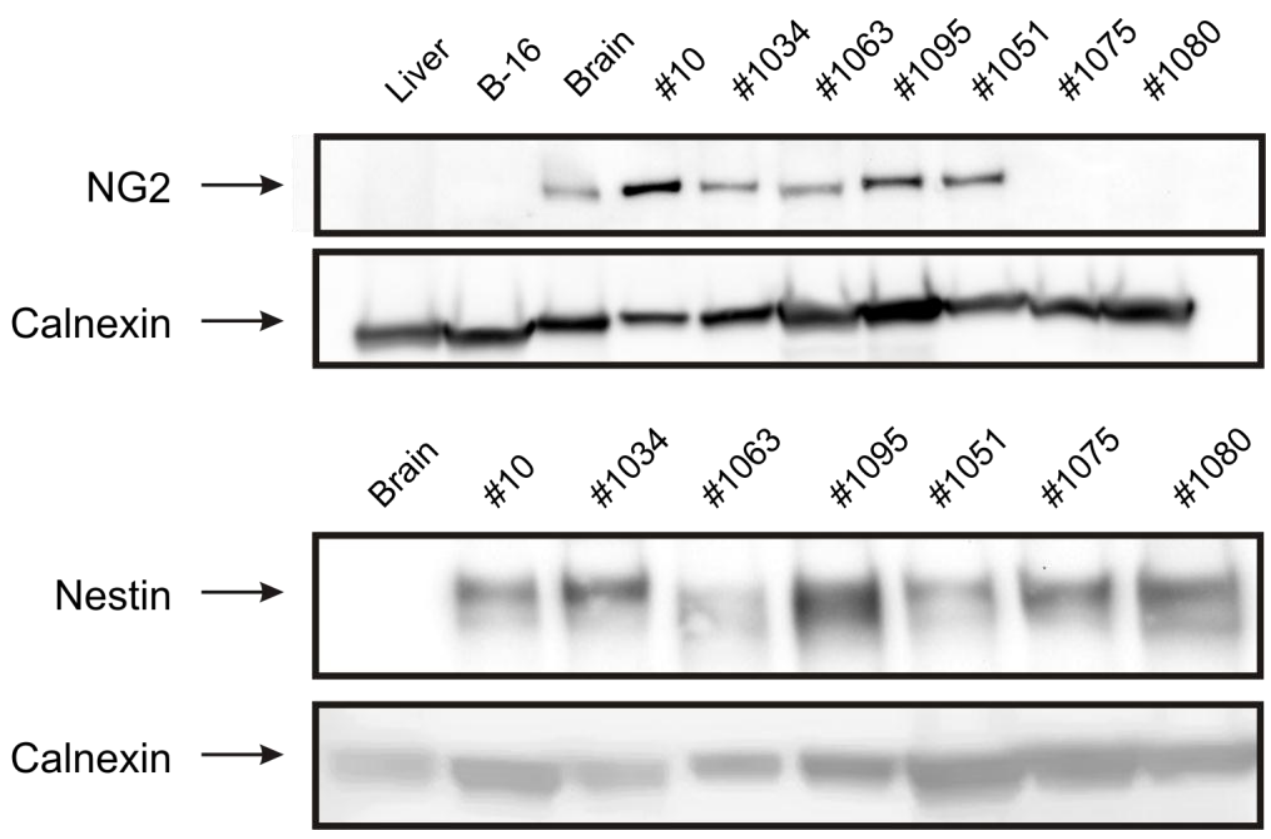

Figure 1. NG2 and nestin protein expression in BTICs. Western blot using anti-NG2 specific antibodies shows the presence of a band at $\sim 280 \mathrm{kDa}$ in 5 out of 7 BTIC lines tested. Mouse total brain protein was used as a positive control and mouse liver and the NG2 negative mouse melanoma cell lines were used as negative controls. A band at $\sim 240 \mathrm{kDa}$ was detected using an anti-nestin antibody in all BTICs. An antibody against calnexin ( 90 kDa) was used as a loading control. Note a higher relative intensity of the NG2 band in \#10 and \#1034.

To test whether the difference in NG2 expression was due to the presence of mixed subpopulations (e.g. $\mathrm{NG2}^{+} / \mathrm{NG}$ ) or a general lower protein amount in the majority of cells, we performed flow cytometric analysis. By using an NG2-specific antibody directly coupled to phycoerythrin (PE) (R\&D Systems), we can determine the percentage of live cells with membrane-associated NG2. The experiments revealed 
that the whole population had a shift in the fluorescence intensity of approximately one to two orders of magnitude in all cell lines studied. Furthermore, at least $80 \%$ of the cells showed a fluorescent signal above the levels of background fluorescence (Figure 2 , page 18). No changes in fluorescence intensity were detected in B16, a NG2negative mouse melanoma line (Burg et al., 1998).

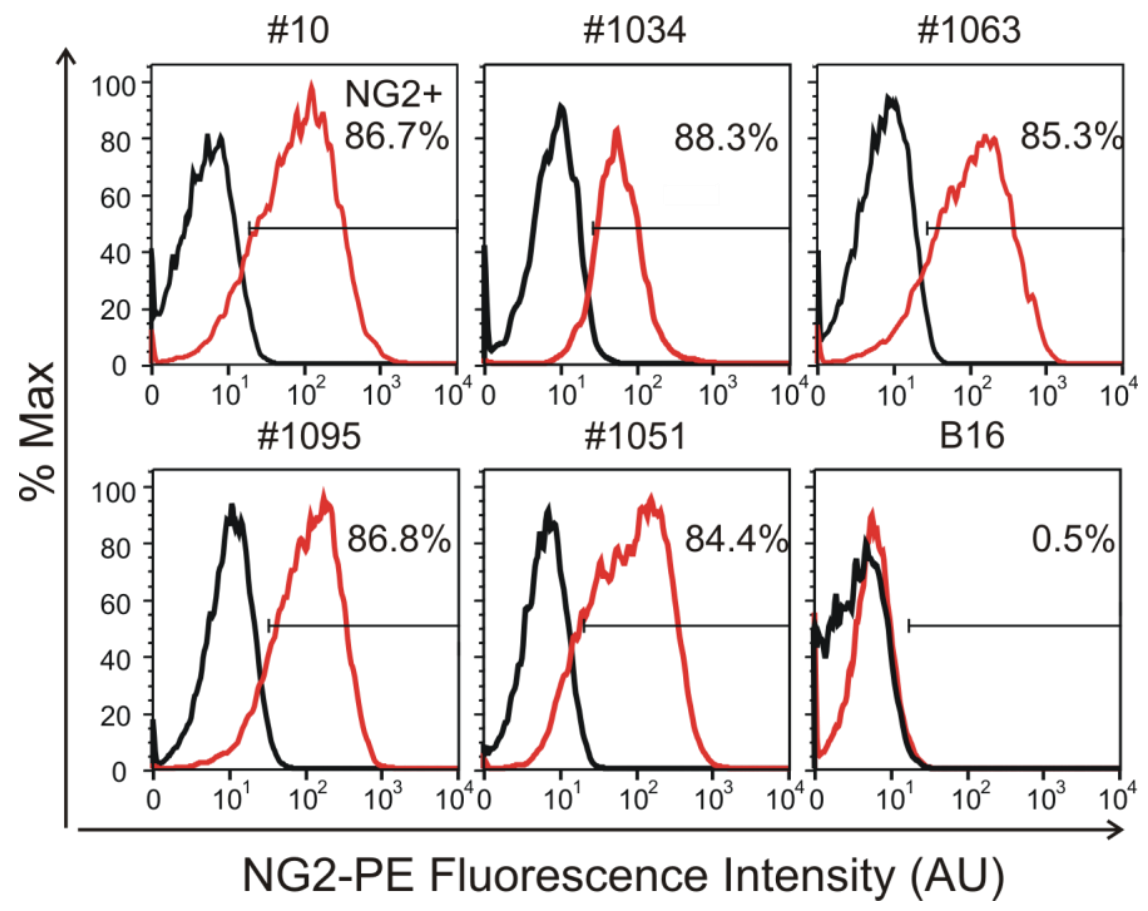

Figure 2. Membrane expression of NG2 In all BTIC lines, the amount of labeled cells was above $80 \%$ (red), as evidenced by the increase of fluorescence intensity above unlabeled controls (black). No shift in the mean fluorescence intensity was observed in B16 cells (lower right pane). The horizontal line shows an arbitrary gate to define percentage of positive cells above background fluorescence. $\mathrm{AU}=$ Arbitrary Units.

To determine the subcellular localization of NG2, an immunocytochemical approach was used. The NG2 signal was localized in a non-uniform fashion to the cell membrane. In the case of \#10 and \#1034, there was a strong overall staining of the membrane with an accumulation in some cell processes. For lines \#1063, \#1095 and \#1051, the focal expression in processes was predominant and was accompanied by a non-homogeneous and weaker staining of the cell membrane (Figure 3, page 19).

Since NG2 serves as a marker of OPCs/NG2 glia in physiological states, we tested for the expression of another OPC specific marker, the platelet derived growth factor receptor alpha (PDGFRa) (Nishiyama et al., 1996). All NG2 positive cells analyzed also expressed PDGFRa (\#10 n=141, \#1034 n=52, \#1051 n=34, \#1063 n=30, \#1095 n=21) 
(Figure 3, page 19). Very few cells (less than 2\%) expressed PDGFRa without clear NG2 expression.

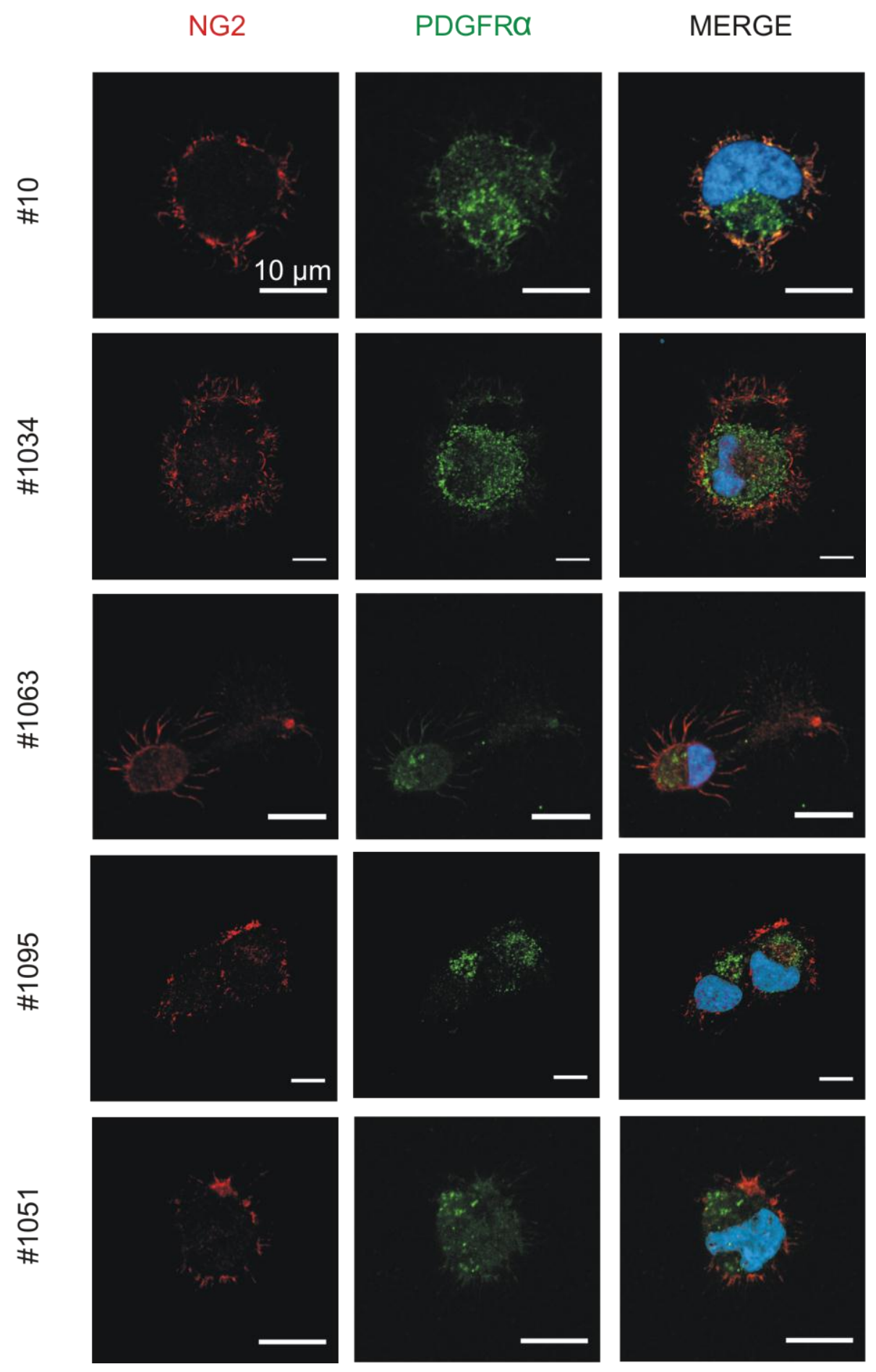

Figure 3. BTICs co-express NG2 and PDGFRa. Representative images of cells labeled for NG (red) and PDGFRa (green). Note the peripheral localization of NG2 with a markedly uneven expression in some processes (left column). Scale bars $=10 \mu \mathrm{m}$. 
Then, we wondered if nestin, a protein often found in progenitors and BTICs (Vescovi et al., 2006) was also expressed in our series of cell lines. Consequently, using western blot analysis with a specific anti-nestin antibody (Millipore) a band of $\sim 240 \mathrm{kDa}$, compatible with the molecular weight of nestin, was detected in all BTICs (Figure 1Figure, page 17). To determine if nestin exhibited a heterogeneous expression pattern we used an immunocytochemical approach and found a strong signal in $\sim 98 \%$ of the cells.
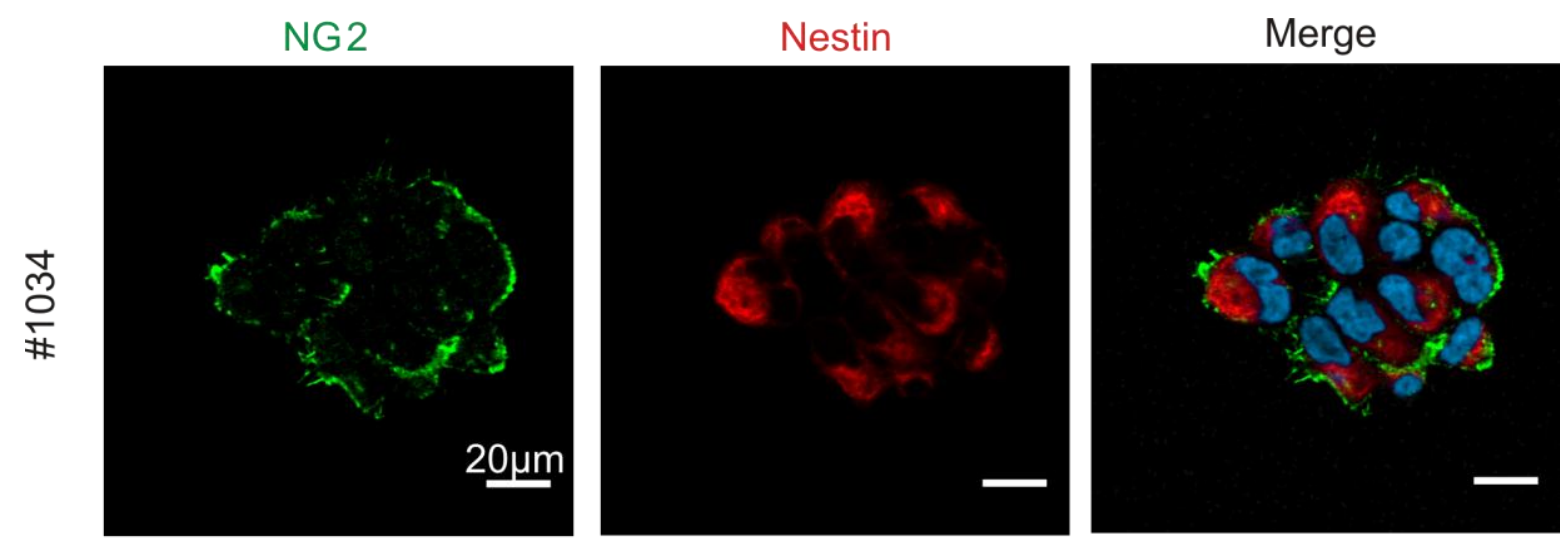

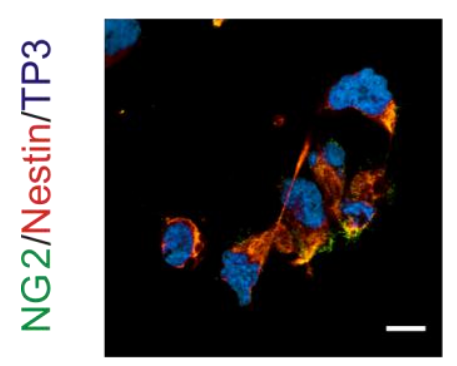

\#10

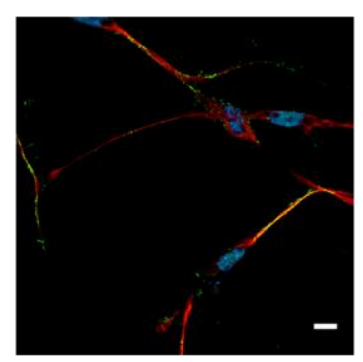

$\# 1063$

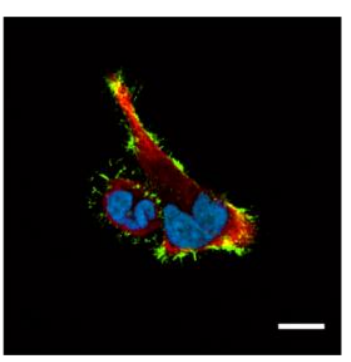

\#1095

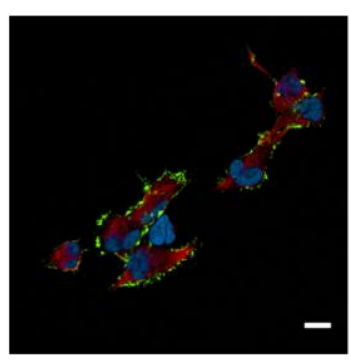

\#1051

Figure 4. BTICs co-express nestin and NG2. Representative cells from each line labeled with specific anti-NG2 (green) and anti-nestin (red) antibodies. NG2 signal has a pattern compatible with a membrane staining showing enhancement in cellular processes. Nestin has an intracellular localization. An exemplary line \#1034, is shown in an enlarged display (top row) to better appreciate the structural details. TO-PRO-3 (TP3) was used as a nuclear marker (blue). Scale bars $=20 \mu \mathrm{m}$.

According to the expression of glial fibrillary acidic protein (GFAP), the cell lines could be divided into those which had a GFAP ${ }^{+}$population, namely \#10 and \#1034 with $41.15 \pm 8.56 \%$ and $30.57 \pm 1.86 \%$ positive cells respectively and those lines where no GFAP could be detected (\#1063, \#195 and \#1051). 

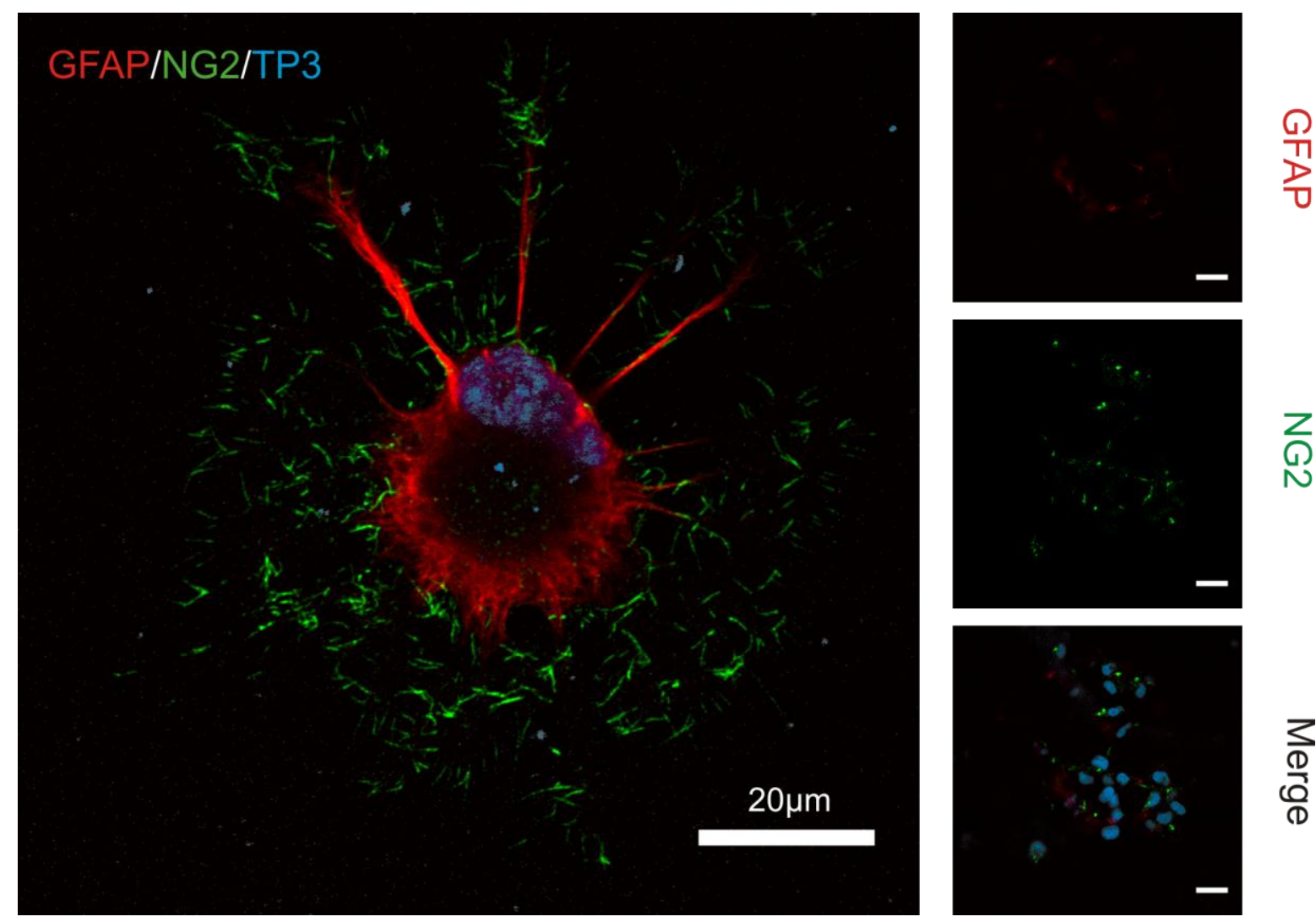

Figure 5. GFAP ${ }^{+}$cells express NG2. NG2 signal (green) is observed in the majority of \#1034 cells (right, middle panel), whereas GFAP (red) is expressed in a subpopulation of cells (right, top panel). In GFAP ${ }^{+} \mathrm{NG}^{+}$cells (left panel), the expression of the GFAP seems to be confined to the intracellular compartment, while the NG2 signal is more abundant in the periphery. Nuclei were counterstained with TO-PRO-3 (blue). Scale bars $=20 \mu \mathrm{m}$.

No reactivity was observed for the oligodendrocyte specific protein myelin basic protein (MBP) or the neuron specific protein neuronal nuclei (NeuN).

Given the ubiquitous expression of nestin and NG2, we hypothesized that both proteins should co-localize to the same cells. A simultaneous labeling with anti-NG2 and anti-nestin specific antibodies confirmed that a vast majority of cells were $\mathrm{NG}^{+} /$nestin ${ }^{+}$(Figure 4, page 20). Likewise, GFAP ${ }^{+}$cells also expressed NG2 (Figure 5, page 21) and nestin (Figure 6, page 22). 

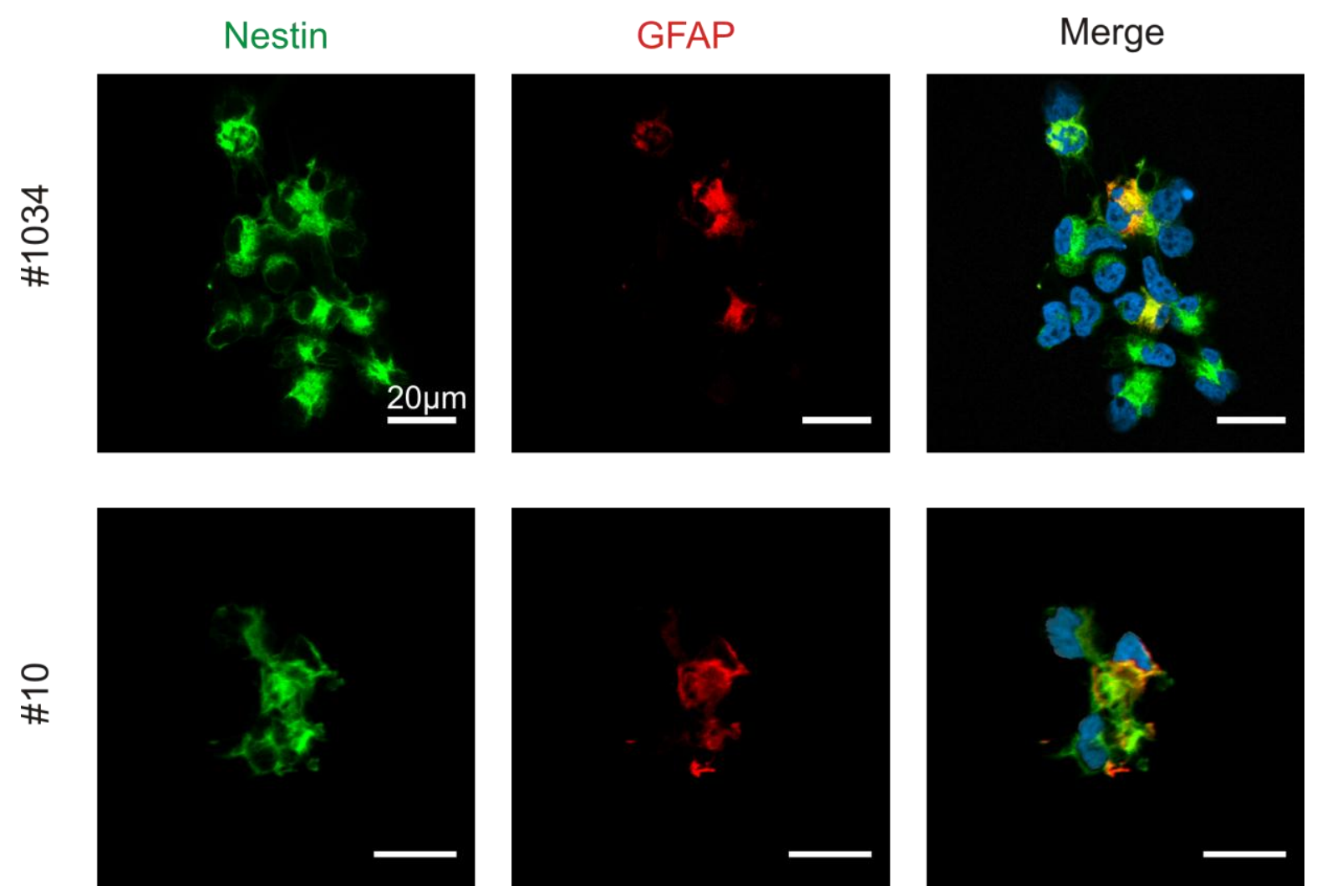

Figure 6. GFAP ${ }^{+}$cells express nestin. GFAP ${ }^{+}$cells (red) from \#10 (top row) and \#1034 (bottom row) co-expressed the NSC-marker nestin (green). All GFAP- cells were also nestin ${ }^{+}$. Nuclei were counterstained with TO-PRO-3 (blue). Scale bars $=20 \mu \mathrm{m}$.

\subsection{BTICs have a restricted differentiation potential}

The capacity of a cell to produce a heterogeneous lineage is a common finding of BTICs and has even been proposed as defining criteria since this feature might explain the ability of BTICs to recapitulate the cellular heterogeneity of the tumor (Clarke et al., 2006). Also, the response to particular factors can provide valuable information about the identity of the cells. Therefore, we treated the cells with either $10 \%$ fetal calf serum (FCS), tri-iodothyronine (T3), $100 \mathrm{ng} / \mathrm{ml}$ ciliary neurotrophic factor (CNTF) or $10 \mu \mathrm{M}$ forskolin (FORS) and measured the changes in the expression of markers of astroglial, oligodendroglial and neuronal lineages.

As expected from the differentiation pattern described for normal NSCs (Galli et al., 2004; Ignatova et al., 2002) and OPCs (Stallcup and Beasley, 1987), the addition of $10 \%$ FCS produced a significant increase in the percentage of GFAP-positive cells in all lines. Those cell lines that had a heterogeneous expression of GFAP (\#10 and \#1034) showed an increment of 30-50\%. The effect was even more dramatic in those 
cell lines where no initial GFAP expression was detected, where increments of 15 and up to $63 \%$ were observed (Figure 7 ). NeuN and MBP were not detected after exposure to FCS.

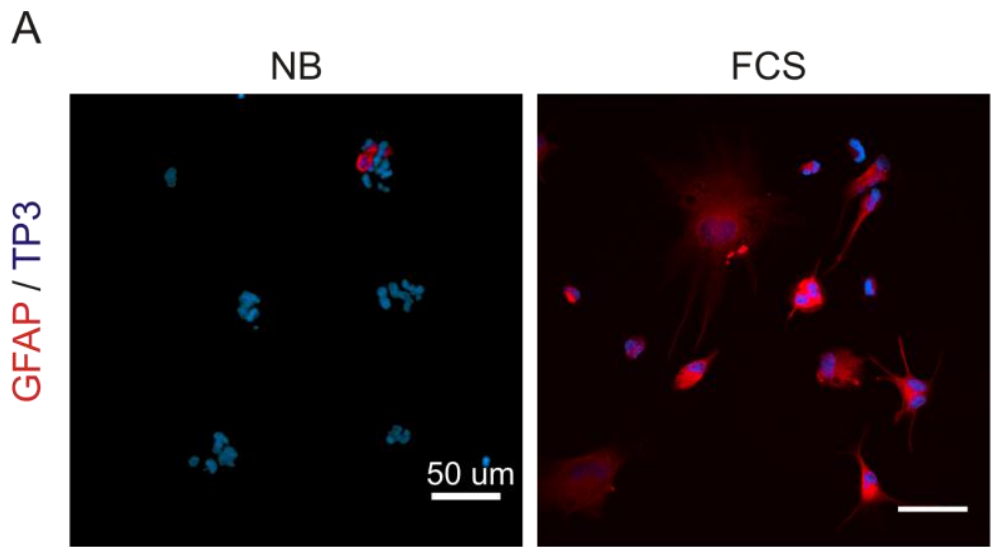

B

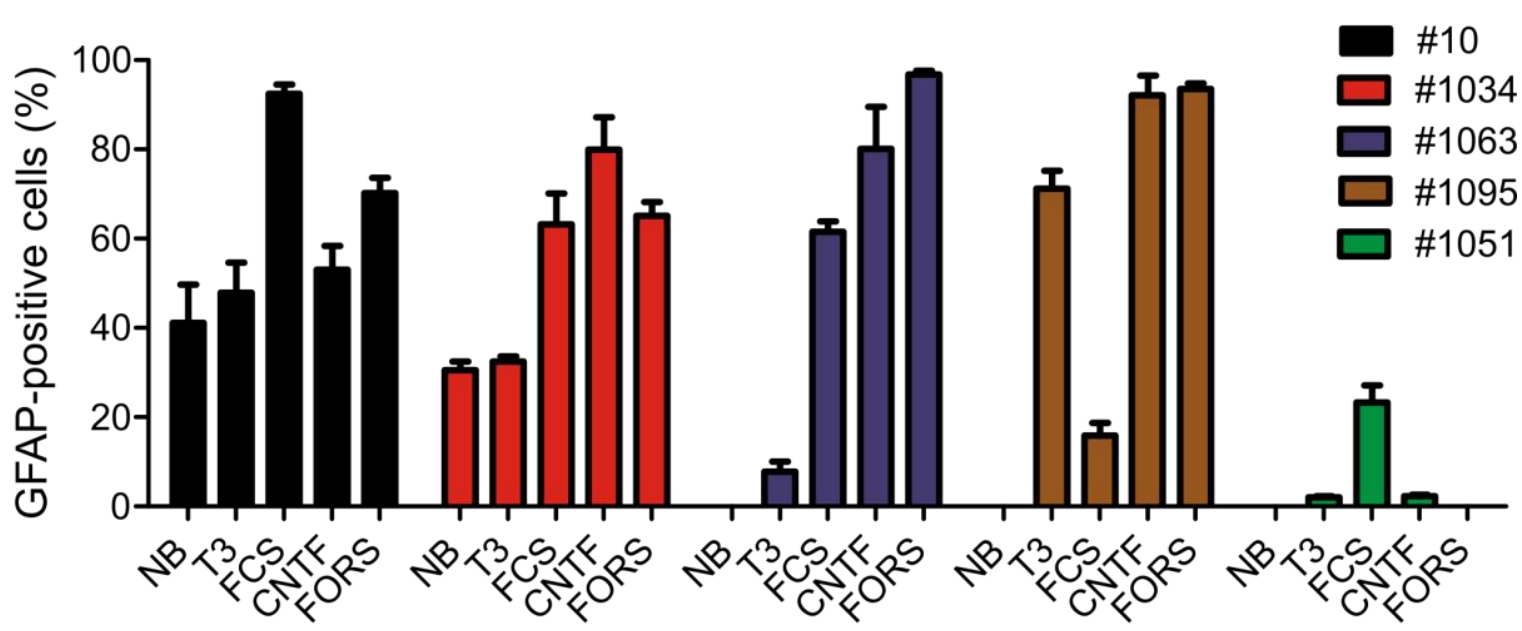

Figure 7. Differentiation potential of BTICs A. Representative confocal image of \#1034, showing GFAP ${ }^{+}$cells (red) after 5 days in neurobasal medium (NB, left panel) or NB supplemented with $10 \%$ FCS (FCS, right panel). B. The increase in the GFAP ${ }^{+}$population was also observed when the medium was supplemented with T3, CNTF or Forskolin (FORS). No NeuN or MBP was detected in any of the conditions.

Given the expression of NG2 and the increase in $\mathrm{GFAP}^{+}$cells observed under $10 \%$ FCS (Stallcup and Beasley, 1987), we wanted to test whether the cell lines followed a differentiation pattern analogous to that of OPCs and could therefore be induced to differentiate along the oligodendroglial lineage. Consequently, BTICs were grown in the presence of T3 and CNTF, factors known to drive the differentiation of normal OPCs into oligodendrocytes (Fitzner et al., 2006; Mayer et al., 1994). Surprisingly, no MBP was detected after 5 days. To rule out the possibility of a flawed differentiation regime, normal cultured mouse OPCs were used as a positive control. In this model, MBP expressing cells were observed after 5 days (Figure 8, page 25). 
Nevertheless, a significant increment in the percentage of $\mathrm{GFAP}^{+}$cells was again observed in those cell lines which were otherwise GFAP' when grown in neurobasal medium, namely: \# 1063 8\% increase, $p=0.03$; \#1051, 2.1\% increase, $p=0.01$ and \#1095 71\% increase, $p<0.0001$ (Figure 7, page 23).

Interestingly, in \#1095 the increase in $\mathrm{GFAP}^{+}$cells was larger in the presence of T3 than in 10\% FCS. Line \#10 also showed a statistically not significant increase in GFAP ${ }^{+}$ cells upon exposure to either T3 or CNTF. A similar effect was observed in \#1034 and \#1051 in response to T3 or CNTF. Again, no NeuN expression was detected.

Further, we tested the effect of forskolin, a factor known to induce differentiation of NSCs into the neural lineage (Persson et al., 2010). Unexpectedly, a significant increase in $\mathrm{GFAP}^{+}$cells was observed in all cell lines, with the exception of \#1051, where only a slight increment was observed (Figure 7, page 23). We were not able to detect NeuN or MBP under any of the differentiation conditions used. 

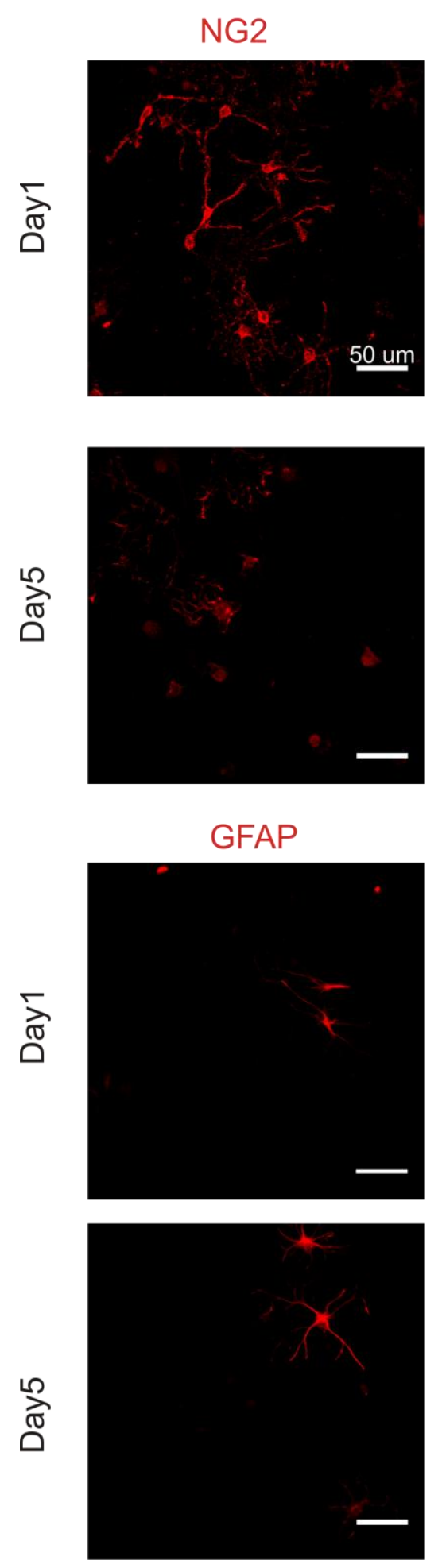
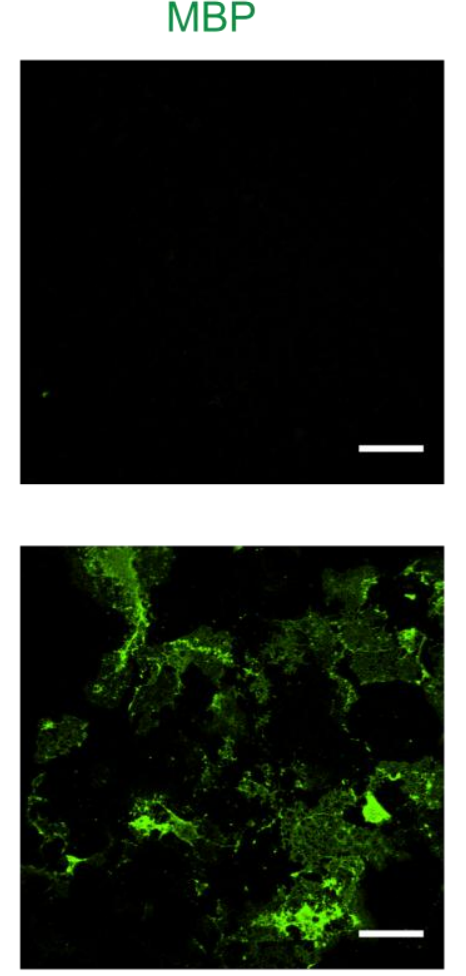

NeuN
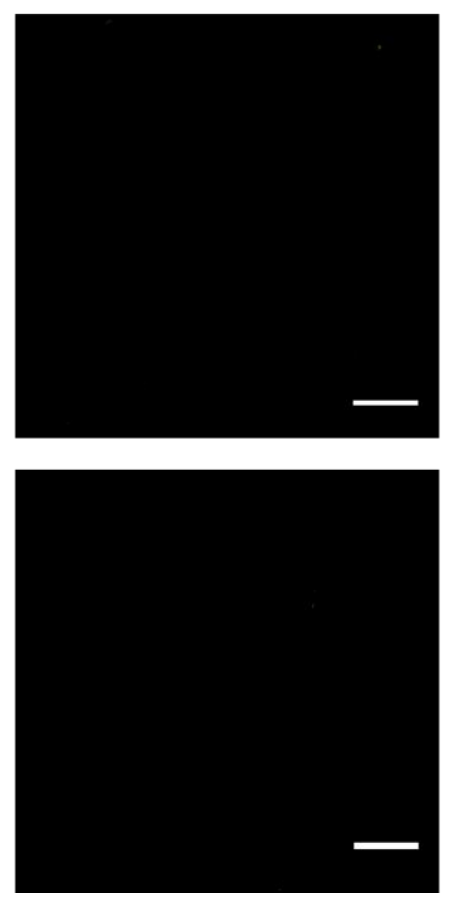

Merge
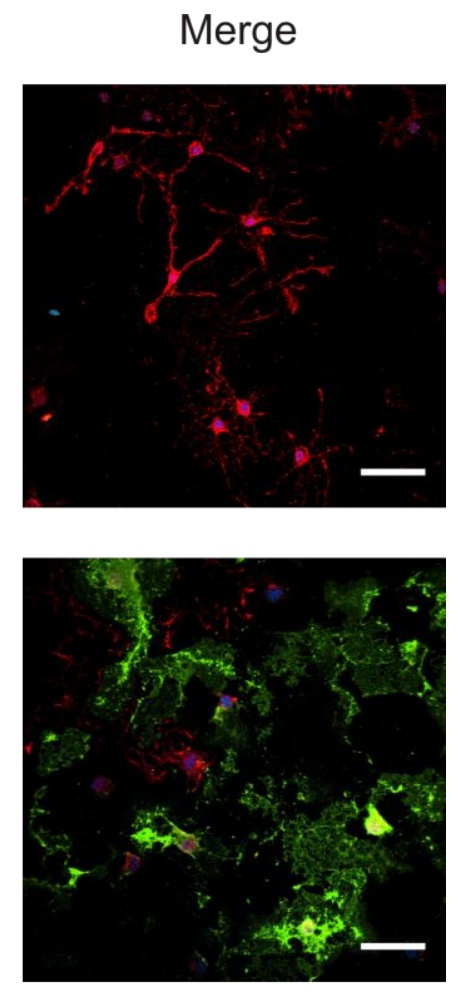

Merge
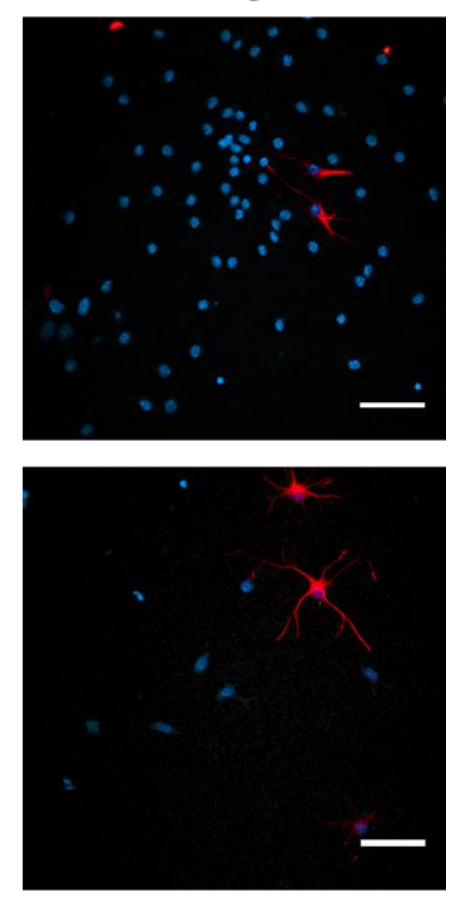

Figure 8. Differentiation of mouse OPCs. After 5 days in the presence of T3, mouse OPCs express MBP and reduce the number of $\mathrm{NG}^{+}$cells (middle upper row). No differences are observed in the number of GFAP or NeuN expressing cells (lowermost row). Scale bars = $50 \mu \mathrm{m}$. 


\subsection{Membrane Properties of BTICs: Electrophysiology}

The expression of NG2, PDGFRa, nestin and GFAP and a differentiation potential restricted to the astroglial lineage does not conform to the behavior described for any of the normal CNS subpopulations. Therefore we wanted to know whether BTICs exhibit physiological features attributed to normal NSCs, NG2 glia or rather of terminally differentiated neuronal or glial populations. Consequently, we performed whole-cell patch clamp recordings of dissociated spheroids, to study the functional expression of ionic currents and membrane properties of BTICs.

\subsubsection{BTICs have a moderate membrane resistance}

Most cell types of the CNS have been described in terms of their membrane resistance. For example, low values have been reported for astrocytes ( 10 $\mathrm{M} \Omega$ ) (Bergles et al., 2000; Lin and Bergles, 2004; Mueller et al., 2009) and oligodendrocytes $(<200 \mathrm{M} \Omega$ ) (Tripathi et al., 2011). The membrane resistance of NG2 cells at voltages close to the resting potential has been described as intermediate and ranges between $200 \mathrm{M} \Omega$ and $1 \mathrm{G} \Omega$ (Káradóttir et al., 2008; Kukley et al., 2010; Mueller et al., 2009). On the other hand, neurons and NSCs have very high input resistances (up to $4 \mathrm{G} \Omega$ ) (Wang et al., 2003).

Therefore, we calculated the membrane resistance of BTICs by dividing the voltage response of the membrane to a stepwise current injection as described elsewhere (Llinas and Sugimori, 1980) (Figure 9.A, page 27). Although significant variations in membrane resistance were found between lines (one-way ANOVA, $p=0.0015$ ), all values ranged between $300 \mathrm{M} \Omega$ and $600 \mathrm{M} \Omega(\# 10397.3 \pm 36.46 \mathrm{M} \Omega, \mathrm{n}=8 ; \# 1034$ $497.0 \pm 158.5 \mathrm{M} \Omega, \mathrm{n}=4 ; \# 1063631.8 \pm 45.9 \mathrm{M} \Omega, \mathrm{n}=15 ; \# 1095401.1 \pm 44.24 \mathrm{M} \Omega, \mathrm{n}=8$; \#1051 $331.7 \pm 39.75 \mathrm{M} \Omega, \mathrm{n}=10$ ) (Figure 9.B, page 27). 
A

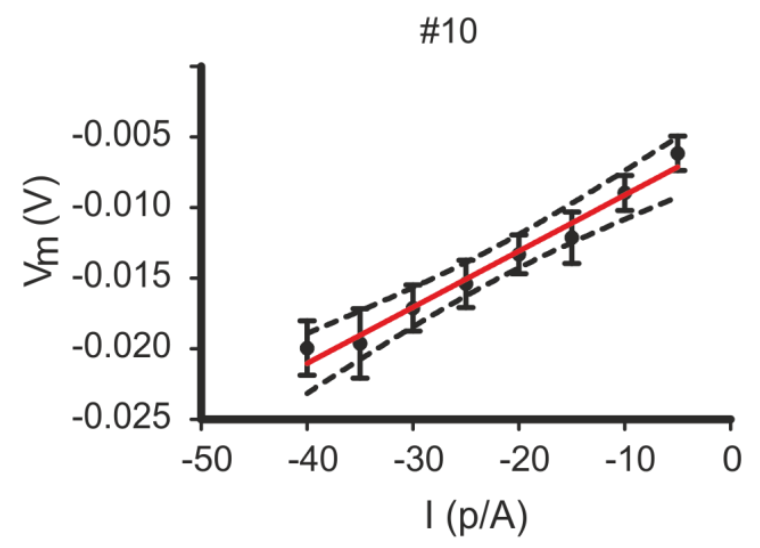

B

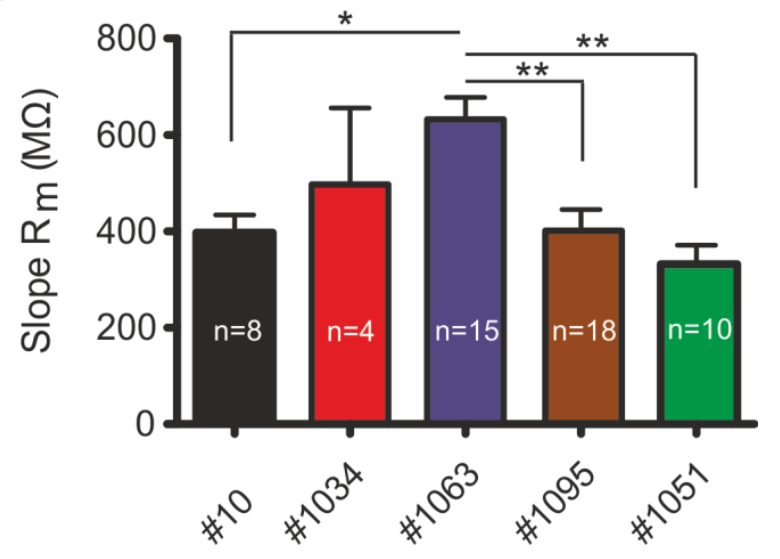

Figure 9. Intermediate membrane resistance of BTICs. A. Representative voltage response to a stepwise current injection in $\# 10(n=8)$. The red line represents the best linear fit to the data. The dotted line represents $95 \%$ confidence intervals. B. Slope of the curve (as in A) for all cell lines tested. Asterisks represent zeros after the decimal point in the value of $p$ and are only displayed for values where $p<0.05$. Error bars in $B$ represent standard error of the mean (s.e.m.).

\subsubsection{BTICS express voltage dependent $\mathrm{Na}^{+}$currents and regenerative voltage transients}

In all cell lines we observed a transient inward current within the first $2 \mathrm{~ms}$ of a depolarizing pulse between -40 and $40 \mathrm{mV}$ from a holding potential of $-60 \mathrm{mV}$ (Figure 10.A) The current density, which was calculated by dividing the peak current amplitude at $0 \mathrm{mV}$ by the cell capacitance, ranged from $1.4 \pm 0.5 \mathrm{pA} / \mathrm{pF}$ in \#1051 to $8.7 \pm 0.9$ $\mathrm{pA} / \mathrm{pF}$ in $\# 10$ and was significantly different among lines (One Way ANOVA, $p<0.001$ ) (Figure 10.B and $\mathrm{C}$ ). The current density values for the remaining lines were: \#1034 $6.54 \pm 0.76 \mathrm{pA} / \mathrm{pF}, \# 10635.10 \pm 1.09 \mathrm{pA} / \mathrm{pF}(\mathrm{n}=18)$ and \#1095 $6.93 \pm 0.91 \mathrm{pA} / \mathrm{pF}$ $(n=35)$. 
A
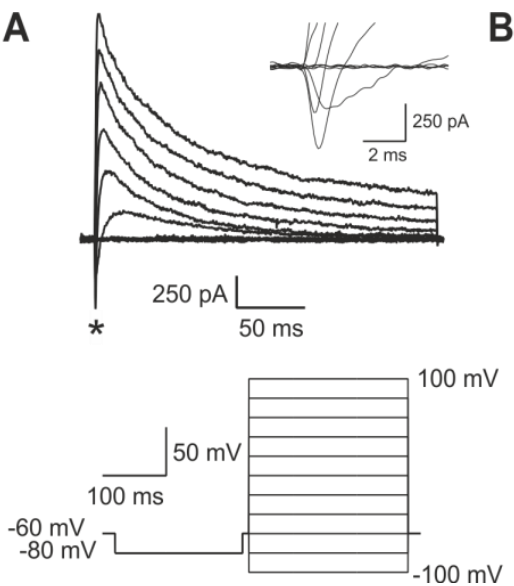

B

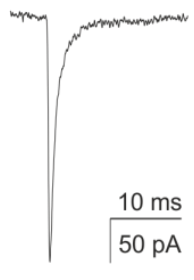

C

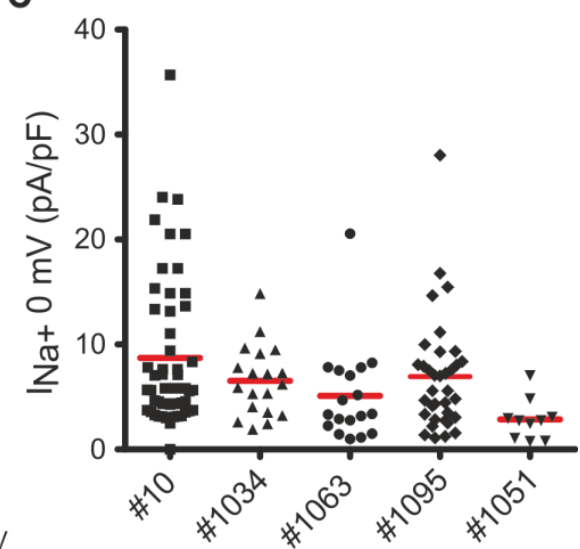

Figure 10. Transient inward currents in BTICs. A. Current response of a representative $\# 1095$ cell (upper panel) to variable voltage steps from a holding potential of $-80 \mathrm{mV}$ (lower panel). The current has fast activating and fast inactivating components and reaches steadystate towards the end of the pulse. Note the presence of a fast transient current in the first few milliseconds of the voltage pulse (upper panel, inset). B. Inward current elicited in response to a depolarization to $0 \mathrm{mV}$, from a holding potential of $-60 \mathrm{mV}$ (lower panel). C. Current density values of the inward current of individual cells in all cell lines tested. Red lines represent the mean.

Despite the differences in current density, when the current-voltage (I-V) relationship was plotted and fitted for all groups of cells (Figure 11.A) we observed no significant differences in half maximal activation (\#10 -24.5 $\pm 1.2 \mathrm{mV}, \mathrm{n}=11$; \#1034 $26.5 \pm 1.9 \mathrm{mV}, \mathrm{n}=12 ; \# 1063-28.0 \pm 1.9 \mathrm{mV}, \mathrm{n}=12 ;$ \#1095 -28.4 $\pm 1.6 \mathrm{mV}, \mathrm{n}=19$ and \#1051 -22.6 $\pm 8.5 \mathrm{mV}, \mathrm{n}=4$; One way ANOVA, $\mathrm{p}=0.59$ ) (Figure 11.B) or reversal potential (\#10 -24.5 $\pm 1.2 \mathrm{mV}, \mathrm{n}=11$; \#1034 -26.5 $\pm 1.9 \mathrm{mV}, \mathrm{n}=12 ; \# 1063-28.0 \pm 1.9$ $\mathrm{mV}, \mathrm{n}=12 ; \# 1095-28.4 \pm 1.6 \mathrm{mV}, \mathrm{n}=19$ and \#1051 -22.6 $\pm 8.5 \mathrm{mV}, \mathrm{n}=4$; One way ANOVA, $p=0.68$ ) (Figure 11.C). 

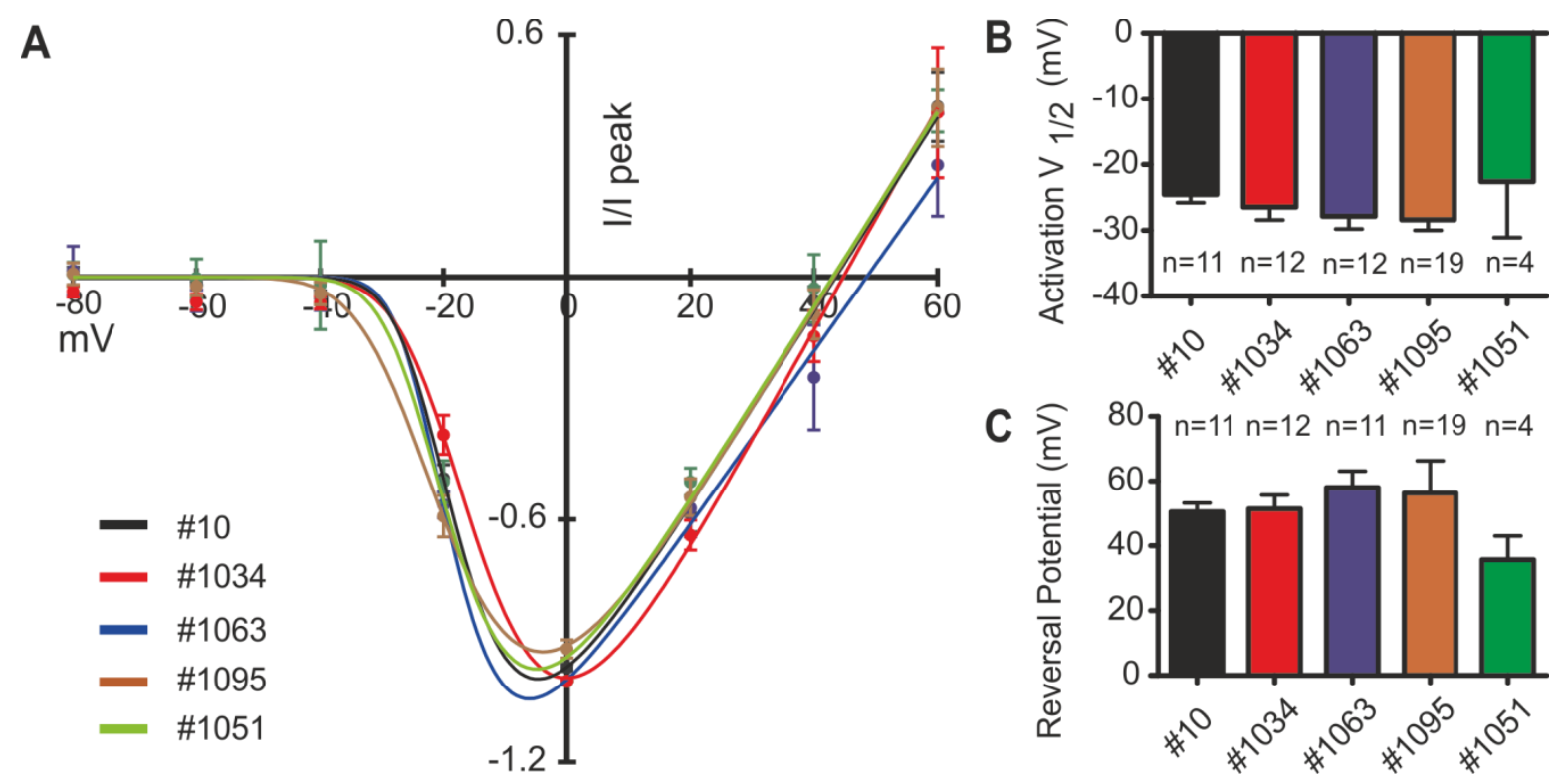

Figure 11. Voltage dependence of transient inward currents A. Current - Voltage (I-V) relationship of the transient inward current exhibits a similar behavior in all BTIC lines. B. No significant differences between lines were observed in half maximal activation or reversal potential (C.). Error bars represent standard error of the mean.

More than $95 \%$ of the current was reversibly blocked, in all cases, by application of 500 nM TTX (\#10 98.1 $0.7 \%(n=7) ; \# 103497.2 \pm 1.6 \%(n=4) ; \# 106391.2 \pm 4.2 \%$ $(n=4) ; \# 109594.7 \pm 2.1 \%(n=7)$; and, \#1051 95.1 $\pm 2.1 \%(n=5))$ (Figure 12, page 29). The kinetic and pharmacological characteristics indicate that the inward current is compatible with a current mediated by voltage-gated sodium channels.

A

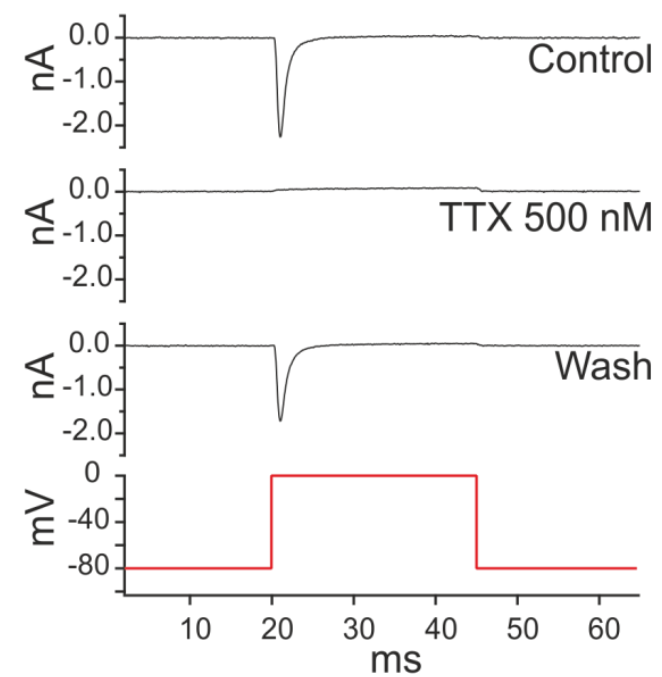

B

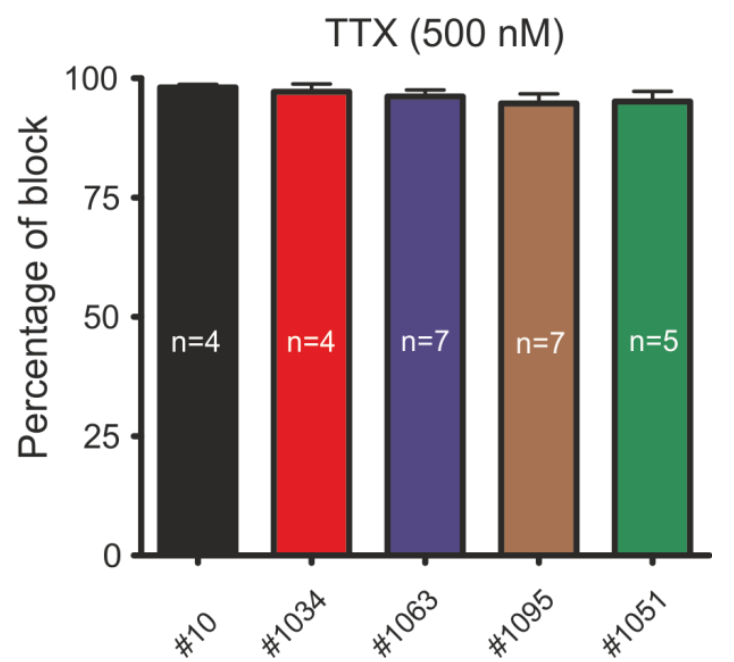

Figure 12. Transient inward currents are sensitive to TTX. A. Current response of a \#1095 cell to a voltage stimulus of $0 \mathrm{mV}$ from a holding potential of $-80 \mathrm{mV}$ (bottom panel). The control response (uppermost panel) can be blocked by applying $500 \mathrm{nM}$ TTX to the bath solution (middle upper panel) and can be reverted by removal of the toxin (middle lower panel). To better illustrate the effect of TTX on the sodium current, a cell with low outward current 
density was used. B. TTX blocked above $95 \%$ of the current in all cell lines tested. Error bars represent standard error of the mean.

The currents mediated by voltage-gated sodium channels could be found in the majority of cells within a given culture: \#10 98\% positive cells (53 out of 54 cells), \#1034 100\% ( $n=23$ ), \#1063 82\% (18 out of 22 cells) and \#1095 97\% (36 out of 37 cells) with the exception of \#1051, where only 10 out of 30 cells had sodium currents.

Given the heterogeneous expression of sodium currents, we decided to implement an imaging approach to further quantify the percentage of cells expressing sodium channels. To do this, the cells were labeled with a pan-sodium channel antibody (Sigma). The labeling showed a signal cluster adjacent to the nucleus and in some cases a peripheral pattern suggestive of membrane localization. The proportion of positive cells was similar to that found by electrophysiology in most cases, namely: \#10, 96\%; \#1034, 93\%; \#1063, 76\%. For the remaining two cell lines, both methods show somehow different results, where \#1095 shows less (56\%) and \#1051, shows more $(72 \%)$ positive cells than by electrophysiology $\left(X^{2}=19.94, p=0.0005\right)$ (Figure 13, page 31$)$. This might possibly be because immunocytochemistry detects channels in both the intracellular and membrane compartments whereas electrophysiology can only detect membrane bound, functional channels. 

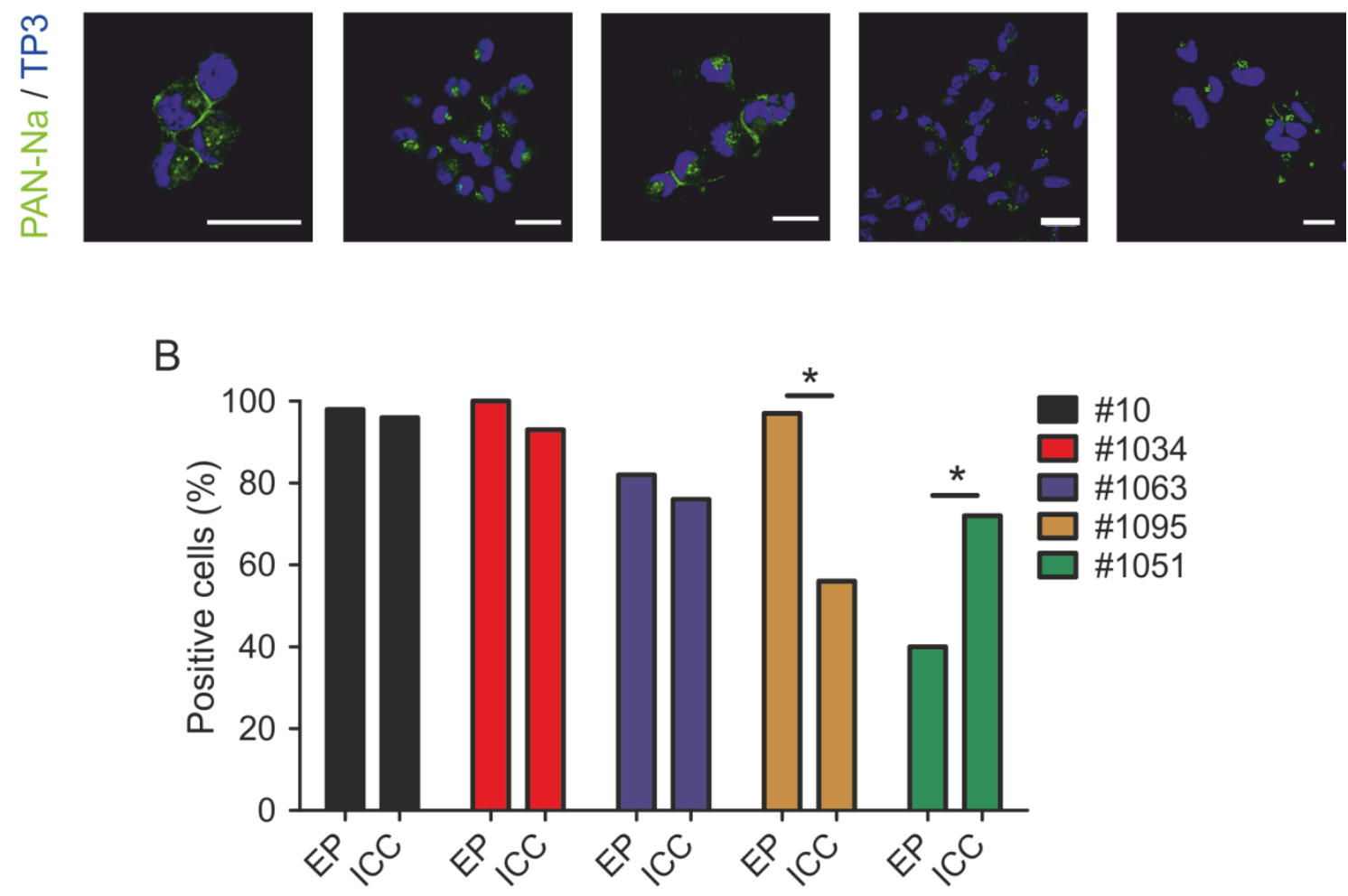

Figure 13. Expression pattern of voltage-gated sodium channels in BTICs. A. Immunostaining using an antibody against a common epitope of voltage-gated sodium channels (Pan-Na, green) revealed a signal cluster adjacent to cell nuclei (blue) and in some lines it could be observed as a clear membrane staining (\#10 and \#1063). The cells were identified by staining the nuclei with TO-PRO3 (TP3, blue). Scale bars $=50 \mu \mathrm{M}$. B. Two methods, electrophysiology (EP) and immunocytochemistry (ICC) were used to determine the percentage of positive cells. A discrepancy between the two methods was observed in lines \#1095 and $\# 1051$, probably due to the different sensitivity of both techniques. The asterisks represent a $p$ value $<0.05$. Error bars represent standard error of the mean.

After confirming the expression of voltage-gated sodium channels, we tested the excitability of the cell membrane by measuring the voltage response to the injection of variable current pulses. Surprisingly, upon current stimuli $>40 \mathrm{pA}$, we were able to elicit a single regenerative voltage transient in about one third of the cells (\#10, 5 out of 18 cells; \#1063 7/19, \#1095 9/26, \#1051 3/8) and in all \#1034 cells ( $n=5)$ (Figure 14., page 32). Although reminiscent of an action potential, the regenerative voltage transient occurred in a much slower time scale and will therefore not be referred to as an action potential. 
A

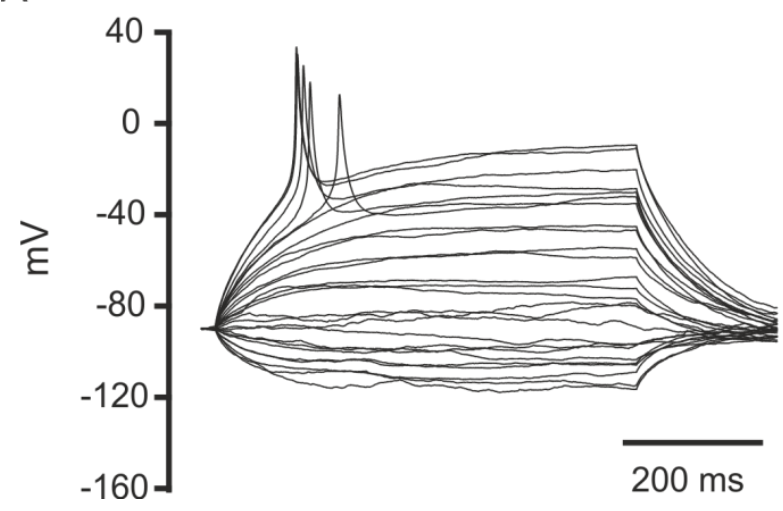

B

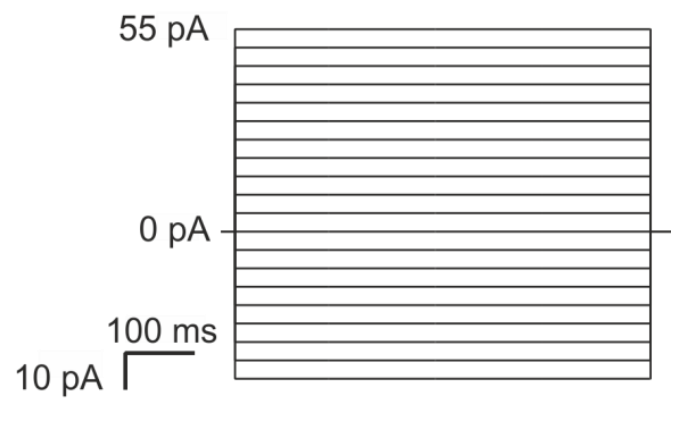

Figure 14. Outward regenerative voltage transients. A. Voltage response to a step-wise current injection protocol shown in B. Note the appearance of a single, broad voltage transient at the beginning of the pulse in response to larger current injection.

Besides the initial transient, which was regenerative in nature, the continuous current stimulation eventually reached a steady state (Figure 14.A, page 32); therefore we defined a post-transient baseline (PTB) as the average voltage in in the last $500 \mathrm{~ms}$ of the pulse as a reference point to calculate properties of the transient (Figure 15.A, page 33).

The mean absolute peak of the transient was above $0 \mathrm{mV}$ in most of the cases (\#10 $17.8 \pm 3.7, \mathrm{n}=5 ; \# 103415.3 \pm$ 4.3, n=5; \#1063 $8.6 \pm 3.7, \mathrm{n}=7 ; \# 10957.4 \pm 5.8, \mathrm{n}=7$ ) with the exception of \#1051 where the value was $-1.9 \pm 3.8, n=3$ (Figure 15.B, page 33).

Nevertheless, the regenerative transient could be recognized due to the fact that in all cells measured, it had an overshoot larger than the PTB $10.23 \pm 1.8 \mathrm{mV}(\mathrm{n}=5)$ in $\# 10,16.01 \pm 3.3 \mathrm{mV}(\mathrm{n}=5)$ in \#1034, $7.2 \pm 3.5 \mathrm{mV}(\mathrm{n}=7)$ in \#1063, $20.3 \pm 8.83 \mathrm{mV}$ $(\mathrm{n}=7)$ in \#1095 and $8.02 \pm 0.1 \mathrm{mV}(\mathrm{n}=3)$ in \#1051 (Figure 15.C, page 33). Also a relative afterhyperpolarization (AHP) could be seen with mean values of $-1.3 \pm 1.3 \mathrm{mV}$ $(n=5)$ for \#10, $-7.0 \pm 3.9 \mathrm{mV}(\mathrm{n}=5)$ for \#1034, $-4.86 \pm 1.3 \mathrm{mV}$ for \#1063 $(\mathrm{n}=7),-8.9 \pm$ $3.38 \mathrm{mV}$ for \#1095 $(\mathrm{n}=7)$ and $-2.24 \pm 2.13 \mathrm{mV}$ for \#1051 ( $\mathrm{n=3}$ ) (Figure 15.D, page 33). 
A

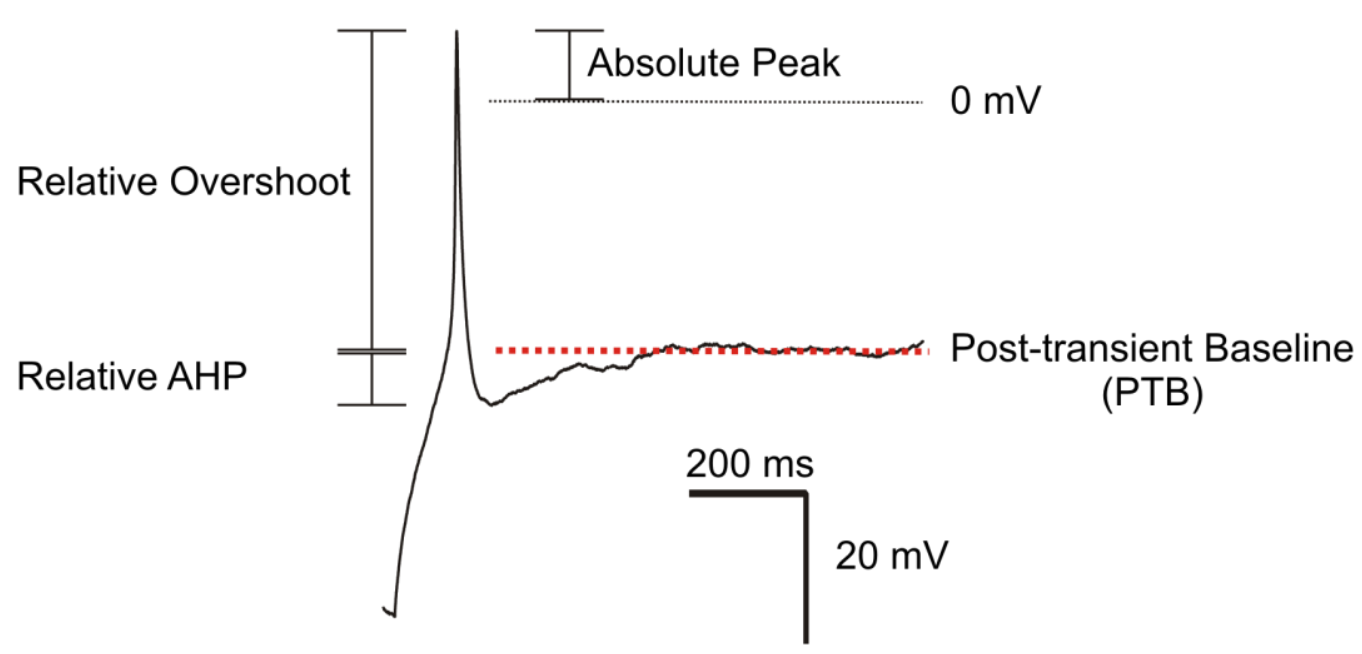

B

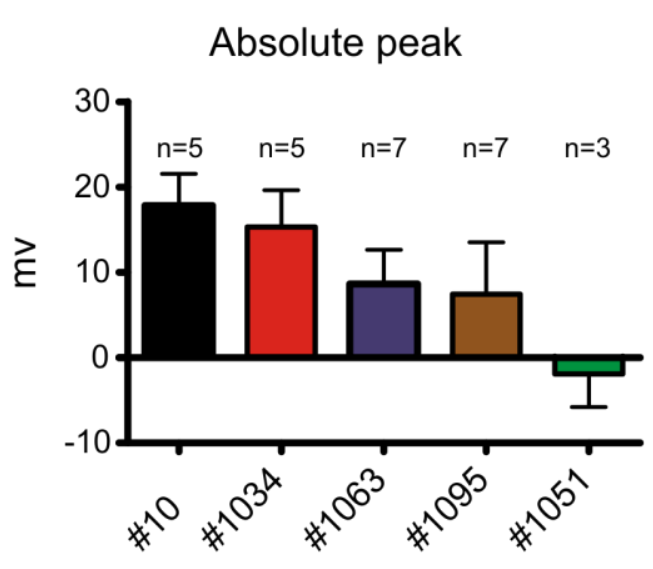

$D$

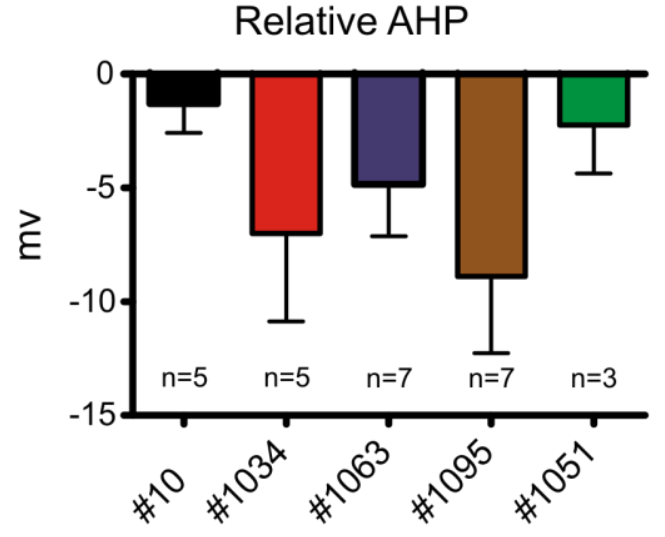

C

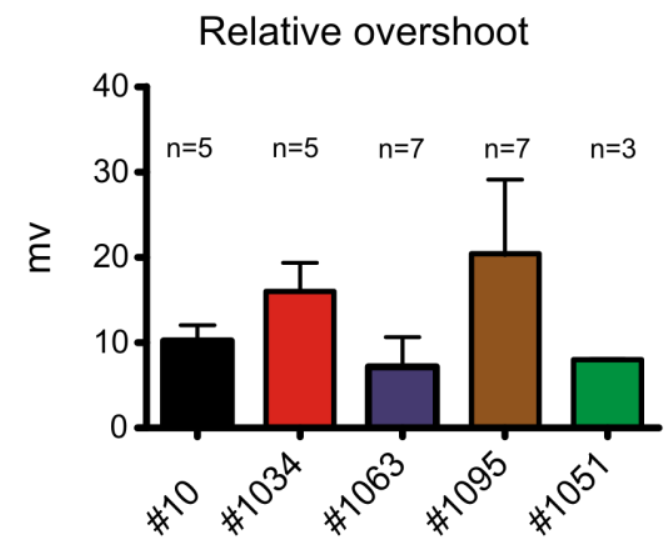

$\mathrm{E}$

Transient width at PTB

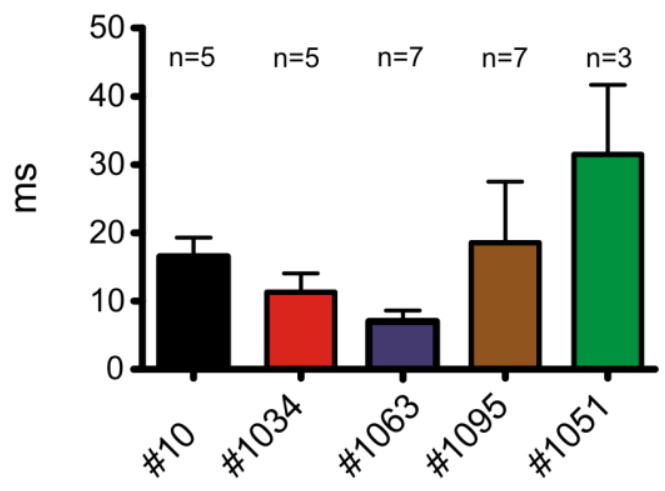

Figure 15. Biophysical parameters of regenerative voltage transients A. Representative voltage trace from a \#1034 cell, showing a schematic representation of the reference points used to measure different biophysical parameters. The mean values for absolute regenerative transient peak (B), relative overshoot (C), relative afterhyperpolarization (D) and transient width (E), are represented for each cell line. Error bars represent standard error of the mean. 
The transient was broad and slow when compared to typical action potentials of mouse granule cell neurons (Figure 16, page 35). It had a width at baseline of 16.5 $\pm 2.85 \mathrm{~ms}$ for \#10 ( $\mathrm{n}=5), 11.34 \pm 2.73 \mathrm{~ms}$ for \#1034 $(\mathrm{n}=5), 7.24 \pm 1.6 \mathrm{~ms}$ for \#1063 $(n=7), 18.6 \pm 8.92 \mathrm{~ms}$ for \#1095 ( $\mathrm{n}=7), 31.5 \pm 10.2 \mathrm{~ms} \# 1051(\mathrm{n}=3)$ (Figure 15.E, page 33). The speed was measured in terms of maximum rate of rise (MRR) and maximum rate of fall (MRF). The mean MMR for the different cell lines was $8.2 \pm 0.97 \mathrm{~V} / \mathrm{s}$ for $\# 10$ $(n=5), 15.65 \pm 2.6 \mathrm{~V} / \mathrm{s}$ for \#1034 $(\mathrm{n}=5), 13.75 \pm 2.6 \mathrm{~V} / \mathrm{s}$ for \#1063 $(\mathrm{n}=7), 20.26 \pm 4.3 \mathrm{~V} / \mathrm{s}$ for \#1095 $(n=7)$ and $4.95 \pm 1.16 \mathrm{~V} / \mathrm{s}$ for \#1051 $(\mathrm{n}=3)$ and the mean MRF $-2.5 \pm 0.4 \mathrm{~V} / \mathrm{s}$ $(n=5)$ for \#10, $-6.2 \pm 2.8 \mathrm{~V} / \mathrm{s}(\mathrm{n}=5)$ for \#1034, $-5.82 \pm 1.8 \mathrm{~V} / \mathrm{s}$ for \#1063 $(\mathrm{n}=7),-4.67 \pm$ $0.85 \mathrm{~V} / \mathrm{s}$ for \#1095 $(\mathrm{n}=7)$ and $-1.69 \pm 0.24 \mathrm{~V} / \mathrm{s}$ for \#1051 $(\mathrm{n}=3)$ (Figure 16, page 35 ). Both MMR and MRF were at least 20 fold higher in neurons. 


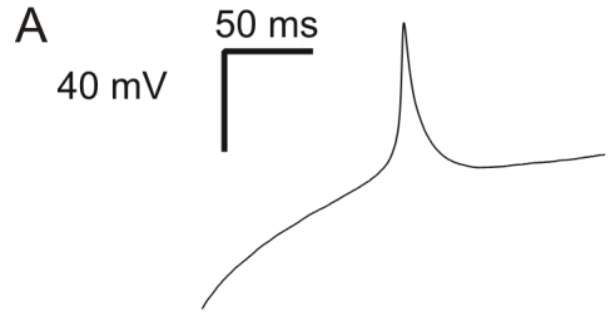

\#10

B

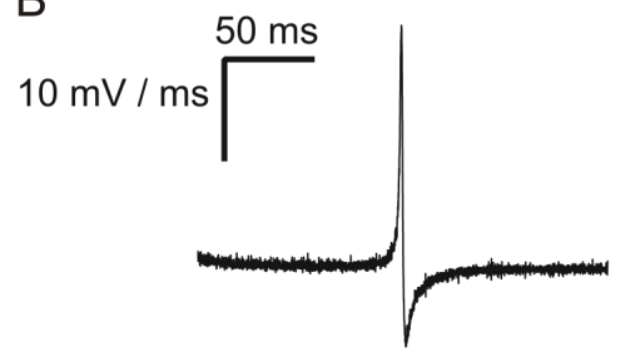

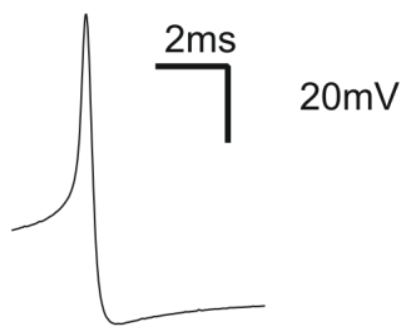

Neuron

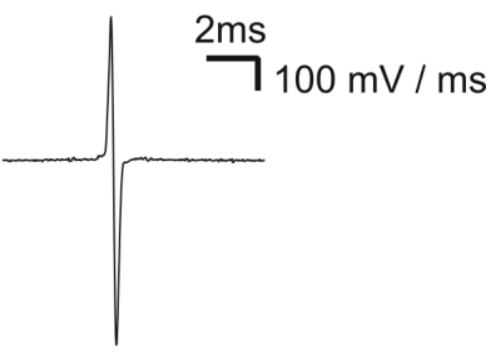

C Maximum rate of rise / Maximum rate of fall

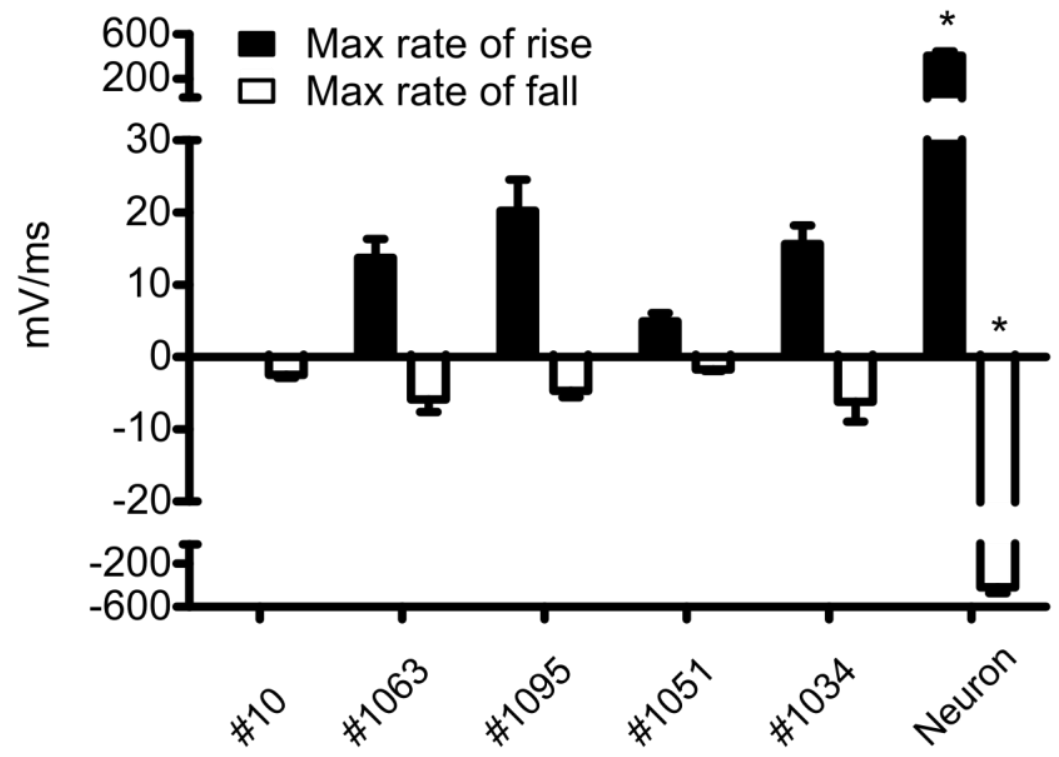

Figure 16. Speed of the regenerative voltage transient. A. Representative regenerative voltage transient of a \#10 cell (left panel) and its respective differential (B left pane). The regenerative transient is much slower than mouse granule cell neurons ( $\mathbf{A}$ and $\mathbf{B}$, right panel). Note the large difference in the scale bars. $\mathbf{C}$. Speed of the regenerative transient represented in terms of its differential as maximum rate of rise (MRR) and maximum rate of fall (MRF). No significant differences were observed between lines. The MRR and MRF of neurons were $>20$ fold larger than that of BTICs. Asterisks represent $p$ values $<0.05$. Error bars represents standard error of the mean.

Then we wondered if the sodium current density was related to the ability of the cells to produce voltage transients. Indeed, we found that those cells in which 
transients could be elicited had a significantly higher sodium current density in \#1095 (t-test, $\mathrm{p}=0.002$ ) and \#1051 (t-test, $\mathrm{p}=0.04$ ). In the remaining cell lines, a similar tendency was observed although no significance was reached $(\# 10$, t-test, $p=0.16$; $\# 1063$, t-test, $p=0.22$ ).

Regarding the sustained component of the outward current $\left(I_{K D R}\right)$ (Section 3.3.3.1, page 38) the occurrence of the spike did not correlate with its density, except in \#1063 (\#1063, t-test, $p=0.016 ; \# 10$, t-test, $p=0.94 ; \# 1095$, t-test, $p=0.74 ; \# 1051$, t-test, $\mathrm{p}=0.56$ ) (Figure 16, page 35).

We also found no differences when the $I_{K D R} / I_{N a}$ ratio (density of the sustained outward component at $40 \mathrm{mV}$ divided by the peak sodium current density at $-20 \mathrm{mV}$ ) as compared between cells with and without transient (\#1063, t-test, $\mathrm{p}=0.8$; \#10, t-test, $p=0.9$; \#1095, t-test, $p=0.95$; \#1051, t-test, $p=0.17$ ). No differences were calculated for \#1034 since transients were observed in all cells. 

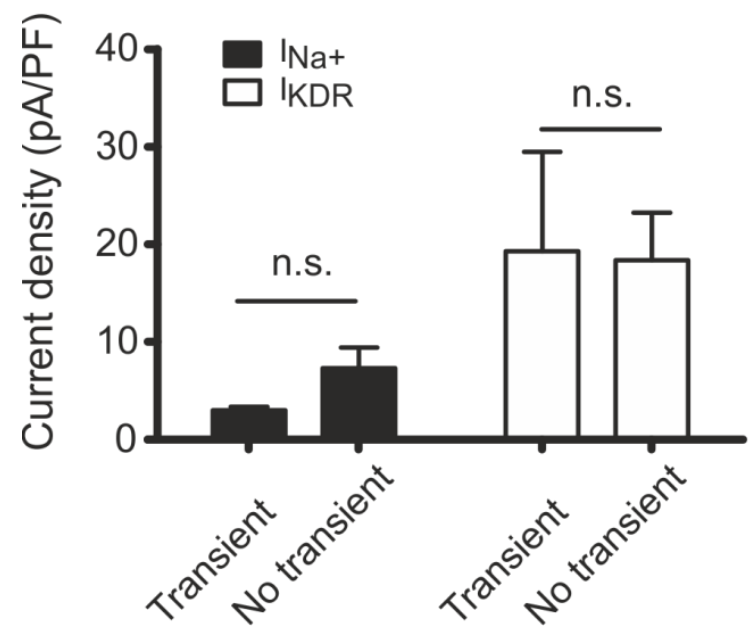

\#1095

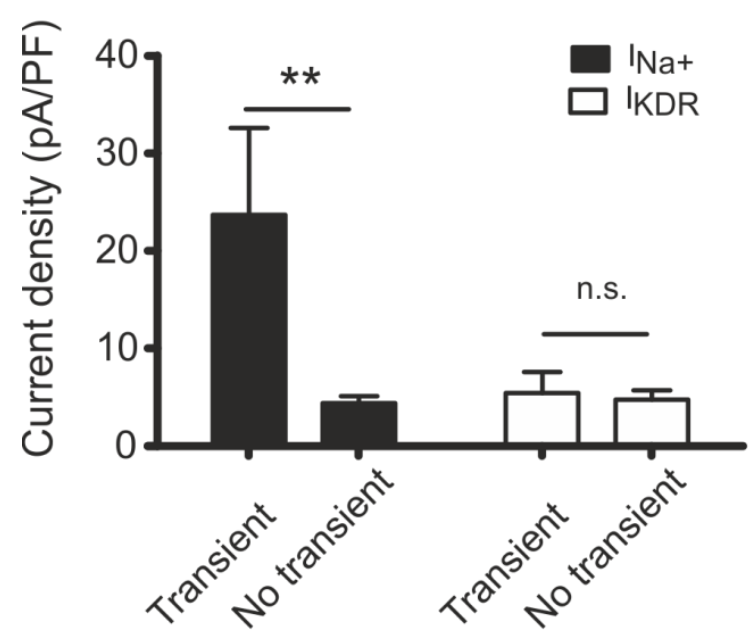

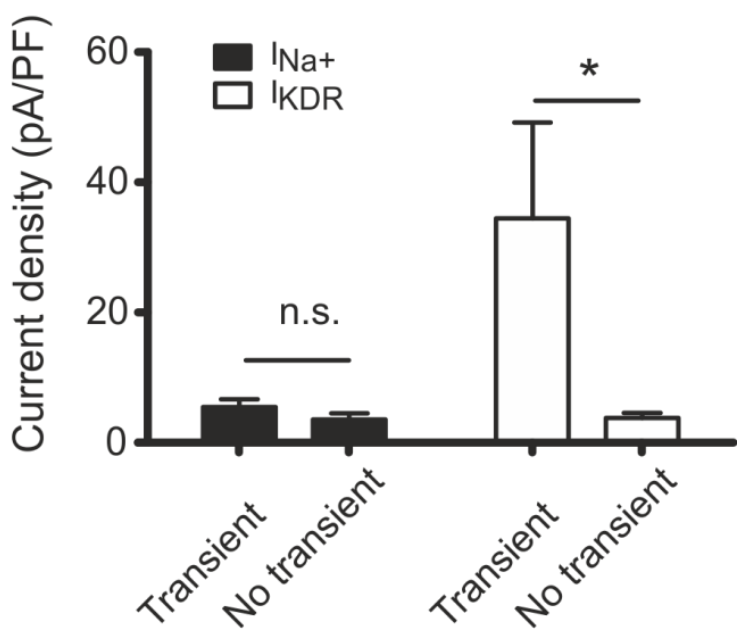

\#1051

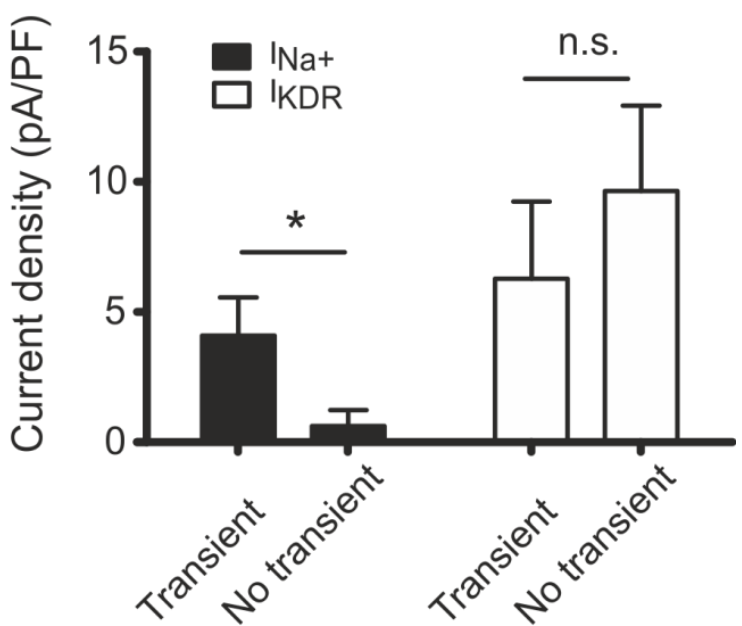

Figure 17. Sodium and potassium channel density and transient generation. The sodium and potassium channel density was compared in cells that exhibited transients and cells that did not, for \#10 (upper left panel), \#1063 (upper right panel), \#1095 (lower left panel) and \#1051 (lower right pane/). Significance was calculated using unpaired t-test. The asterisks represent zeros after the decimal point for $p$ value $<0.05$. n.s. $=$ non-significant. Error bars represent standard error of the mean.

The data suggest that the ability of a cell to produce a regenerative transient relies mainly on its content of sodium channels. To further test this hypothesis, we applied $500 \mathrm{nM}$ TTX to the extracellular solution, where we observed an abolishment of the transients (\#10, $n=1 ; \# 1063, n=1 ; \# 1095, n=5)$. 


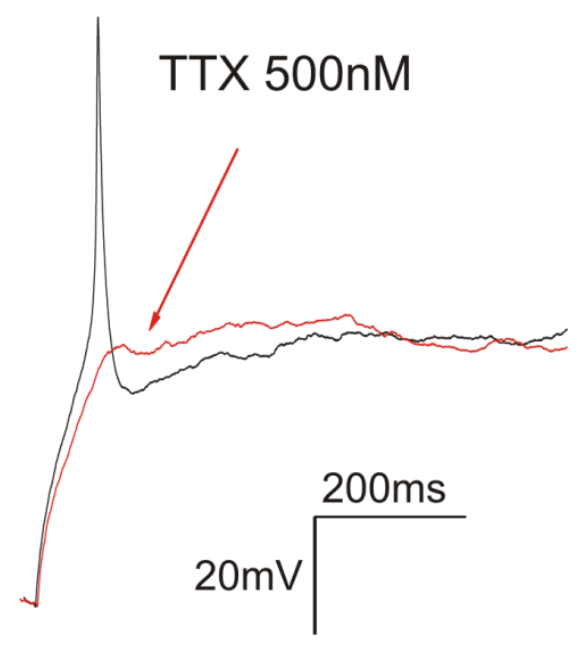

Figure 18. Regenerative voltage transients are sensitive to TTX. Representative voltage transient in a \#1095 cell (black) was abolished by the application of 500nM TTX (red).

\subsubsection{Voltage dependent outward currents}

Outward voltage dependent currents were recorded from all cells studied irrespective of cell line. An inactivating $\left(I_{K A}\right)$ and a sustained $\left(I_{K D R}\right)$ component were elicited when depolarizing steps from -100 and up to $100 \mathrm{mV}$ were given for $250 \mathrm{~ms}$ from a holding potential of $-60 \mathrm{mV}$ (Figure 9 page 27 ).

\subsubsection{Non-inactivating outward current $\left(I_{K D R}\right)$}

In order to isolate $\mathrm{I}_{\mathrm{KDR}}$ we applied a $200 \mathrm{~ms}$ pre-pulse to $-20 \mathrm{mV}$ that inactivated the current carried by the decaying component (Figure 20.A, page 39). The $\mathrm{I}_{\mathrm{KDR}}$ was reversibly and partially blocked ( 70\%) by $10 \mathrm{mM}$ TEA in all cell lines tested (\#10 $n=6$, \#1034 $n=6, \# 1063 n=4, \# 1095 n=7, \# 1051 n=10$ ), suggesting that the current is mediated by voltage-gated potassium channels. 
A
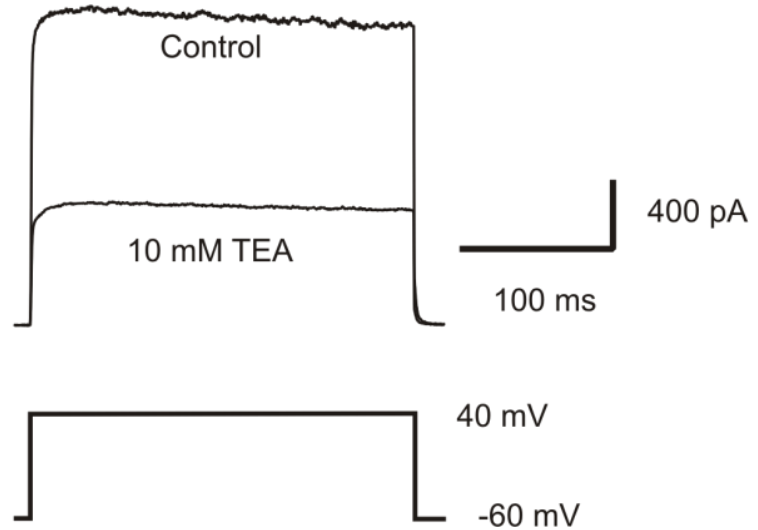

B

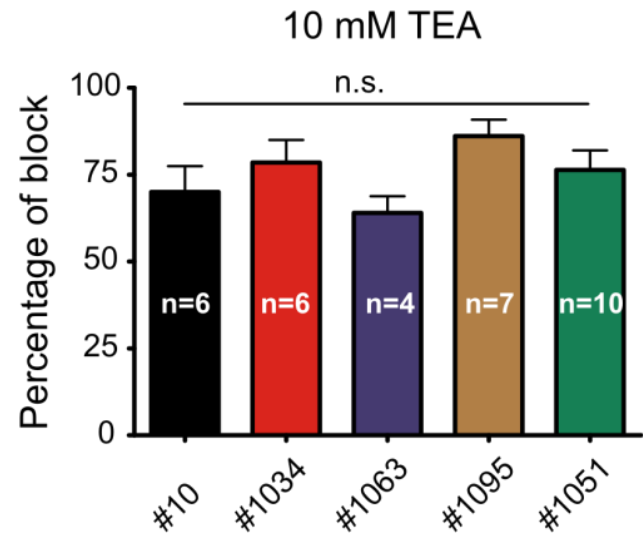

Figure 19. $\mathrm{I}_{\mathrm{KDR}}$ is blocked by TEA. A. Representative current response to a voltage pulse to $40 \mathrm{mV}$ (lower panel), before and after the application of $10 \mathrm{mM}$ TEA. B. The current was blocked to about $70 \%$ in all cell lines. Error bars represent standard error of the mean.

With respect to the average steady state current density at $40 \mathrm{mV}$, it was possible to identify lines with a higher overall current density \#10SP $45.2 \pm 3.8 \mathrm{pA} / \mathrm{pF}(\mathrm{n}=46)$, \#1034 $39.4 \pm 6.4 \mathrm{pA} / \mathrm{pF}(\mathrm{n}=18)$ and \#1063 $17.7 \pm 4.9 \mathrm{pA} / \mathrm{pF}(\mathrm{n}=25)$ and others with lower values, like \#1051 $8.4 \pm 1.3 \mathrm{pA} / \mathrm{pF}(\mathrm{n}=28)$ and \#1095 $6.0 \pm 1.0 \mathrm{pA} / \mathrm{pF}(\mathrm{n}=35)$ (Figure 20.B, page 39).

A
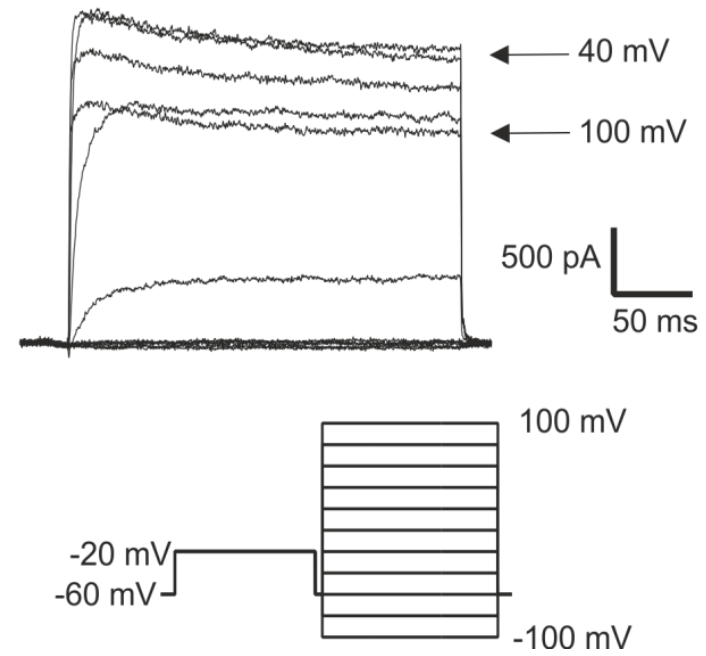

B

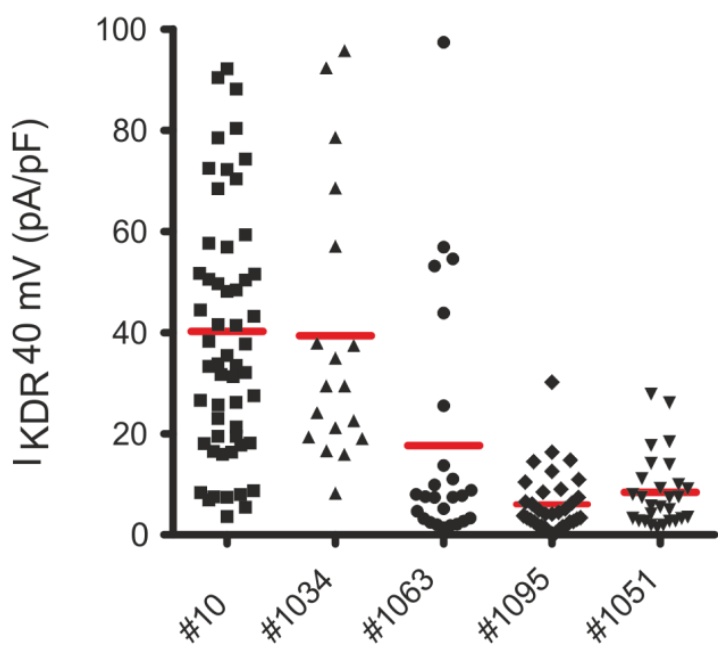

Figure 20. $I_{\mathrm{KDR}}$ density. A. Representative current response of a \#10 cell (upper panel) to variable voltage stimuli (lower panel). Note that the current towards the end of the pulse is larger by depolarization to $40 \mathrm{mV}$ than to $100 \mathrm{mV}$ (arrows). B. $\mathrm{I}_{\mathrm{KDR}}$ density at $40 \mathrm{mV}$ of individual cells, for all cell lines tested. Red lines represent the mean value.

Despite their differences in current density, the I-V relationship of $\mathrm{I}_{\mathrm{KDR}}$ revealed a similar half activation potential of about $-13 \mathrm{mV}$ for all cell lines $(\# 10-13.7 \pm 1.6 \mathrm{mV}$ $(n=24) ; \# 1034-13.8 \pm 1.5 \mathrm{mV}(\mathrm{n}=11) ; \# 1063-13.7 \pm 1.7 \mathrm{mV}(\mathrm{n}=14) ; \# 1051-14.3 \pm 1.6$ $\mathrm{mV}(\mathrm{n}=17) ; \# 1095-8.6 \pm 2.6 \mathrm{mV}(\mathrm{n}=6)$ (One way ANOVA, $\mathrm{p}=0.58)$ and a half maximal 
block potential $\sim 95 \mathrm{mV}$, which was also not significantly different between groups (One way ANOVA $p=0.11$ ) (Figure 21.B, page 40).

A

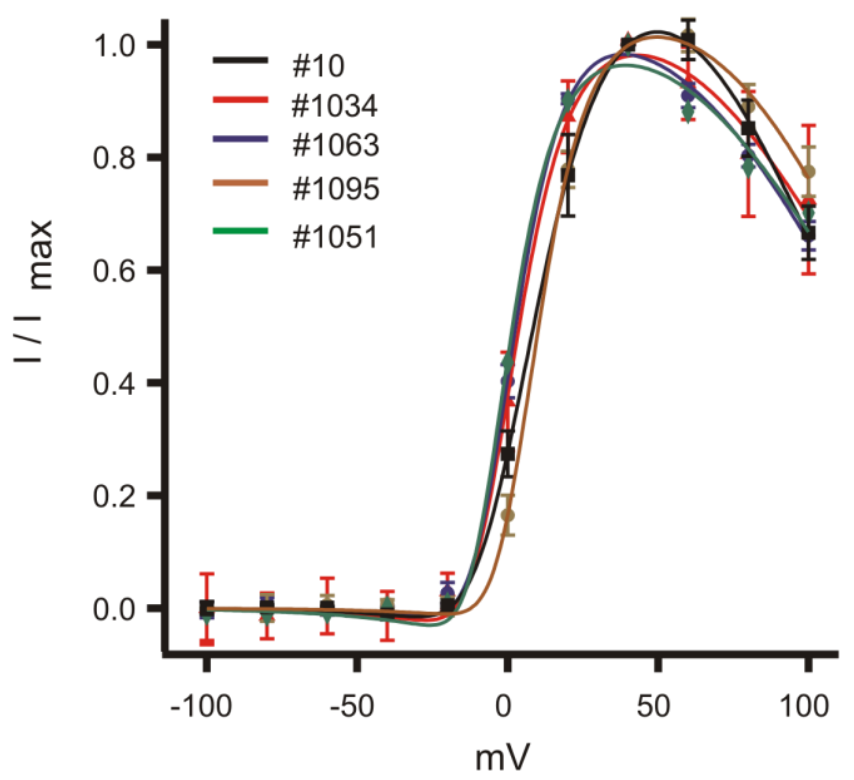

B

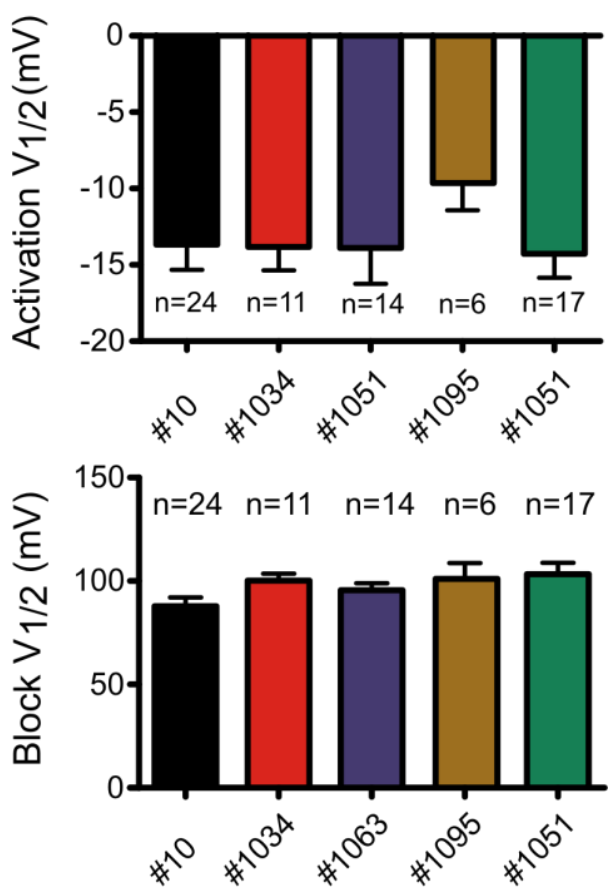

Figure 21. Voltage dependence of $I_{K D R}$. A. I-V relationship of $I_{K D R}$, notice the rectification at $\sim 40 \mathrm{mV}$ and a similar behavior in all cell lines. No differences were observed in half maximal activation potential (B, upper panel) or half maximal block potential (B, lower panel). Error bars represent standard error of the mean.

A rectification of the current at about $40 \mathrm{mV}$ was also observed in all groups (Figure 21.B, page 40 ). The rectification was present in more than $95 \%$ of the cells in $\# 10$ (100\%, n=40), \#1034 (100\%, n=15) and \#1051 (95\%, 18 of 19 cells). For \#1063 and \#1095, the percentage of positive cells was about $60 \%$ (14 of 22 and 11 of 17 cells, respectively) (Figure 23.B, page 41). Interestingly, the cells that did show rectification, had a significantly larger current density which in average was two to six times larger than that of cells without rectification (\#1063 $p=0.01$ and \#1095 $p=0.04$ ), suggesting that the phenomenon was related to current magnitude (Figure 23.C, page 41).
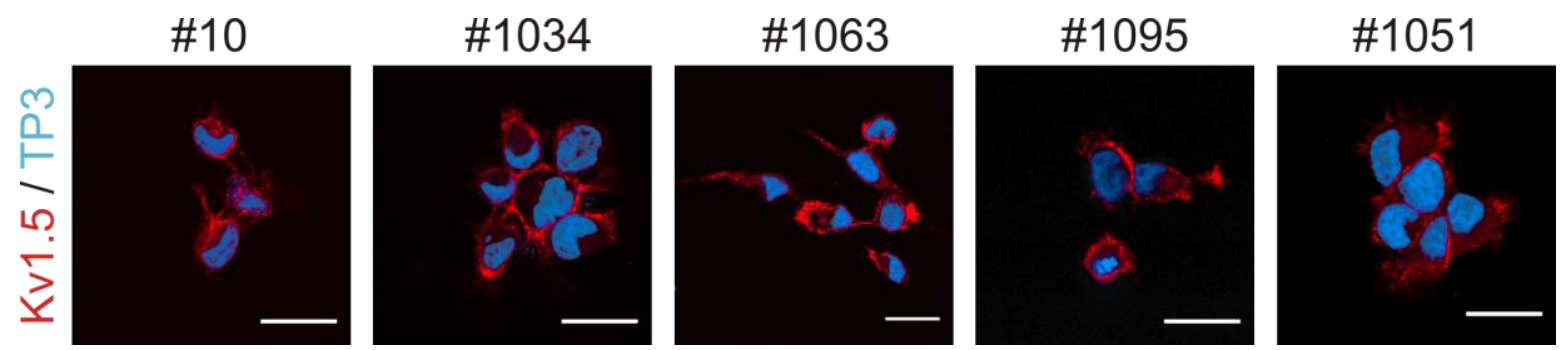

Figure 22. Kv1.5 expression in BTICs. A specific anti Kv1.5 antibody (red) produced a staining in the cell periphery in all cell lines tested. Nuclei were labeled with TO-PRO-3 Scale bars $=20 \mu \mathrm{m}$. 
Most of the potassium current in normal NG2 cells, is known to flow through homomeric $\mathrm{K}_{\mathrm{v}} 1.5$ or heteromeric channel complexes (Schmidt et al., 1999). Also, it has been shown that $\mathrm{K}_{\mathrm{v}} 1.5$ currents can exhibit magnesium-dependent rectification (Tammaro et al., 2005). Therefore, we decided to explore the effect of magnesium on the voltage dependence of $I_{K D R}$, using $\# 10$ as a representative line. We observed that after removal of magnesium from the intracellular solution, the rectification was abolished $(n=6)$, suggesting a magnesium dependent mechanism (Figure 23.D, page 41). Furthermore, immunocytochemical studies using antibodies against Kv1.5 revealed a strong signal compatible with a membrane staining in all cells studied (Figure 22, page 40).

A

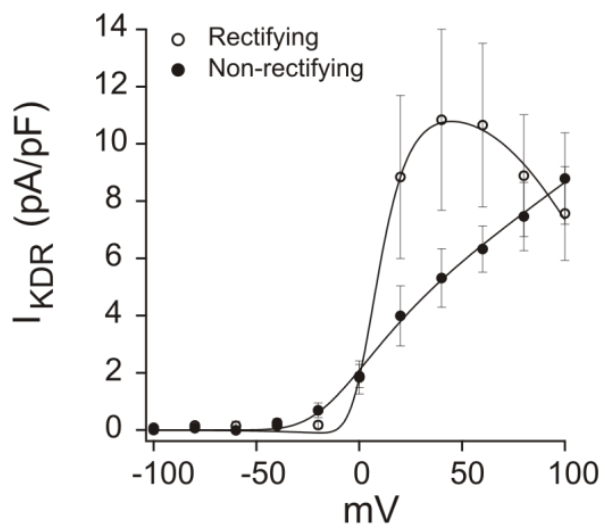

C

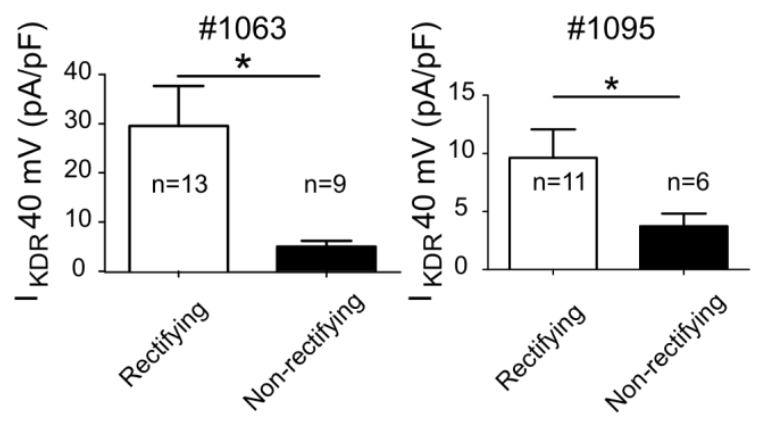

$\mathrm{B}$
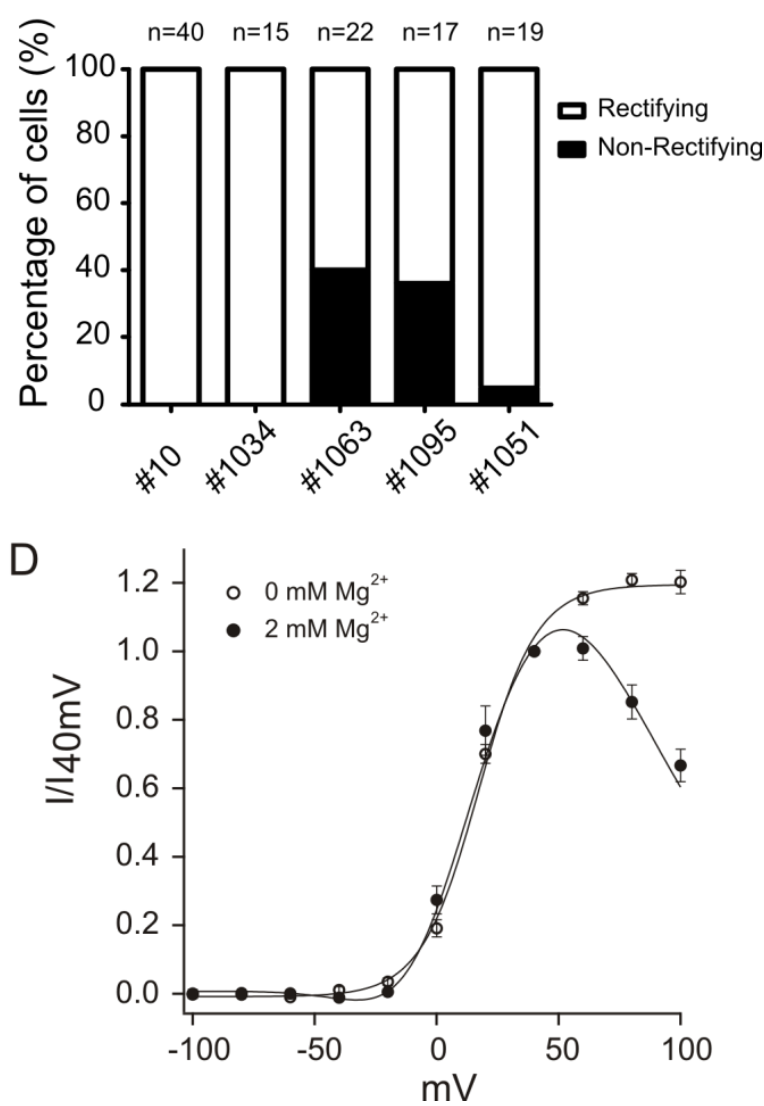

Figure 23. Rectification of $I_{K D R}$. A. I-V relationships of rectifying (open circles) and nonrectifying (solid circles) \#1095 cells. B. The majority of the cells in all groups had rectification. C. Significant differences were found in the current density at $40 \mathrm{mV}$ in \#1063 and \#1095 between cells with (white) and without (black) rectification. D. Normalized I-V relationship of \#10 cells in the presence (solid circles) or absence (open circles) of intracellular magnesium. Solid lines represent a fit to the data. Error bars represent standard errors of the mean and are in some cases obscured by the markers. Asterisks represent $p$ value $<0.05$. 


\subsubsection{Inactivating outward current $\left(I_{K A}\right)$}

The inactivating $I_{K A}$ component was isolated by digitally subtracting $I_{K D R}$ from the total outward current elicited when the prepulse was held at $-80 \mathrm{mV}$ (see page 38). The $I_{K A}$ had a fast rising phase, with a similar time to peak current in all cell lines of about 2 $\mathrm{ms}(\# 10,2.65 \pm 0.65 \mathrm{~ms}, \mathrm{n}=11$; \#1034, $1.6 \pm 0.16 \mathrm{~ms}, \mathrm{n}=9$; \#1063, $1.9 \pm 0.36 \mathrm{~ms}, \mathrm{n}=9$; \#1095, $1.5 \pm 0.12 \mathrm{~ms}, \mathrm{n}=17$; \#1063, $2.2 \pm 0.61 \mathrm{~ms}, \mathrm{n}=8$; One way ANOVA, $\mathrm{p}=0.21$ ).

The current decay can best be described by a double exponential where the fast component had a mean inactivation time constant $\left(\tau_{\text {fast }}\right)$ for all cell lines of $8.6 \pm 0.6 \mathrm{~ms}$ (\#10, $9.8 \pm 3.6 \mathrm{~ms}, \mathrm{n}=18$; \#1034, $7.2 \pm 1.4 \mathrm{~ms}, \mathrm{n}=11$; \#1063, $7.1 \pm 3.0 \mathrm{~ms}, \mathrm{n}=10$; \#1095, $7.1 \pm 1.8 \mathrm{~ms}, \mathrm{n}=8$; \#1051, $9.9 \pm 3.8 \mathrm{~ms}, \mathrm{n}=5$ ) and a slow component with a global mean inactivation time constant $\left(\tau_{\text {slow }}\right)$ of $97.7 \pm 27.1 \mathrm{~ms}(\# 10,58.0 \pm 18.0 \mathrm{~ms}$, $\mathrm{n}=17 ; \# 1034,81.2 \pm 24.8 \mathrm{~ms}, \mathrm{n}=11 ; \# 1063,200.2 \pm 102.8 \mathrm{~ms}, \mathrm{n}=8 ; \# 1095,48.1 \pm 7.0$ $\mathrm{ms}, \mathrm{n}=10 ; \# 1051,99.7 \pm 53.5 \mathrm{~ms}, \mathrm{n}=6)$. No significant differences were found in the inactivation time constants (One way ANOVA; $\tau_{\text {fast, }} \mathrm{p}=0.96 ; \tau_{\text {slow, }} \mathrm{p}=0.14$ ). 
A
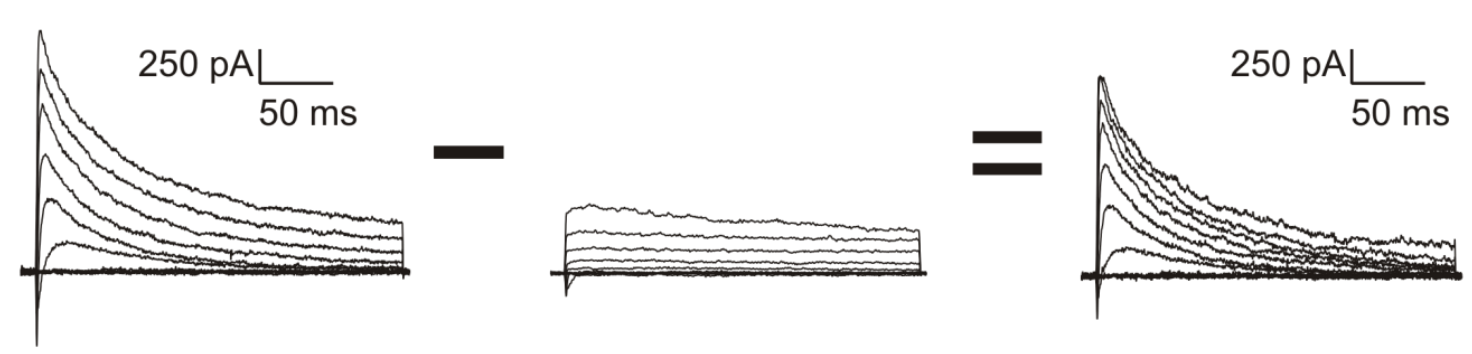

B

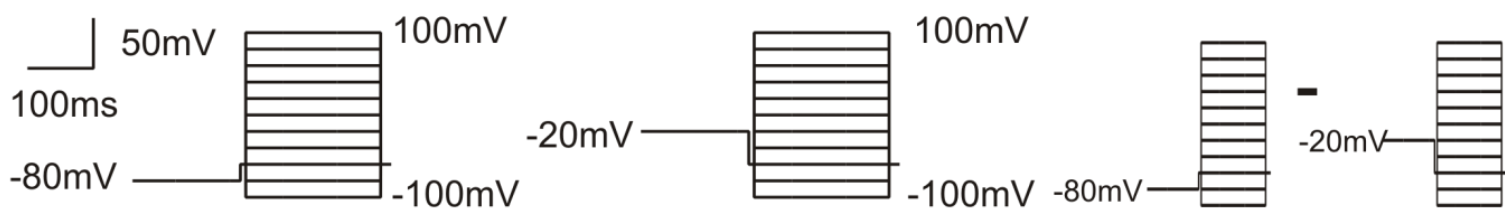

C
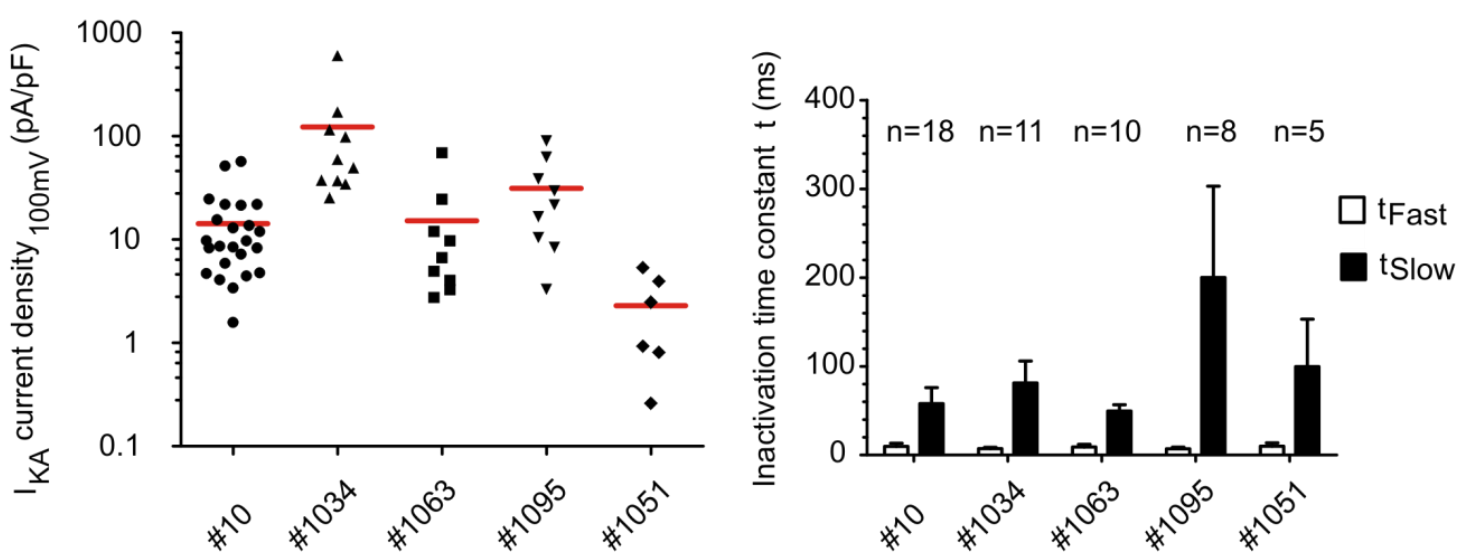

Figure 24. Peak current density and decay of $I_{K A} A$. Representative current responses of a \#1095 cell to its corresponding voltage protocols (B). A transient outward current can be isolated by subtracting $I_{K D R}(A$, middle panel) from the mixed current ( $A$, left panel). C. Peak current density of individual cells at $100 \mathrm{mV}$. Red lines represent mean value. D. No significant differences were found in the inactivation time constants of $I_{K A}$. Error bars represent standard error of the mean.

$\mathrm{I}_{\mathrm{KA}}$ was expressed in all cell lines tested and in the majority of the cells within a line namely: \#10 24 of 32 cells, \#1034 19 of 20 cells, \#106311 of 17 cells, \#1095 26 of 28 cells and \#1051 16 of 24 cells. As for $I_{K D R}$, a significant variation was observed in the $I_{K A}$ density ( $p=0.003$ ) where the values ranged from $2.29 \pm 0.8 \mathrm{pA} / \mathrm{pF}$ in $\# 1051(n=6)$ to $122.9 \pm 55.07 \mathrm{pA} / \mathrm{pF}$ in \#1034 $(\mathrm{n}=10)$ with intermediate values for \#10, $14.3 \pm 2.8$ $\mathrm{pA} / \mathrm{pF}(\mathrm{n}=24), \# 1063,15.2 \pm 7.1 \mathrm{pA} / \mathrm{pF}(\mathrm{n}=9)$ and \#1095 $31.35 \pm 9.5 \mathrm{pA} / \mathrm{pF}(\mathrm{n}=9)$. Again, despite the differences in current density, the voltage dependence of the current showed no significant differences between lines, as evidenced by the I-V relationship 
with a global mean half activation of $-33.5 \pm 3.1 \mathrm{mV}(\mathrm{p}=0.11)$ and a global mean half inactivation of $-74.5 \pm 1.5 \mathrm{mV}(\mathrm{p}=0.13)$.

A

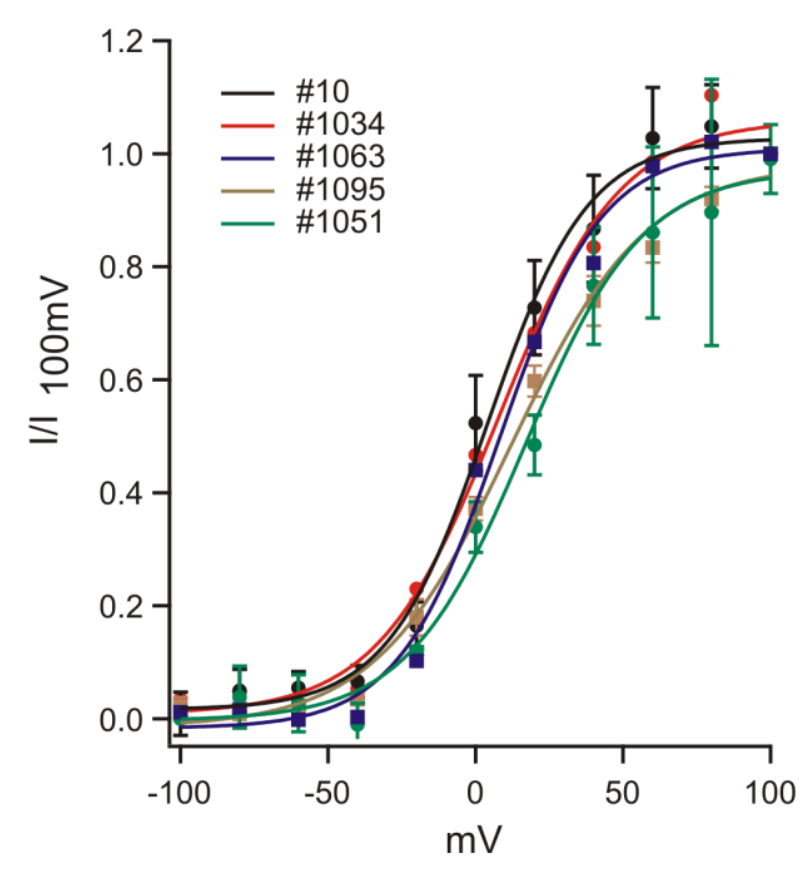

B

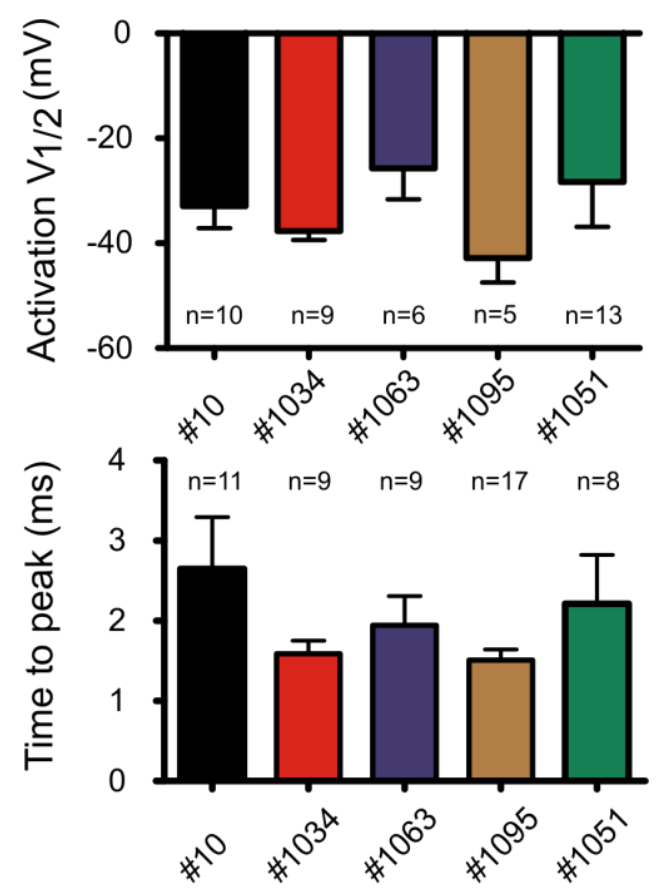

Figure 25. Voltage dependent activation and time to peak current in $I_{K A}$. A. Similar I-V relationships of isolated $I_{K A}$ were observed in all cell lines tested. Solid lines represent a fit to the data. The half maximum activation potential (B, upper panel) and the time to peak current (B, lower panel) showed no significant differences. Error bars represent standard error of the mean.

The voltages of half maximal activation of the individual lines were: $\# 10,-32.9 \pm 4.2$ $m V, n=10 ; \# 1034,-37.6 \pm 1.7 \mathrm{mV}, \mathrm{n}=9$; \#1063, -25.7 $\pm 6.0 \mathrm{mV}, \mathrm{n}=6$; \#1095, $-42.8 \pm 4.7$ $\mathrm{mV}, \mathrm{n}=13$ and \#1051, $-28.31 \pm 8.6 \mathrm{mV}, \mathrm{n}=5$ and for half maximal inactivation were: \#10, -69.3 $\pm 1.5 \mathrm{mV}, \mathrm{n}=7$; \#1034, -76.0 $\pm 1.6 \mathrm{mV}, \mathrm{n}=7$; \#1063, -72.9 $\pm 4.1 \mathrm{mV}, \mathrm{n}=3$; $\# 1095,-77.6 \pm 4.0 \mathrm{mV}, \mathrm{n}=5$ and \#1051, $-76.9 \pm 3.3 \mathrm{mV}, \mathrm{n}=4$ (Figure $24 \mathrm{~B}$, page 43). 
A

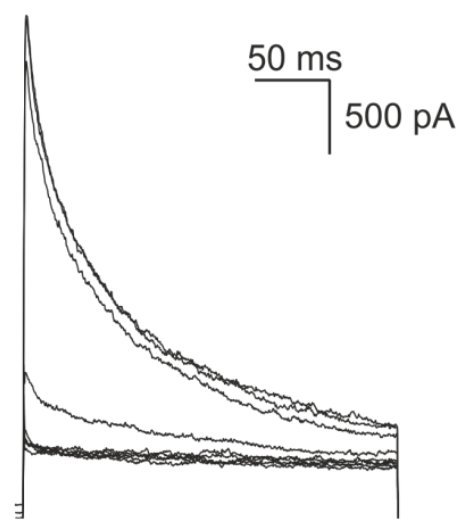

B

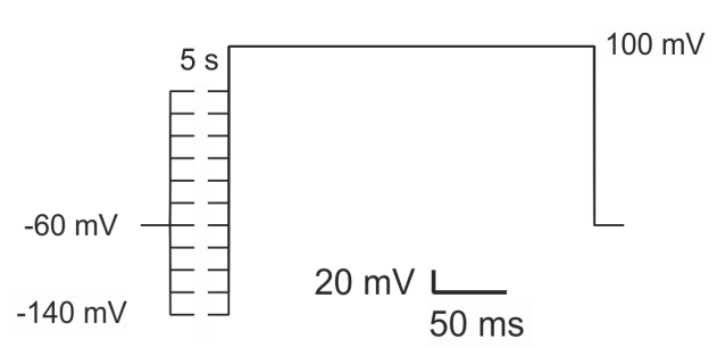

C
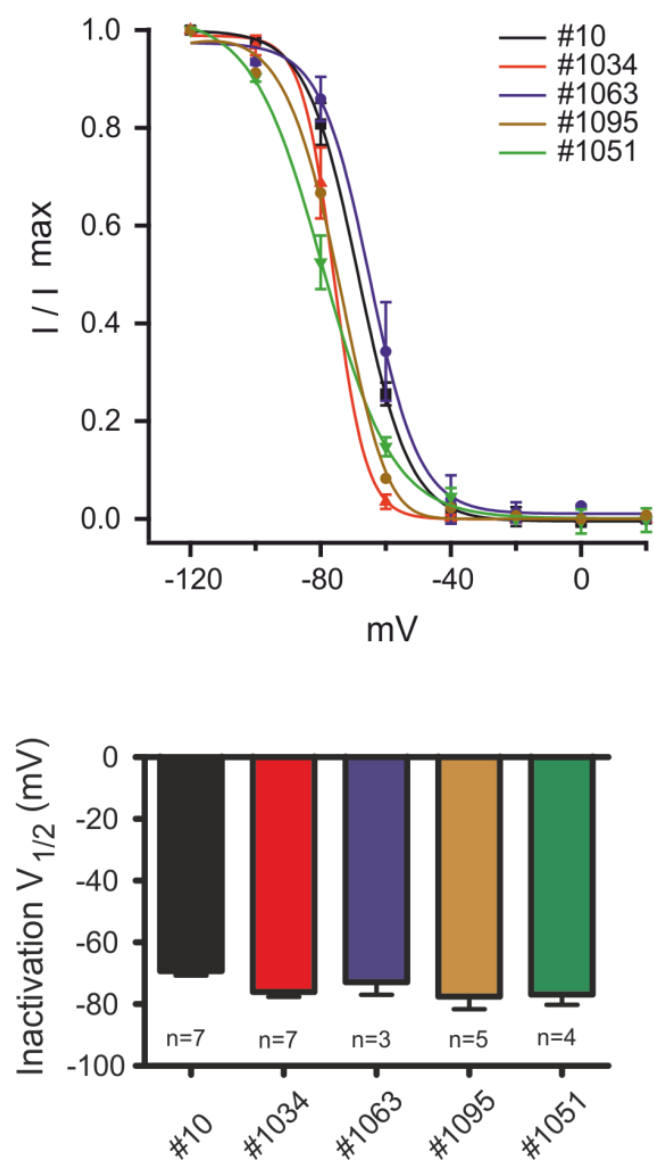

Figure 26-27. Voltage dependent inactivation $\left(h_{\infty}\right)$ of $I_{\text {KA. }}$ A. Representative current trace of a \#1095 cell upon stimulation to $100 \mathrm{mV}$ after variable voltage pre-pulses (B). C. Peak current to pre-pulse voltage relationship with similar half inactivation potential for all lines (D). Error bars represent standard error of the mean.

\subsubsection{BTICs express functional glutamate receptors}

To test whether BTICs also express functional glutamate receptors, we recorded the current response at $-80 \mathrm{mV}$ when $150 \mu \mathrm{M}$ AMPA was applied to the bath solution for 2 seconds. In all cells tested (\#10 n=15, \#1063 n=7, \#1095 n=7, \#1051 n=9 and \#1034 $n=11$ ), we measured an inward current which had an average current density that ranged from $0.5 \pm 0.12 \mathrm{pA} / \mathrm{pF}$ in \#1063 to $2.5 \pm 0.9 \mathrm{pA} / \mathrm{pF}$ in \#10. The current average was calculated from a 1 second time interval, $200 \mathrm{~ms}$ after the application of the solution. 
AMPA $150 \mu \mathrm{M}$

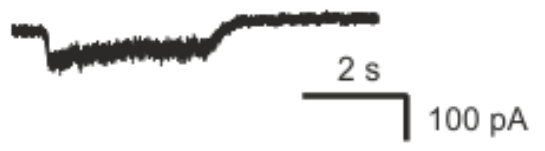

B

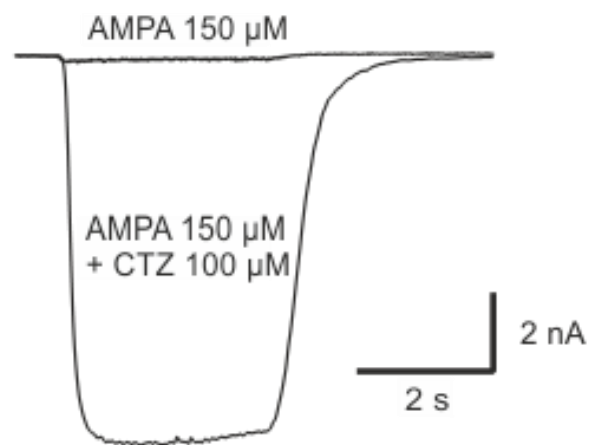

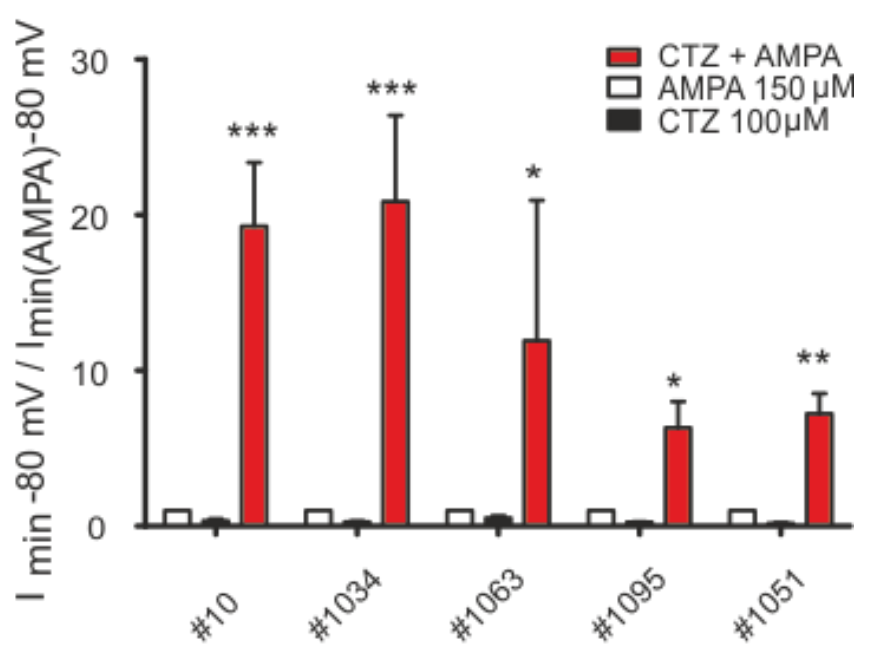

Figure 28. Cyclothiazide (CTZ) potentiates AMPA currents in BTICs. A. An inward current was observed when AMPA $(150 \mu \mathrm{M})$ was applied to the bath solution. B. The AMPA current was potentiated by application of CTZ. C. Normalized mean current showing a significant increase (up to 20 fold) in the AMPA mediated current by CTZ. The effect was observed in all cell lines tested. Asterisks represent zeroes after the decimal point for $p$ values $<0.05$. Error bars represent standard error of the mean.

After a 4-second application of $100 \mu \mathrm{M}$ Cyclothiazide we observed a significant 6 to 20 fold increase in the current elicited by AMPA (\#10 $p<0.0001, n=15 ; \# 1063 p=0.015$, $\mathrm{n}=7$; \#1095, $\mathrm{n}=7 \mathrm{p}=0.03$; \#1051 $\mathrm{p}=0.003, \mathrm{n}=9$, \#1034 $\mathrm{p}=0.001, \mathrm{n}=11$ ) (Figure 28.C, page 46). Also, the current was linearly related to the voltage (at voltage pulses from $80 \mathrm{mV}$ to $80 \mathrm{mV}$ ) and had a mean reversal potential for all lines of $2.6 \pm 3 \mathrm{mV}$ (Figure 29.A-B, page 47).

The functional and pharmacological features of $I_{A M P A}$, suggest that the current is carried by glutamate receptors of the AMPA type (Bergles et al., 2000; Chittajallu et al., 2004; Fucile et al., 2006). To further test this hypothesis, we used an immunocytochemical approach and detected the expression of GluR1 in all cell lines. The staining had a punctate pattern, reminiscent of that of neurons. Line \#1051 had a peripheral staining, compatible with a membrane pattern (Figure 29.C, page 47). 
A

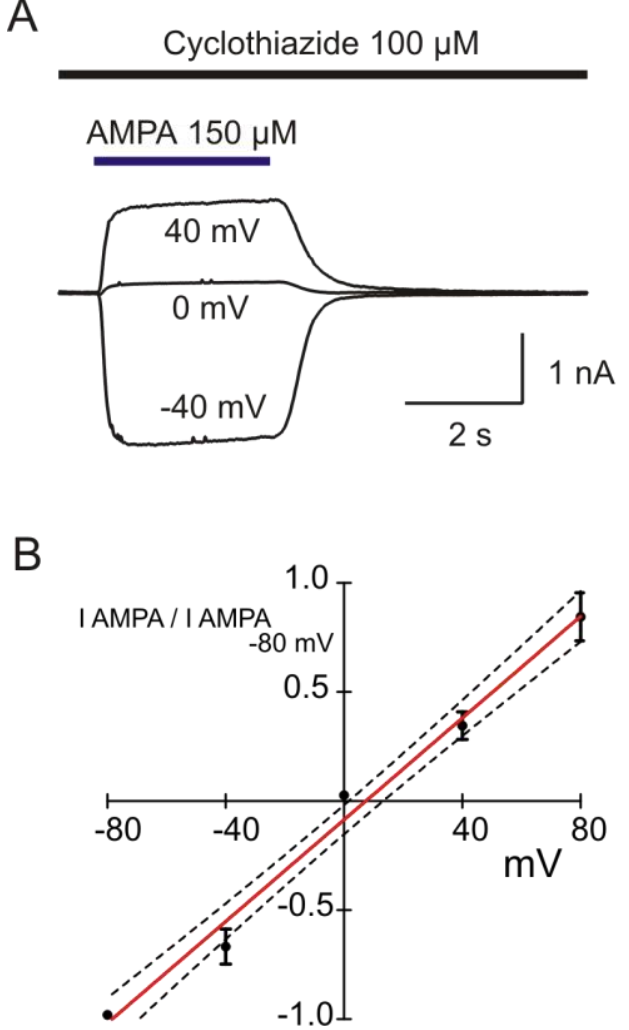

C

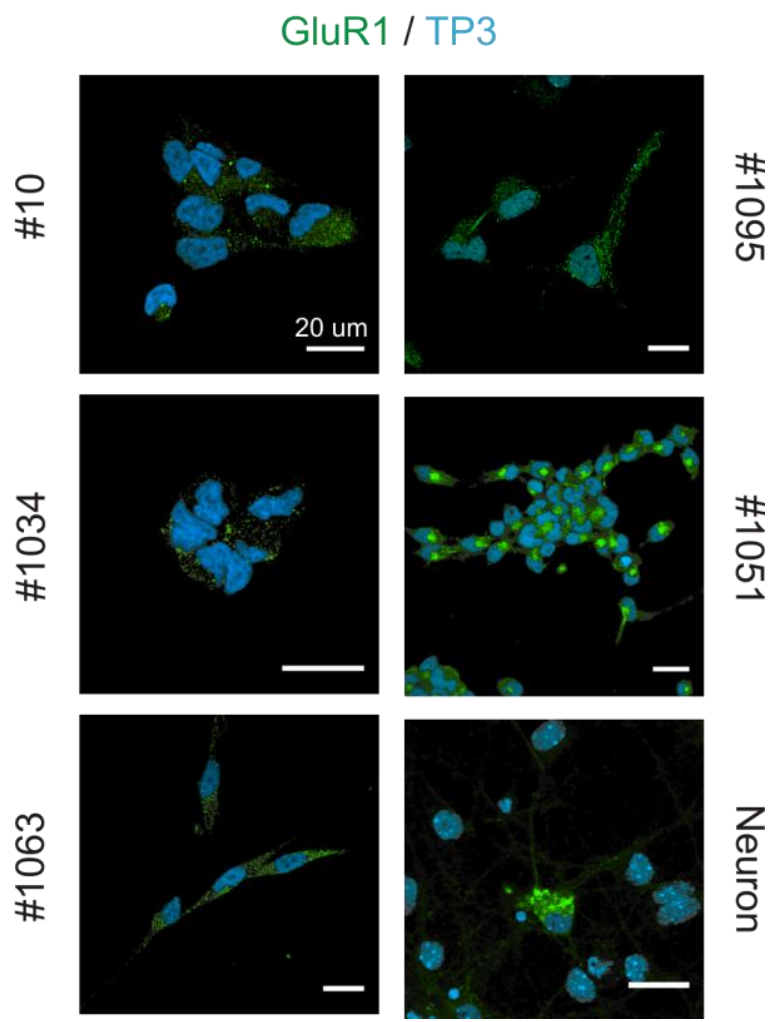

Figure 29. BTICs express GluR1 and have a linear $I_{A M P A}-V$ relationship. A. AMPA elicited inward or outward currents depending on the holding potential. B. The normalized I AMPA exhibited a linear I-V relationship. Error bars represent standard errors of the mean C. Immunostaining of GluR1 (green) showing a punctate signal in all cells. Note that neuronal cultures from primary hippocampus (lowermost panel, right) have a heterogeneous staining. Nuclei were stained with TOPRO-3 (blue). Scale bars $=20 \mu \mathrm{m}$.

\subsubsection{No detectable dye-coupling in cultured BTICs}

The extent of gap-junctional communication represents another membrane property that can be characteristic of specific cell types. For example, astrocytes (Schools et al., 2006), oligodendrocytes (Wasseff and Scherer, 2011) and grafted NSCs (Jäderstad et al., 2010) exhibit major intercellular connection in dye-coupling experiments whereas NG2 cells filled with fluorescent dyes shown no communication with neighboring cells (Akopian et al., 1996; Bergles et al., 2000).

Therefore, after successful loading of single cells with Lucifer Yellow (LY) we imaged after one, ten and thirty minutes. With the exception of one \#10 cell, it was not possible to detect spreading of fluorescence signal to nearby cells in any of the cell lines tested (\#10, $n=7 ; \# 1034, n=8 ; \# 1063, n=4 ; \# 1095, n=9 ; \# 1051, n=5)$ (Figure 30, page 48). 

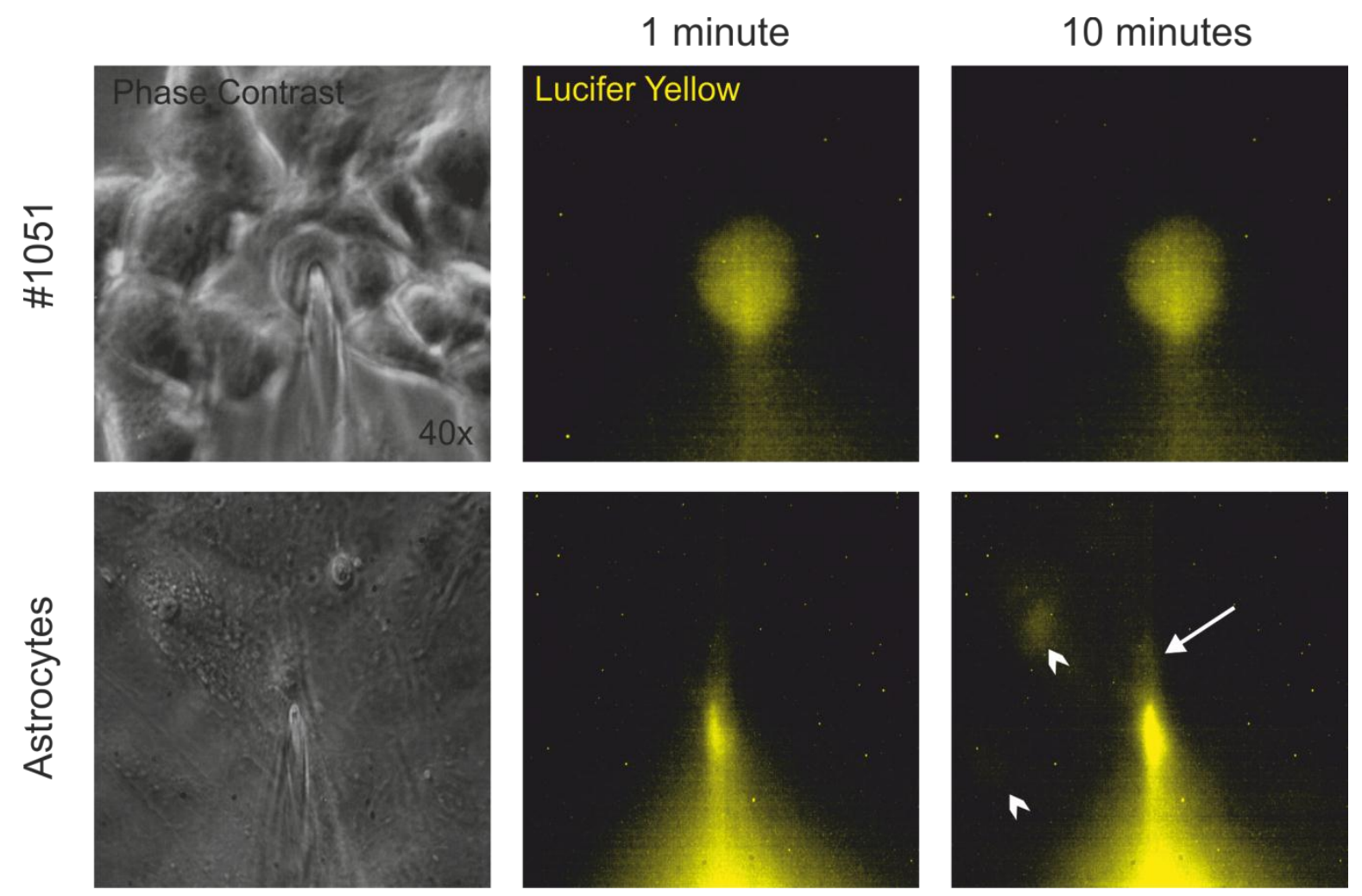

Figure 30. No dye coupling in BTICs. Representative \#1051 cell showing no dye-coupling with neighboring cells after injection with lucifer yellow in a 10 minute time span (upper row). In mouse astrocytes (lower row), a fluorescent signal was detected in near-by cells (arrow heads) besides the injected one (arrow) after the same time period. 


\section{Discussion}

In this study, we examined the molecular, physiological and functional characteristics of human primary BTICs, which according to current paradigms might represent the responsible subpopulation for propagating brain tumors (Clarke et al., 2006). We show that the cells express the OPC markers NG2 and PDGFRa, but also the NSC marker nestin and GFAP. Further, the cells show a restricted differentiation potential towards the astroglial lineage.

Furthermore, we profit from the well-characterized physiological membrane properties of normal CNS subpopulations to introduce a new level of classification in human BTICs, namely a functional phenotypic electrophysiological characterization.

\subsection{Isolation of BTICs: Conceptual and technical considerations}

The BTICs used in this work, have been isolated from human GBM specimens using the NSA (Section 2.4.4 Brain tumor initiating cells and the cancer stem cell hypothesis, page 9) as reported by others (Galli et al., 2004) and can been referred to as BTICs, since they are able to initiate tumors with hallmarks of GBM (Section 6.1 Cell culture, page 66). Although the NSA is the method of choice to isolate BTICs (Beier et al., 2007; Hemmati et al., 2003; Singh et al., 2003), any result obtained by using this approach should be interpreted within a certain conceptual framework.

The NSA is based on the fact that the culture conditions do not support the longterm survival of the majority of cells, leading to their subsequent death. It promotes, however, the survival and expansion of cell populations that are responsive to EGF, bFGF, or both, which normally include stem- and progenitor cells (Reynolds and Rietze, 2005).

Even if under physiological conditions neural stem- and progenitor-cells respond to the above mentioned growth factors, the fact that brain tumor cells proliferate in the presence of EGF/bFGF does not necessarily identify them as NSC/progenitor cells. Nevertheless, the presence of specific markers of NSC/progenitor cells and pseudodifferentiation potential certainly point towards an NSC/progenitor phenotype of BTICs. 
Also, the possibility that the cellular populations that do not survive the NSA also contribute to tumorigenesis cannot be ruled out.

Once a successful neurosphere culture has been established, technical considerations emerge. For example, progenitor cells of the mouse dentate gyrus have been shown to exhibit spheroid growth, but were unable to self-renew, meaning that no new spheres were obtained after subculturing (Seaberg and Van Der Kooy, 2002). Other groups have isolated spheres which could be subcultured up to five times before they stopped dividing (Louis et al., 2008). In practical terms, the passage number at which an experiment is performed might clearly influence the result. If a measurement is done in primary neurospheres of early passage, one could observe properties of cells with limited self-renewal, whereas experiments in later passages could be characteristic of cells with more robust self-renewal capabilities (Reynolds and Rietze, 2005). Especially in the case of BTICs, where the isolated cells have an unknown behavior, the prolonged passaging might increase the risk of adaptation and artifacts induced by culture conditions.

Even though a single cell can give rise to a neurosphere, the cellular population in a mature neurosphere is not homogeneous. By dissociating single neurospheres it has been determined that $<3 \%$ of the cells are stem cells (i.e. retain the ability to form secondary neurospheres) (Louis et al., 2008). This observation raises the concern that if no further methods are used to identify the "true" stem cells within a neurosphere, measurements in bulk neurosphere cultures could yield results about stem-cell progeny rather than stem cells.

The above mentioned considerations emerge mostly from the field of normal neural stem cells, where a hierarchical organization has been thoroughly described and is amenable to recognition by reliable markers. In spheroids isolated from brain tumors, not only their progeny, but their identity and their functional meaning remain poorly understood, underscoring these concerns.

As discussed above, neurospheres can be heterogeneous, either because they arise from different cellular populations (i.e. progenitors or NSCs) and/or because the cellular populations in a neurosphere can exhibit different properties. In the context of brain tumors, another source of heterogeneity should be considered and is that of genetic abnormalities (Visvader, 2011). Even when two neurospheres in a BTIC culture 
originate from transformed NSCs, they might still have a radically different genetic background, due to genomic instability and/or mutations.

Finally, even if bona fide NSC/progenitor-like cells can be isolated from brain tumors the finding per se would not prove the relevance of these cells in glioma progression. This problem is further stressed by the lack of reliable prospective identification methods (Section 2.4.4 Brain tumor initiating cells and the cancer stem cell hypothesis, page 9).

\subsection{Molecular characterization and differentiation potential of BTICS}

Based solely on the expression of lineage markers and leaving aside the considerations about their utility in tumor cells (Section 2.4.5 Nestin and NG2: Lineage markers in pathological states? page 12), the BTICs used in our series, could be considered to have an immature phenotype.

BTICs did not express markers of mature neurons (NeuN) or oligodendrocytes (MBP). On the other hand, markers used for less differentiated cells in a physiological context were expressed in the majority of the cells.

The NSC marker nestin is commonly found in GBM derived cells (Section 2.4.3 Lineage markers in human gliomas, page 8). In our series nestin was present in all cells, and co-expressed with GFAP, a feature of neural progenitors (Namba et al., 2011).

On the other hand, nestin also co-expressed with the OPC marker NG2, which was present in the majority of the cells. A thorough marker analysis in the mouse brain has shown that SVZ cells expressing doublecortin and DIx2 did not co-express NG2, though in this study nestin was not used as marker for NSCs (Komitova et al., 2009). On the other hand, $\mathrm{NG}^{+}$cells have been reported to co-express nestin both in the normal brain (Belachew et al., 2003) as well as in human GBM (Svendsen et al., 2011).

In agreement with other reports, the expression of NG2 was not found in all GBM derived samples (Chekenya et al., 1999; Shoshan et al., 1999; Svendsen et al., 2011). Also, NG2 ${ }^{+}$cells were characterized for co-expressing PDGFRa, a cardinal feature of 
NG2 glia (Nishiyama et al., 1996). Additionally, in human glioblastomas $\mathrm{NG}^{+} / \mathrm{PDGFRa}^{+}$cells also correspond to the majority of the $\mathrm{NG}^{+}$population (AlMayhani et al., 2011; Chekenya et al., 1999), but NG2/PDGFRa ${ }^{-}$and NG2/PDGFRa ${ }^{+}$ cells have also been observed (Al-Mayhani et al., 2011).

While these observations might suggest that BTICs have a marker phenotype more characteristic of NG2 glia than of NSCs, NG2 cells do not express GFAP under physiological conditions (Belachew et al., 2003; Komitova et al., 2009). Furthermore, during regeneration after a CNS lesion, it has been proposed that reactive astrocytes might express NG2 (Komitova et al., 2011) and nestin (Clarke et al., 1994; Frisén et al., 1995; Lin et al., 1995; Oki et al., 2010; Tamagno and Schiffer, 2006) opening up the possibility that these cells share the phenotype of reactive astrocytes. However, GFAP was expressed in only two cell lines in less than $50 \%$ of the cells and whether nestin ${ }^{+} / \mathrm{NG}^{+} / \mathrm{GFAP}^{-}$reactive astrocytes exists is unknown.

Further considering the possibility that the phenotypical features of BTICs correspond to that of normal NG2 glia, the expression of GFAP could be the result of differentiation into the astroglial lineage (Belachew et al., 2003). This would be supported by the fact that only two cell lines and not all the cells express GFAP.

A cardinal feature of normal OPCs is their ability to give rise to heterogeneous oligo/astroglial progeny in vitro depending on culture conditions (Stallcup and Beasley, 1987). BTICs were cultured in medium containing 10\% FCS and compatible with an OPC phenotype (Persson et al., 2010; Stallcup and Beasley, 1987) an increase in the GFAP $^{+}$population was observed in all cell lines.

However, when the cells were grown in the presence of L-tyroxine and triiodothyronine (Fitzner et al., 2006) or CNTF (Mayer et al., 1994), as a mean to force differentiation into the oligodendroglial lineage, no MBP expression was observed. Furthermore, the cells responded by increasing the $\mathrm{GFAP}^{+}$fraction, a phenomenon also observed when forskolin, a substance used to promote neuronal differentiation, was added to the medium.

Although these observations suggest a limited differentiation potential of BTICs, it does not reflect the typical differentiation pattern of OPCs nor NSCs (Tanner et al., 2011). However, the increase in $\mathrm{GFAP}^{+}$cells is in perfect agreement with the GBM origin of the BTICs. GBMs are primarily astrocytic gliomas (Louis et al., 2007b), mostly 
characterized by heterogeneous expression of GFAP (Wilhelmsson et al., 2003) where less than $8 \%$ of the cases exhibit an oligodendroglial component (Kraus et al., 2001; Salvati et al., 2009).

The fact that BTICs repeatedly responded to differentiation conditions by expressing GFAP and failed to express MBP could be explained in several ways. First of all, even though the antigen expression of BTICs is in some aspects reminiscent to that of NG2, several considerations about the use of lineage markers in disease have been highlighted (2.4.5 Nestin and NG2: Lineage markers in pathological states? Page 12) and therefore their expression alone might not suffice to determine the BTICs phenotype.

Second, even if BTICs did faithfully represent NG2 glia, given their neoplastic origin it is possible that to achieve an effective oligodendroglial differentiation, different concentrations of growth factors that those reported for normal mouse OPCs might be required. This could be due to mutations in the respective receptor or abnormal signaling pathways. However, the changes in GFAP expression speak in favor of an effective differentiating stimulus, but an aberrant response.

The atypical reaction to thyroid hormones and CNTF could also be explained by defective signal transduction mechanisms. Differentiation studies of GBM BTICs using retinoic acid have also shown a preferential differentiation into the astrocytic lineage, which was attributed to the Wnt and Notch signaling pathways (Ying et al., 2011). Notch is frequently found in GBM (Sivasankaran et al., 2009), can trans-activate the gene for GFAP (Ge et al., 2002) and regulate the differentiation of progenitors into astrocytes (Wu et al., 2003). The possible regulatory mechanisms of differentiation were not further explored.

Another possible explanation is that the identified tumoral nestin ${ }^{+} / \mathrm{NG}^{+}$cells represent a less defined progenitor with an astroglial commitment. It has been described that NG2 glia can give rise to astrocytes in vivo (Zhu et al., 2008) and it is likely that they represent a heterogeneous population in the adult brain (Peters, 2004; Stallcup and Huang, 2008; Trotter et al., 2010).

Although previous reports have described multipotential differentiation of BTICs (Vescovi et al., 2006), we could not demonstrate the expression of markers of neurons or oligodendrocytes. This is probably related to the choice of markers to define CNS 
populations. While other studies have mostly used the early appearing beta III tubulin and GalC as neuronal and oligodendrocytic markers respectively, we used NeuN and MBP proteins known to appear later in the lineage development.

\subsection{Functional membrane phenotype of BTICs}

By using antibody-based lineage marker analysis and by studying differentiation potential we have determined that in these two aspects, BTICs do not conform to any of the known CNS cellular components. However, BTICs seem to belong to a less differentiated phenotype, rather than to a well-defined terminally differentiated lineage. Most CNS cell types have a well-characterized robust electrophysiological signature (Section 2.4.5 Nestin and NG2: Lineage markers in pathological states? page 12). Therefore, to obtain further quantitative evidence about the identity of BTICs, we have measured their physiological membrane properties using the patch clamp technique. This method allows the high resolution, simultaneous measurement of several membrane parameters at a functional level in real time.

Before proceeding with the detailed discussion of the multiple electrophysiological parameters, it should be kept in mind that we dealt with human cultured tumor cells, whose identity was unknown (see Section 2.4 Cellular heterogeneity:, page 4). Therefore, the paired human control was impossible to obtain. Even under the premise that BTICs might be enriched in NG2 glia or NSCs, logistic difficulties impeded the acquisition of matching normal human counterparts. Therefore most of the electrophysiological parameters for comparison purposes are derived from the literature, which fortunately is both detailed and abundant. Here again, it should be noted that most of the experiments found in the literature have been performed in rodents.

Regarding membrane resistance, it is known that normal CNS cell types vary considerably among each other. In the lower range of the spectrum are astrocytes, with membrane resistances of $\sim 10 \mathrm{M} \Omega$ (Bergles et al., 2000; Lin and Bergles, 2004; Mueller et al., 2009) and oligodendrocytes with slightly higher values <200 M $\Omega$ (Tripathi et al., 2011). NG2 glia have a "moderate" membrane resistance with reported values at voltages close to the resting potential between $200 \mathrm{M} \Omega$ and $1 \mathrm{G} \Omega$ (Káradóttir et al., 2008; Kukley et al., 2010; Lin and Bergles, 2004; Mueller et al., 2009). Finally neurons 
and NSCs have a very high membrane resistance up to $4 G \Omega$ (Wang et al., 2003). In our study, all cell lines had a membrane resistance between 300 and $600 \mathrm{M} \Omega$, a value in the range of that described for NG2 cells.

It has been postulated that the low membrane resistance of astrocytes might be due to the presence of underlying $\mathrm{K}^{+}$leak channels. The large $\mathrm{K}^{+}$leak currents might also account for the linear I-V relationships observed in voltage clamp experiments (Lin and Bergles, 2002; Mueller et al., 2009). Oligodendrocytes derived from OPCs have also been reported to become "ohmic" (Tripathi et al., 2011).

On the other hand, the currents of normal NG2 glia and NSCs have a strong voltage dependence and are characterized by the expression of outward delayed rectifier potassium currents (Belachew et al., 2003; Bergles et al., 2000; Chittajallu et al., 2004; Ge et al., 2006; Kukley et al., 2010; Lai et al., 2010; Schmidt et al., 1999; Wang et al., 2003).

In our study, we could demonstrate that in the majority of cells in all BTIC lines, the currents also exhibit strong voltage dependence and express delayed rectifier outward currents (Figure 21, page 40). Some of the cell lines even had delayed rectifier and transient outward current densities in the range reported for OPCs $(25-80 \mathrm{pA} / \mathrm{pF}$ and $\sim 60$ pA/pF, respectively) (Chittajallu et al., 2004; Kukley et al., 2010).

We could also demonstrate the expression of transient outward currents $\left(I_{K A}\right)$, a feature reported for NG2 glia and astrocytes (Lin and Bergles, 2002). The expression of $I_{K A}$ in NSCs has been reported by one group (Schaarschmidt et al., 2009) whereas two other groups do not recognize $\mathrm{I}_{\mathrm{KA}}$ as a characteristic NSC feature (Lai et al., 2010; Wang et al., 2003). Additionally, the values for half maximal activation for both delayed rectifier and transient outward currents were also in a similar range to that of NG2 cells (Chittajallu et al., 2004).

Regarding the characteristics of inactivation of $I_{K A}$, they could be described by a double exponential with two time constants, a very fast component ( $\sim \mathrm{ms})$ and a slow component close to $100 \mathrm{~ms}$. The value for the fast component is larger than that reported for any of the A type channels (Gutman et al., 2005) and it might be explained by the presence of an instantaneous current of the channels that have been inactivated by the $5 \mathrm{~ms}-60 \mathrm{mV}$ pre pulse. An uncompensated capacitance could represent such a fast event, however, the finding is constant in all cells measured and the capacitance 
was adequately compensated before each measurement, making it a less likely explanation. Also, it is important to note that the amplitude of the slow component is much larger, meaning that the current can be best described by its slow and not its fast inactivation time constant. The slow component, on the other hand, has a typical inactivation time constant for A-type channels (Gutman et al., 2005).

The transient outward current $\left(I_{K A}\right)$ was present in the majority of cells in all BTIC lines. However, the $I_{K A}$ current density was variable and in some cells $(<20 \%)$ it could not be detected. First of all, it is possible that the voltage protocol used to elicit $I_{K A}$ might systematically lead to an under estimation of the current density and hence, of the total number of $I_{\mathrm{KA}}$ expressing cells. Before the depolarizing pulse to $100 \mathrm{mV}$, we applied a $5 \mathrm{~ms}$ prepulse to $-60 \mathrm{mV}$ and given that the measured half maximal inactivation of $I_{K A}$ was $\sim-70 \mathrm{mV}$, it is likely that some of the channels were inactivated before the depolarizing pulse.

Another factor that might play a role in the variability of $I_{K A}$ density is the differentiation status of a particular cell. As discussed above, at least for normal neurospheres, it is common to have diverse differentiation status within a population (see Section 4.1 Isolation of BTICs: Conceptual and technical considerations, page 49). Also, it has been shown in the context of neural progenitors and NG2 cells that $I_{K A}$ magnitude inversely correlates with differentiation state (Kukley et al., 2010; Schaarschmidt et al., 2009). Considering that we are dealing with heterogeneous tumor derived cells, the absence of $I_{K A}$ could be a consequence of a genetic or epigenetic defect or simply a characteristic of a different cellular population.

The percentage of cells expressing sodium channels was determined independently by electrophysiology and immunocytochemistry. In three out of five BTIC lines, there was an agreement between both methods whereas for the remaining two lines slightly different results were obtained. The statistical power of the electrophysiological approach is limited due to the reduced number of observations; therefore the antibody-based technique might offer a more reliable estimate of the total number of cells expressing sodium channels. However, it must be kept in mind that the information obtained by each method has a completely different character since electrophysiology determines functional aspects and immunocytochemistry determines expression of the protein regardless of its function. Furthermore, since the methods were not used simultaneously, it is impossible to correlate fluorescent signal with 
functionality. Nevertheless although both methods provided slightly different results, it is safe to assume that in all BTIC lines the expression of functional $\mathrm{Na}^{+}$channels was heterogeneous and occurred in at least $\sim 40 \%$ of the cells.

To explain the heterogeneity of sodium channel expression, similar arguments could be used as with the heterogeneity of $I_{K A}$ (see above), namely a differentiation dependent downregulation (Kukley et al., 2010), mitosis dependent upregulation (Ge et al., 2009), genetic aberrations and cellular populations with different electrophysiological signatures. Sodium channels are widely expressed in mature as well as in immature normal CNS cell types. In NG2 glia for example, $\mathrm{Na}^{+}$channel expression seems to be heterogeneous per se. Tripathi and co-workers report that in $35 \%$ of the cells no $\mathrm{Na}^{+}$currents could be recorded (Tripathi et al., 2011) and it has even been proposed that sodium channels can distinguish between fundamentally distinct OPC subpopulations (Káradóttir et al., 2008).

The presence of sodium channels led us to test the excitability of BTICs. We were able to measure single TTX sensitive regenerative voltage transients that were broad, slow, and most of them overshot zero. To our knowledge, this feature has only been reported for astrocytes (Sontheimer et al., 1992) and NG2 glia. The presence and nature of regenerative voltage transients in NG2 has been the center of extensive debate. Some groups have described that a subpopulation of NG2 cells was able to fire single (Ge et al., 2009) or even multiple action potentials (Káradóttir et al., 2008). Others have refrained from the term "action potential", but report that a fraction of the cells have a TTX sensitive single voltage transient or spike, characterized for a slow rise, long duration, that may or may not overshoot $0 \mathrm{mV}$ (Chittajallu et al., 2004; Zhou et al., 2006). Finally other groups explicitly reported not detecting action potentials (Bergles et al., 2000; Ziskin et al., 2007).

In agreement with reports on normal NG2 glia, just a fraction of the cells in all BTICs exhibited voltage transients. Chittajalu and co-workers report spikes in 19 out of 56 cells tested (Chittajallu et al., 2004) and Ge an co-workers report the presence of spikes in $30 \%$ of the cells (Ge et al., 2009).

From the above mentioned controversies it can be said that NG2 cells may or may not have voltage transients. Nevertheless, since no voltage transients of such characteristics have been described in other glial cells besides OPCs and astrocytes, we consider it safe to assume that the presence of a spike is suggestive of an NG2 or 
astroglial identity. Unless, of course, the spike represents a peculiar trait of glioma cells, irrespective of cell lineage.

Two interesting studies in human brain tumors have reported a similar phenomenon. In 1998, Bordey and co-workers performed whole cell patch clamp recordings in cells form fresh human low-grade astrocytoma biopsies. They report measuring astrocytoma cells with a membrane resistance $>500 \mathrm{M} \Omega$ that upon current injection generated a spike with an amplitude of $52.2 \mathrm{mV}$ and a width of $12 \mathrm{~ms}$. Neighboring astrocytes failed to generate spikes (Bordey and Sontheimer, 1998).

In a comparable study in oligodendroglioma, a tumor which is most likely derived from NG2 glia (Persson et al., 2010), Patt and co-workers detected action potentials in oligodendroglioma cells from fresh human material. Also, they describe that the excitability of the cells diminished after a few days in culture. Understandably for the state of knowledge in 1996, they conclude "Our physiological study has not settled the debate on the origin of these tumors ... Since action potential generating glial cells have not been described in situ so far their occurrence in oligodendroglial tumors implies that oligodendroglial tumor cells may belong to the neuronal cell lineage" (Patt et al., 1996). Twelve years later Ragnhildur Káradóttir and collaborators would comment on these experiments in the light of their findings that NG2 cells can fire action potentials. They would offer what she calls a parsimonious explanation "... these tumor cells are derived from the $\mathrm{Na}^{+}$channel-expressing class of OPC, reconciling their production of action potentials with their expression of oligodendrocyte lineage markers." (Káradóttir et al., 2008).

Still, the physiological meaning of the sodium current and spike in NG2 cells remains unresolved. Ge proposes that the synaptic input to NG2 cells may induce glial spikes in vivo, depolarizing the cell with consequent activation of voltage-gated calcium channels. The resulting calcium influx might regulate gene expression and proliferation. The link to proliferation is probably based on the observation that, in their experiments, most dividing cells presented spikes ( $\mathrm{Ge}$ et al., 2009). Lin and Bergles propose a similar scenario, where sodium influx leads to the activation of other voltage-gated sodium channels, however they also state that in the absence of excitability, the sodium influx could serve to regulate the efficiency of sodium dependent transporters (Lin and Bergles, 2002). Káradóttir proposes that action potentials in NG2 cells, 
triggered by synaptic input, might serve as a signal for myelination (Káradóttir et al., 2008).

The expression of sodium channels and/or spikes in BTICs might confer an advantage to tumor cells via proliferation using an analogous mechanism to that suggested for normal OPCs (see above). Also, for other tumors, splice variants and neonatal forms of $\mathrm{Na}^{+}$channels have been proposed to enhance migration and invasion (Brackenbury et al., 2008; Onkal and Djamgoz, 2009). In GBM patients, mutations in $\mathrm{Na}^{+}$channels have been shown to correlate with low survival, which might give a clue to the importance of these channels in brain tumor pathogenesis (Joshi et al., 2011). The regulation of $\mathrm{Na}^{+}$dependent transporters, is another indirect mechanism by which $\mathrm{Na}^{+}$channels might influence cell migration in glioma (Kapoor et al., 2009). Finally, the presence of sodium channels and/or spikes might offer no particular advantage to a tumor cell and might represent a mere remnant of its cellular identity or an epiphenomenon. In any case, specific studies tackling the question of the functional role of $\mathrm{Na}^{+}$channels in glioma might prove beneficial for basic understanding of tumor biology and development of new therapeutic strategies.

We were also able to demonstrate the expression of functional glutamate receptors of the AMPA type. Relating this finding to normal CNS lineages, the expression of functional AMPA receptors has been shown in astrocytes (Mcdougal et al., 2011) and has been extensively studied in normal NG2 cells, particularly in the context of synaptic coupling between NG2 glia and neurons (Bergles et al., 2000; Chittajallu et al., 2004; Paukert and Bergles, 2006; Tripathi et al., 2011). AMPA receptors have also been identified in vivo in neural precursor cells of the olfactory bulb (Darcy and Isaacson, 2010) and have been reported to be absent in an in vitro based approach using NSCs (Muth-Köhne et al., 2010). Interestingly, the expression of AMPA receptors and the ability to release glutamate is also a frequent finding in glioma (De Groot et al., 2008; De Groot and Sontheimer, 2011).

AMPA receptors are heteromultimers composed of GluR1-GluR4 subunits, the absence of GluR2 or the presence of an unedited subunit render the channel $\mathrm{Ca}^{+}$ permeable. Human gliomas often lack GluR2 (De Groot and Sontheimer, 2011). Furthermore, the loss of the gene codifying for GluR2 (GRIA2) was a predictor of poor prognosis in a gene expression analysis of human GBM (Colman et al., 2010) suggesting that the function of AMPA receptors in glioma might be related to calcium 
influx upon activation. In fact, the overexpression of calcium permeable AMPA receptors increased proliferation and migration of glioma cells whereas transfection with GluR2 reduced motility and induced apoptosis (Ishiuchi et al., 2002).

NG2 glia receive direct synaptic input from neurons, where the EPSCs are mediated by ionotropic glutamate receptors of the AMPA type (Bergles et al., 2000; Chittajallu et al., 2004; Paukert and Bergles, 2006; Tripathi et al., 2011). Furthermore, AMPA receptors in NG2 glia have been shown to lack GluR2, therefore suggesting that AMPA receptor activation function might be linked to calcium influx (Bergles et al., 2000). Since AMPA receptor activation can regulate OPC differentiation in vitro (Gallo et al., 1996), it has been speculated that neuronal input may also play a role in determining OPC faith in vivo (Paukert and Bergles, 2006).

In astrocytes, the activation of AMPA receptors alters astrocyte morphology and can modulate gene expression (Seifert and Steinhäuser, 2001).

In the present work, we did not determine the calcium permeability of the AMPA receptors. Nevertheless, the expression of AMPA receptors is rather common in astrocytes, progenitors and glioma cells. Even though this observation does not shed light upon the lineage identity of BTICS, the finding of functional AMPA receptors opens the door to some interesting speculations. For example, given that BTICs exhibit other membrane properties of NG2 glia it seems plausible that that they might also receive synaptic input. Further, if synaptic input determines the differentiation of NG2 glia, is it a factor to consider in the initial steps of malignant transformation?

Also, this finding might give insight into the interaction of BTICs with other tumor populations. For instance, the secretion of glutamate from glioma cells, might serve as a positive feed-back mechanisms to regulate the growth and proliferation of BTICs. However, it would first be crucial to determine if BTICs also have the ability to secrete glutamate and to test their response to glutamate in terms of proliferation, migration and differentiation.

Finally, the extent of gap-junctional communication represents another membrane property that can be characteristic of specific cell types. For example, astrocytes (Schools et al., 2006), oligodendrocytes (Wasseff and Scherer, 2011), grafted NSCs (Jäderstad et al., 2010) and neural progenitors (Cheng et al., 2004) exhibit major intercellular connection in dye-coupling experiments whereas NG2 cells filled with 
fluorescent dyes shown no communication with neighboring cells (Akopian et al., 1996; Bergles et al., 2000).

Although many of the electrophysiological membrane properties described so far in this study are shared by both NG2 glia and astrocytes, the absence of dye coupling in BTICs, makes them more compatible with an NG2 phenotype.

Interestingly, connexin $43(\mathrm{C} \times 43)$ the most abundant gap junctional protein in astrocytes is heterogeneously expressed in GBM (Cottin et al., 2011). Further, studies using GBM BTICs have shown a lack of both Cx43 and functional dye-coupling, that later appear upon differentiation (Yu et al., 2012).

Overall, the BTICs used in our series have currents that show strong voltage dependence, characterized by a TEA sensitive sustained outward component, a transient outward current and TTX sensitive transient inward currents. In current clamp experiments, the cells exhibited a slow, broad TTX sensitive regenerative voltage transient and had a moderate membrane resistance. Furthermore, they exhibited inward currents upon application of AMPA that were sensitized by CTZ, and had no dye coupling.

Although some of the characteristics are shared by two or more CNS cell types and glioma cells (delayed rectifier currents, TTX sensitive inward currents, AMPA receptors, regenerative voltage transient), the combination of features is reminiscent of that described for NG2 glia.

Despite its similarities with NG2 glia in terms of membrane physiology and lineage marker expression, we cannot conclude that BTICs are in fact NG2 cells. First, the cells responded to differentiating stimuli by overexpressing GFAP exclusively, an expected response for GBM derived cells but not for NG2 glia. Second, if the function of lineage marker proteins offers selective advantage to tumor cells, its correspondent electrophysiological properties might also represent cellular adaptation and not lineage.

The fact that BTICs resemble NG2 glia could be supported by recent studies using transgenic mouse models, where OPCs have been proposed as the cell of origin of malignant glioma (Liu et al., 2011). However, the relationship between the cell of origin in animal models of gliomagenesis and human BTICs is unclear. 


\subsubsection{Molecular correlates of $I_{K D R}$ and $I_{K A}$}

The precise molecular identification of the ion channels responsible for the recorded currents lies outside the scope of this work. However, besides serving as a functional fingerprint of cell lineage, it is well established that particular ion channels are involved in tumorigenesis (Pardo et al., 2005; Pardo et al., 1999). Furthermore, ion channels have certain properties that make them ideal therapeutic targets 1) they are membrane proteins, 2) a vast array of specific drugs that already on the market act on ion channels and 3) the efficacy of new agents can be tested directly at the functional level.

In glioma, specific splice variants of BK channels have been described (Liu et al., 2002) and toxin based therapies targeting ion channels and associated molecules have been approved for clinical trials (Sontheimer, 2008). In neurogenesis, $\mathrm{K}^{+}$channels have been involved in cellular proliferation and migration (Schwab, 2001).

It has been proposed that homomeric $\mathrm{K}_{\mathrm{v}} 1.5$ and heteromeric channel complexes represent the molecular identity of the channels underlying the delayed rectified currents in OPCs (Schmidt et al., 1999). Although in our model we could not demonstrate directly that $I_{K D R}$ is carried by $K_{V} 1.5$ channels, certain clues suggest it as a candidate for the molecular correlate of $\mathrm{I}_{\mathrm{KDR}}$ :

1) We could demonstrate a voltage dependent rectification at $40 \mathrm{mV}$ in all cell lines,

2) in a representative line, we showed that the rectification is magnesium dependent, a property described for $\mathrm{K}_{\mathrm{v}} 1.5$ (Tammaro et al., 2005);

3) the current was readily blocked by TEA and

4) the $\mathrm{K}_{\mathrm{v}} 1.5$ protein was readily detected in a cell membrane- reminiscent pattern by immunocytochemistry in all lines. To our knowledge, no specific $\mathrm{K}_{\mathrm{v}} 1.5$ blockers exist, therefore to establish a functional correlate to $I_{K D R}$, gene silencing strategies should be used.

It is important to consider that the expression of $\mathrm{K}_{\mathrm{v}} 1.5$ is rather ubiquitous in the CNS and can be found in NG2 glia, astrocytes, neurons and microglia (Pannasch et al., 2006; Roy et al., 1996; Whyment et al., 2011). 
No molecular correlates have been proposed for $I_{K A}$ in NG2 glia, NSCs or astrocytes. However, we determined that $I_{K A}$ in BTICs was sensitive to 4-AP, and resistant to TEA. So we hypothesized that the current could be carried by channels of the $K_{v} 4$ family (Gutman et al., 2005), to test this hypothesis, the specific $K_{v} 4.2 / K_{v} 4.3$ blocker Phrixotoxin-2 (Diochot et al., 1999) was used and no block was observed. Therefore, we propose that the current is carried either by $\mathrm{K}_{\mathrm{v}} 4.1$ channels, channels of the $\mathrm{K}_{\mathrm{v}} 1$ family associated to beta subunits (Rettig et al., 1994), or heteromers. 


\section{Summary}

Malignant astrocytomas are the most frequent and aggressive primary brain tumors in adults. The development of rational therapies is partially hindered by the limited understanding of the mechanisms of glioma- genesis and progression. One of the hallmarks of glioblastoma multiforme (GBM), the most common malignant astrocytoma, is its extensive heterogeneity in marker expression, cell morphology and genetic lesions. Therefore, the contribution to tumor progression of individual neoplastic subpopulations remains largely unknown.

Traditionally, gliomas have been thought to derive from dedifferentiation of mature glia. However, experiments of induced gliomagenesis in animal models and the identification of markers of NSCs and NG2 glia/OPCs in GBM, suggest a role for these immature subpopulations in glioma.

Therefore by using culture conditions to isolate normal NSCs/progenitors in human GBM samples, it has been possible to isolate tumor cells that express markers of NSC and have a multipotent differentiation potential. These stem-like subpopulations are thought to contribute to tumor progression since they are able to give rise to tumors that recapitulate the hallmarks of GBM upon implantation in immunodeficient mice and have therefore been called brain tumor initiating cells (BTICs).

Despite its potential role in tumor propagation, the identity of BTICs is poorly understood. BTICs usually express markers of NSCs and NG2 glia, and have therefore been considered to be transformed NSC/progenitors. However the expression of certain markers (e.g. nestin/NG2) might confer selective advantages to cells in the tumor microenvironment and might not adequately represent lineage in pathological states.

To overcome this problem, in this work we introduce a new approach to characterize BTICS, where traditional cell culture and marker based strategies are complemented with the measurement of electrophysiological parameters. This strategy relies on the fact that the electrophysiological properties of normal CNS populations have been thoroughly described and represent a fingerprint of cell lineage. 
In this study we characterized a panel of five BTICs derived from human glioblastoma multiforme. The cells co-expressed the NSC marker nestin and the OPC marker NG2 and two lines had additionally an heterogeneous expression of GFAP. Although NG2 glia might co-express nestin under certain circumstances, the differentiation pattern of BTICs did not conform to that of NG2 glia. Upon exposure to different growth factors known to induce differentiation into neuronal, oligo- or astroglial lineages, the cells responded by increasing the expression of GFAP in all cases and no expression of MBP or NeuN could be induced.

Finally, the BTIC currents had strong voltage dependence, characterized by a TEA sensitive sustained outward component, a transient outward current and TTX sensitive transient inward currents. The cells exhibited a slow, broad TTX sensitive regenerative voltage transient upon current injection and had a moderate membrane resistance. Furthermore, they exhibited inward currents upon application of AMPA that were sensitized by CTZ. Also no effective dye coupling was observed in confluent cultures.

Although individual electrophysiological parameters can be shared by many of the normal CNS subpopulations, the combination of functional membrane features described is reminiscent of that of NG2 glia.

Overall our data show that BTICs do not represent any of the "pure" CNS cellular subpopulations. Nevertheless, they exhibit characteristics of an immature phenotype, which besides the restricted differentiation potential into the astrocytic lineage, is closer to that of NG2 cells. Our findings indicate that the expression of lineage markers in brain tumors might relate, at least partially, with additional functional aspects of lineage supporting the interpretation that BTICs might be related to immature cell types. 


\section{Materials and Methods}

\subsection{Cell culture}

Primary glioma lines \#10, \#1034, \#1063, \#1095, \#1051, \#1080 and \#1075 were provided by Dr. Ella Kim (Neurosurgery Clinic, Universitätsmedizin Mainz). All lines were derived from human samples diagnosed as GBM according to the World Health Organization guidelines by a certified neuropathologist (Department of Neuropathology, Universitätsmedizin Göttingen).

The cell lines were produced according to the method described by Galli and Gritti (Galli et al., 2004; Gritti et al., 1996). Shortly, the specimens were dissociated to a single cell suspension, and were plated at a density of $2500-5000$ cells / ml. The cells were kept at $37^{\circ} \mathrm{C}$ and $5 \% \mathrm{CO}_{2}$ in a humidified atmosphere and maintained in Neurobasal medium (Gibco) supplemented with bovine serum albumin fraction $\mathrm{V}$ (Roche) and growth factors bFGF (10ng/ml), EGF (20ng/ml) (Biochrom) and B27 supplement without Vitamin A (Gibco). Reagent and media specifications can be found in Table 2 and Table 3.The resulting tumor spheroids were further subcultured and all experiments were performed on cells between passage ten and thirty.

The tumorigenic potential of the cell lines was tested by orthotopic implantation in immunodeficient mice. All lines used in this study produced tumors with morphological criteria of GBM.

Primary cultures of oligodendrocyte progenitor cells (OPCs) were a gift from Sebastian Schmidt (Max-Planck Institute of Experimental Medicine, Göttingen) and were prepared as described elsewhere (Fitzner et al., 2006; Simons et al., 2000). Shortly, newborn (P0) mice brains were dissociated using $0.25 \%$ Trypsin-EDTA at $37^{\circ} \mathrm{C}$ for 10 minutes followed by mechanical trituration. The cell suspension was cultured at $37^{\circ} \mathrm{C}$ and $7.5 \% \mathrm{CO}_{2}$ in BME-Medium (Gibco) supplemented with $1 \%$ Glutamax (Gibco). Once confluence was reached, microglia cells were detached by repeatedly impacting the flask against a solid surface. After, the supernatant was discarded and the medium replaced. The oligodendrocyte progenitors were obtained 
by vigorously shaking the flask and filtering the supernatant through a cell filter into a $50 \mathrm{ml}$ Falcon tube (BD biosciences). After centrifugation, the cell pellet was resuspended in DMEM (Gibco), supplemented with 1\% Glutamax (Gibco) and B-27 (Gibco).

Primary cultures of mouse astrocytes were a kind gift from Gerd-Marten Kuscher (Max-Planck Institute of Experimental Medicine, Göttingen). The cultures were prepared by dissecting the cerebral cortex of P0 mice and homogenizing with an 18gauge needle. The dissociated tissue was placed in DMEM medium (Gibco) supplemented with $10 \%$ FCS. After centrifugation and rehomogenization, the cells were plated in culture flasks (Sarstedt) and were allowed to grow at $37^{\circ} \mathrm{C}$ and $7.5 \%$ $\mathrm{CO}_{2}$ in a humidified atmosphere. Before confluence was reached, the cells were subcultured by dissociation with Trypsin/EDTA (Biochrom).

Primary cultures of mouse hippocampal neurons were prepared by extracting the brains of E18 mice and dissecting their hippocampi in cold dissection solution consisting of HBSS (Gibco) supplemented with 7mM Hepes and Glutamax 1\% (Gibco). Then, the hippocampi were dissociated by applying $2.5 \%$ Trypsin in calcium- and magnesium-free HBSS (Lonza) for 30 minutes at $37^{\circ} \mathrm{C}$. The trypsin reaction was stopped by adding $0.8 \mathrm{mg} / \mathrm{ml}$ of trypsin inhibitor (Gibco) in dissection solution. After centrifugation, the cells were washed three times with Neurobasal medium (Gibco), supplemented with $100 \mu \mathrm{g} / \mathrm{ml}$ insulin (Gibco),100 $\mu \mathrm{g} / \mathrm{ml}$ transferrin (Gibco), 5\% FCS, 2\% B27 (Gibco) and 2mM Glutamax (Gibco). Then the sample was homogenized by trituration with a fire-polished Pasteur pipette, centrifuged, re-suspended in culture medium and plated on Poly-L-lysine coated coverslips.

The data from granule cell neurons were provided by Sünke Mortensen (MaxPlanck Institute of Experimental Medicine, Göttingen). The experiments were done in acute cerebellar slices of P24 mice and were prepared as described elsewhere (Bao et al., 2010).

The commercially available melanoma cell line B16-V was obtained from the German Collection of Microorganisms and Cells (DSMZ). The cells were maintained in their recommended media (Table 3) at $37^{\circ} \mathrm{C}$ under $5 \% \mathrm{CO} 2$ in a humidified atmosphere. The medium was periodically replaced every 2-3 days. The cells were subcultured when an $60-80 \%$ confluence was reached. To do this, the medium was aspirated and the cells were washed twice with DPBS. Then the cells were detached 
by applying Trypsin/EDTA (Biochrom) and incubating at $37^{\circ} \mathrm{C}$ for 4 minutes. The trypsin reaction was stopped by adding culture medium supplemented with $10 \%$ FCS in a 1:1 volume ratio. The cells were centrifuged at $1300 \mathrm{xg}$ for 3 minutes. Then, the cell pellet was resuspended in an appropriate volume of medium to achieve the desired density for replating or according to the experimental needs.

Table 2. Cell culture supplements, growth factors and reagents

\begin{tabular}{lll}
\hline \multicolumn{1}{c}{ Supplement / Growth factor / Reagent } & Manufacturer & \multicolumn{1}{c}{$\begin{array}{c}\text { Catalog } \\
\text { Number }\end{array}$} \\
\hline \hline DPBS & GIBCO/Invitrogen & 1419 \\
Hank's Balanced Salt Solution (HBSS) & GIBCO/Invitrogen & $24020-117$ \\
FCS & PAA & A15.101 \\
Trypsin / EDTA (0.05/0.02\%) v/v & Biochrom AG & L2143 \\
Trypsin / EDTA 0.25\% & Sigma & T4049 \\
Trypsin 2.5\% in HBSS w/o Ca,Mg & Lonza & $17-160 \mathrm{E}$ \\
Trypsin Inhibitor from chicken egg white & Sigma & T9253 \\
Trypsin Inhibitor, soybean & Gibco/Invitrogen & $17075-029$ \\
B27 Supplement without Vitamin A & Gibco/Invitrogen & $12587-010$ \\
Glutamax & Gibco/Invitrogen & $35050-038$ \\
Insulin, human recombinant, zinc solution & Gibco/Invitrogen & $12585-014$ \\
Transferrin, bovine (Holo Form) & Gibco/Invitrogen & $11107-018$ \\
Ciliary Neurotrophic Factor (CNTF), human, & Sigma & C3710 \\
Recombinant & Biochrom AG & W1325.950.500 \\
Human Epidermal Growth Factor (EGF) & Biochrom AG & W1370.950.050 \\
Human FGF-basic & Roche & 10735094001 \\
Bovine Serum Albumin fraction V (BSA) & Calbiochem & 64245 \\
L-3.3',5-Triiodothyronine, Sodium Salt & & \\
\hline
\end{tabular}


Table 3. Cell lines, culture media and supplements

\begin{tabular}{|c|c|c|c|c|}
\hline Cell line & $\begin{array}{l}\text { Culture } \\
\text { Media }\end{array}$ & Manufacturer & $\begin{array}{l}\text { Catalog } \\
\text { Number }\end{array}$ & Supplement \\
\hline Primary BTICs & Neurobasal & GIBCO/Invitrogen & 12348017 & $\begin{array}{l}\text { B27 } \\
\text { BSA(1\%) } \\
\text { EGF(10ng/mL) } \\
\text { FGF(20ng/mL) }\end{array}$ \\
\hline \multirow[t]{2}{*}{$\begin{array}{l}\text { Primary mouse } \\
\text { oligodendrocyte } \\
\text { progenitors }\end{array}$} & $\begin{array}{l}\text { Basal } \\
\text { Medium } \\
\text { Eagle } \\
\text { (BME), no } \\
\text { Glutamine }\end{array}$ & GIBCO/Invitrogen & $\begin{array}{l}21010- \\
046\end{array}$ & Glutamax(1\%) \\
\hline & $\begin{array}{l}\text { Dulbecco's } \\
\text { Modified } \\
\text { Eagle } \\
\text { Medium } \\
\text { (DMEM), no } \\
\text { Glutamine }\end{array}$ & GIBCO/Invitrogen & $\begin{array}{l}11960- \\
044\end{array}$ & $\begin{array}{l}\text { B-27 } \\
\text { Glutamax(1\%) }\end{array}$ \\
\hline $\begin{array}{l}\text { Primary mouse } \\
\text { astrocytes }\end{array}$ & $\begin{array}{l}\text { Dulbecco's } \\
\text { Modified } \\
\text { Eagle } \\
\text { Medium } \\
\text { (DMEM), no } \\
\text { Glutamine }\end{array}$ & GIBCO/Invitrogen & $\begin{array}{l}11960- \\
044\end{array}$ & $\begin{array}{l}\text { Glutamax(1\%) } \\
\text { FCS(10\%) }\end{array}$ \\
\hline $\begin{array}{l}\text { Primary mouse } \\
\text { neurons }\end{array}$ & Neurobasal & GIBCO/Invitrogen & $\begin{array}{l}12348- \\
017\end{array}$ & $\begin{array}{l}\text { B27(2\%) } \\
\text { FCS }(5 \%) \\
\text { Glutamax }(2 \mathrm{mM}) \\
\text { Insulin }(100 \mu \mathrm{g} / \mathrm{ml}) \\
\text { Transferrin }(100 \mu \mathrm{g} / \mathrm{ml})\end{array}$ \\
\hline B16 & $\begin{array}{l}\text { Roswell } \\
\text { Park } \\
\text { Memorial } \\
\text { Institute } \\
\text { (RPMI) } \\
1640, \\
\text { Glutamax }\end{array}$ & GIBCO/Invitrogen & $\begin{array}{l}\text { 61870- } \\
036\end{array}$ & $\mathrm{FCS}(10 \%)$ \\
\hline
\end{tabular}




\subsection{Immunocytochemistry}

\subsubsection{Cell preparation}

Spheroids from primary human glioblastoma were dissociated using Trypsin / EDTA $0.25 \%$ (Sigma) for $10 \mathrm{~min}$ at $37^{\circ} \mathrm{C}$. Then, trypsin inhibitor from chicken egg white (Sigma) was added in a 1:1 volume / volume ratio. To achieve a single cell suspension, the cells were triturated using a fire-polished Pasteur glass pipette. After centrifugation, the cells were re-suspended in complete neurobasal medium and plated on $20 \mathrm{~mm}$ diameter poly-L-lysine (PLL) coated coverslips.

For primary astrocytes, a similar procedure was used, with the difference that the dissociation of the culture was done with Trypsin / EDTA (0.05/0.02\%) v/v (Biochrom) for 5 minutes at $37^{\circ} \mathrm{C}$ and the trypsin reaction was inhibited with culture medium supplemented with FCS. Primary oligodendrocyte progenitors and neurons were plated directly on PLL-coated glass coverslips (see Section 6.1Cell culture, page 66).

\subsubsection{Differentiation conditions}

To test the effect of particular growth factors on the differentiation potential of tumor cells, the cells were prepared as mentioned above (Section 706.2.1 Cell preparation, page 70). The cells were allowed to adhere overnight and the medium was replaced with complete neurobasal medium supplemented with FCS, CNTF, T3 or forskolin (Table 2, page 68). The cells were allowed to differentiate for 3 or 5 days before staining. Cells grown in complete neurobasal medium were used as a control.

\subsubsection{Staining procedure}

The cells were collected at different time points depending on the experiment. First, they were washed 3 times with PBS and fixed with 10\% formalin solution (Sigma) at $4^{\circ} \mathrm{C}$ for 10 minutes. After fixation, the coverslips were placed in a new multi-well plate and were again washed 3 times with PBS. Then, the solution was replaced with PBS 
containing $0.5 \%$ Triton $\mathrm{X}-100$ (Sigma) for 5 minutes, in order to permeabilize the cell membranes.

After permeabilization, the cells were washed 3 times using PBST, a PBS based solution with $0.1 \%$ Tween 20 (Sigma). Unspecific epitopes were blocked by using $10 \%$ BSA (Sigma) in PBST for 1 hour. Then, the cells were incubated with primary antibodies at their optimal dilutions in blocking solution (Table 5., page 72). After three wash steps with PBST, one-hour incubation with the appropriate secondary antibodies followed. Finally, the cells were washed 3 times with PBST and in the last wash TOPRO-3 (Invitrogen) was used to counter-stain cell nuclei in a 1:500 dilution in PBST. The coverslips were mounted on a glass slide (Menzel) using Prolong Gold antifade reagent with DAPI (Invitrogen) and were kept at $4^{\circ} \mathrm{C}$ until visualization.

For those experiments where no permeabilization was used, the incubation with Triton X-100 was omitted and PBST was replaced with PBS.

\subsubsection{Confocal Microscopy}

Fluorescence signals were collected with a LSM 510 Meta laser scanning confocal microscope (Zeiss) using a 40x / numerical aperture (NA) $=1.3$ or $63 x / N A=1.25$ PlanNeofluar oil immersion objective. Alexa Fluor 488 (Invitrogen) and Alexa Fluor 546 (Invitrogen) and TP-PRO-3 (Invitrogen) fluorochromes were excited at 405, 488 and $543 \mathrm{~nm}$ respectively. Emission was collected at 5160-580 nm (Alexa Fluor 488), 558$633 \mathrm{~nm}$ (Alexa Fluor 555) and 655-719 nm (TO-PRO-3). The images were $1024 \times 1024$ pixels with a pixel size of $79.4 \times 79.4 \mu \mathrm{m}$ and $181.9 \times 181.9 \mu \mathrm{m}$ for images acquired using the $63 x$ and the $40 x$ objective respectively. Sequential scanning mode with a $4 x$ line average, a pixel time of 1.6-3.2 $\mu$ s and a pinhole of $112 \mu \mathrm{m}(\sim 1$ Airy unit) were used. The Zeiss LSM AIM software v.2.2.0.121 (Zeiss) was used for image acquisition. Post-acquisition processing was done using the image analysis software FIJI (Schindelin, 2008). 
Table 4. Reagents for immunocytochemistry

\begin{tabular}{lll}
\hline \multicolumn{1}{c}{ Reagent } & Manufacturer & Catalog Number \\
\hline Formalin solution 10\% & Sigma & HT501128 \\
(Neutral Buffered) & Sigma & X-100-500ML \\
Triton X-100 & Sigma & A3059 \\
Albumin from bovine serum & Merck & 655204 \\
Tween 20 & Sigma & P2636 \\
Poly-L-Lysine & Invitrogen & T3605 \\
TO-PRO-3 & Invitrogen & P-36931 \\
Prolong Gold anti fade reagent with DAPI &
\end{tabular}

Table 5. Antibodies for immunocytochemistry

\begin{tabular}{|c|c|c|c|c|}
\hline Antibody & $\begin{array}{l}\text { Host Species / } \\
\text { Clonality }\end{array}$ & Dilution & Manufacturer & $\begin{array}{l}\text { Catalog } \\
\text { number }\end{array}$ \\
\hline $\begin{array}{l}\text { Anti-Nestin, clone } \\
10 \mathrm{C} 2\end{array}$ & $\begin{array}{l}\text { Mouse } \\
\text { Monoclonal }\end{array}$ & $1: 1000$ & Millipore & MAB5326 \\
\hline Anti-PDGFR- $\alpha$ (16A1) & $\begin{array}{l}\text { Mouse } \\
\text { Monoclonal }\end{array}$ & $1: 250$ & $\begin{array}{l}\text { Santa Cruz } \\
\text { Biotechnology }\end{array}$ & sc-21789 \\
\hline $\begin{array}{l}\text { Anti-NG2 Chondroitin } \\
\text { Sulfate Proteoglycan }\end{array}$ & $\begin{array}{l}\text { Rabbit } \\
\text { Polyclonal }\end{array}$ & $1: 500$ & Millipore & AB5320 \\
\hline Anti-GFAP & $\begin{array}{l}\text { Rabbit } \\
\text { Polyclonal }\end{array}$ & $1: 1000$ & Promega & G5601 \\
\hline Anti-GFAP (GA5) & $\begin{array}{l}\text { Mouse } \\
\text { Monoclonal }\end{array}$ & $1: 1000$ & Cell Signaling & $3670 S$ \\
\hline $\begin{array}{l}\text { Anti-Sodium Channel, } \\
\text { Pan antibody (K58/35) }\end{array}$ & $\begin{array}{l}\text { Mouse } \\
\text { Monoclonal }\end{array}$ & $1: 1000$ & Sigma & S8809 \\
\hline Anti-KCNA5 & $\begin{array}{l}\text { Rabbit } \\
\text { Polyclonal }\end{array}$ & $1: 1000$ & Abcam & ab50294 \\
\hline $\begin{array}{l}\text { Anti- Myelin Basic } \\
\text { Protein (MBP) (SMI- } \\
94)\end{array}$ & $\begin{array}{l}\text { Mouse } \\
\text { Monoclonal }\end{array}$ & $1: 1000$ & Covance & SMI-94R \\
\hline $\begin{array}{l}\text { Anti-NeuN, Clone (A- } \\
60)\end{array}$ & $\begin{array}{l}\text { Mouse } \\
\text { Monoclonal }\end{array}$ & $1: 1000$ & Millipore & MAB377 \\
\hline Anti GluR1 & $\begin{array}{l}\text { Mouse } \\
\text { Monoclonal }\end{array}$ & $1: 250$ & Synaptic systems & 182011 \\
\hline $\begin{array}{l}\text { Alexa Fluor } 488 \text { goat } \\
\text { anti-rabbit } \lg G(\mathrm{H}+\mathrm{L})\end{array}$ & Goat Polyclonal & $1: 1000$ & Invitrogen & A11034 \\
\hline
\end{tabular}


Alexa Fluor 488 goat Goat Polyclonal 1:1000 Invitrogen A11029 anti-mouse $\lg \mathrm{G}(\mathrm{H}+\mathrm{L})$

Alexa Fluor 546 goat Goat Polyclonal 1:1000 Invitrogen A11035 anti-rabbit $\lg \mathrm{G}(\mathrm{H}+\mathrm{L})$

Alexa Fluor 546 goat Goat Polyclonal 1:1000 Invitrogen A11030 anti-mouse $\lg G(\mathrm{H}+\mathrm{L})$

\subsection{Flow cytometry}

To process the cells for flow cytometry, a single-cell suspension was prepared as described in section 6.2.1, page 70. Then, the cells were centrifuged at $1200 \mathrm{xg}$ for 2 minutes. For immunostaining of membrane-bound NG2 on live cells, a monoclonal antihuman NG2/MCSP Phycoerythrin (PE) coupled antibody (R\&D Systems) was used according to the manufacturer's instructions. Briefly, after centrifugation the cells were washed three times with DPBS supplemented with $0.5 \%$ BSA. Then, $10^{5}$ cells were incubated in $25 \mu \mathrm{l} 10 \% \mathrm{BSA}$ in DPBS for 15 minutes at room temperature to block nonspecific antibody binding. Subsequently, $10 \mu \mathrm{l}$ of PE-conjugated NG2 reagent were added and incubated for 45 minutes at $4^{\circ} \mathrm{C}$. The cells were washed three times and resuspended in $0.5 \%$ BSA DPBS buffer for analysis.

Before analysis, the samples were further incubated with TO-PRO-3 (1:1000, Invitrogen) for 5 minutes at room temperature, as a mean to test the membrane integrity. The samples were analyzed in a FACSAria flow cytometer (BD Biosciences) using $\operatorname{Ar} 488 \mathrm{~nm}$ and a HeNe 633nm lasers for excitation. The fluorescence emission was collected using 576/26 and 660/20 band pass filters for PE and TO-PRO-3 respectively. Linear forward and side scatter gates were used to discriminate single cells from cell clumps and debris. Events with high fluorescence in the TO-PRO-3 channel were excluded from the analysis. After gating, a minimum of $10^{4}$ events was recorded for each sample. FACS Diva software v5.0 (BD Biosciences) was used for data acquisition and post-acquisition data processing was done with FlowJo v7.5 software (Tree Star). 


\subsection{Electrophysiology}

\subsubsection{Cell preparation and procedure}

All cells types were prepared in the same manner as for immucytochemical experiments (Section 6.2.1 Cell preparation, page 70), but were plated at a lower density of $\left(10^{5}\right.$ cells $\left./ \mathrm{ml}\right)$ on $10 \mathrm{~mm}$ poly-L-lysine coated coverslips (Menzel). The cells were allowed to adhere and were measured 24-48 hours after plating.

Patch clamp experiments were performed at room temperature, using different extracellular and intracellular solutions (Table 6, page 76). Patch pipettes were made from WPI.PG10165-4 glass (World Precision Instruments) using an L/M-3P-A vertical puller (List Medical) in order to attain a pipette resistance of 3-5M $\Omega$. when the pipettes were back-filled with intracellular solution (Table 6, page 76). Before immersion of the pipette, external pressure was applied to avoid obstruction of the tip. The pressure was released when the pipette tip was in close proximity to cell membrane. A tight seal ( $>1$ $\mathrm{G} \Omega$ ) was formed by applying gentle suction when contact with the membrane was achieved (evidenced by an increase in the pipette resistance). To gain electrical access to the cell, the membrane was perforated using brief suction pulses. Pipette capacitance, cell capacitance and series resistance were compensated ( 70-80\%) before the application of each voltage protocol.

Currents were recorded in the whole-cell configuration (Hamill et al., 1981) using an EPC9 patch-clamp amplifier (HEKA Elektronik). Pulse protocol generation and data acquisition were controlled using Pulse software v.6 (HEKA Elektronik). Data were filtered at 2 or $5 \mathrm{kHz}$ and acquired at 10 or $25 \mathrm{kHz}$ respectively. Unless otherwise stated, cells were clamped at a potential of $-80 \mathrm{mV}$.

\subsubsection{Voltage/Current Protocols}

In order to measure the global current response of the cell, we used a protocol consisting of a $200 \mathrm{~ms}$ pre-pulse to $-80 \mathrm{mV}$, followed by a short $(5 \mathrm{~ms})$ step to $-60 \mathrm{mV}$ 
and finally a $250 \mathrm{~ms}$ pulse to variable potentials from $100 \mathrm{mV}$ to $-100 \mathrm{mv}$ in $20 \mathrm{mV}$ steps. A period of $5 \mathrm{~s}$ at holding potential was left between stimulations. To induce inactivation of transient outward currents, a similar protocol was applied where the prepulse potential was kept at $-20 \mathrm{mV}$. A $5 \mathrm{~s}$ pre-pulse potential to variable voltages from 140 to $60 \mathrm{mV}$ in $20 \mathrm{mV}$ steps, followed by a $250 \mathrm{~ms}$ pulse to $100 \mathrm{mV}$ was used to determine the half-inactivation potential of transient outward currents.

To test the effect of tetraethylammonium (TEA) and 4-aminopyridine (4-AP) on outward currents, the cells were held at $-20 \mathrm{mV}$ and a $250 \mathrm{~ms}$ pulse to $40 \mathrm{mV}$ was applied ten times in $5 \mathrm{~s}$ intervals, before and after the application of the blocker. The concentrations used were $10 \mathrm{mM}$ for TEA (Sigma) and $4 \mathrm{mM}$ for 4-AP (Sigma). A similar protocol was applied to test the response of transient outward currents to specific blockers, with the difference that -80 and $100 \mathrm{mV}$ were used for the holding and the test potentials respectively. To determine the effect of $100 \mathrm{nM}$ tetrodotoxin (TTX) (Sigma) on inward currents, a $25 \mathrm{~ms}$ test pulse to $0 \mathrm{mV}$ was applied every $5 \mathrm{~s}$ for five pulses. The solution bathing the cell was completely exchanged in about $100 \mathrm{~ms}$, using an external perfusion system (Nanion).

To test the response to a-amino-3-hydroxy-5-methyl-4-isoxazolepropionic acid (AMPA), the cell was kept at $-80 \mathrm{mV}$. After $1 \mathrm{~s}, 150 \mu \mathrm{M}$ AMPA (Sigma) was applied to the bath solution for $2 \mathrm{~s}$, and then an extra period of $3 \mathrm{~s}$ was recorded under normal extra cellular solution. Afterwards, the same protocol was applied, but $100 \mu \mathrm{M}$ Cyclothiazide (CTZ) (Sigma) were used instead of AMPA. Finally, after a $4 \mathrm{~s}$ CTZ incubation, the response to both agents (CTZ and AMPA) was tested, at potentials from $-80 \mathrm{mV}$ to $80 \mathrm{mV}$ with $40 \mathrm{mV}$ steps.

For current clamp experiments, a constant current was injected to keep the cell at a resting potential of approximately $-80 \mathrm{mV}$. Then relative stimuli were applied from -40 to $240 \mathrm{pA}$ in $20 \mathrm{pA}$ steps for $800 \mathrm{~ms}$. 
Table 6. Solutions for electrophysiological recordings

\begin{tabular}{|c|c|c|}
\hline Solution & \multicolumn{2}{|c|}{ Composition } \\
\hline \multirow[t]{6}{*}{ Standard pipette solution } & $\mathrm{KCl}$ & $130 \mathrm{mM}$ \\
\hline & $\mathrm{NaCl}$ & $10 \mathrm{mM}$ \\
\hline & $\mathrm{MgCl}_{2}$ & $2 \mathrm{mM}$ \\
\hline & HEPES & $10 \mathrm{mM}$ \\
\hline & EGTA & $10 \mathrm{mM}$ \\
\hline & $\mathrm{CaCl}_{2}$ & $2 \mathrm{mM}$ \\
\hline \multirow[t]{5}{*}{ Pipette solution $\left(\mathrm{Mg}^{2+}\right.$ free) } & $\mathrm{KCl}$ & $130 \mathrm{mM}$ \\
\hline & $\mathrm{NaCl}$ & $10 \mathrm{mM}$ \\
\hline & HEPES & $10 \mathrm{mM}$ \\
\hline & HEDTA & $10 \mathrm{mM}$ \\
\hline & $\mathrm{CaCl}_{2}$ & $2 \mathrm{mM}$ \\
\hline \multirow[t]{6}{*}{ Pipette solution ( $\mathrm{K}^{+}$free) } & $\mathrm{CsCl}$ & $130 \mathrm{mM}$ \\
\hline & $\mathrm{NaCl}$ & $10 \mathrm{mM}$ \\
\hline & $\mathrm{MgCl}_{2}$ & $2 \mathrm{mM}$ \\
\hline & HEPES & $10 \mathrm{mM}$ \\
\hline & EGTA & $10 \mathrm{mM}$ \\
\hline & $\mathrm{CaCl}_{2}$ & $2 \mathrm{mM}$ \\
\hline \multirow[t]{5}{*}{ Standard bath solution } & $\mathrm{NaCl}$ & $140 \mathrm{mM}$ \\
\hline & $\mathrm{KCl}$ & $2.8 \mathrm{mM}$ \\
\hline & $\mathrm{MgCl}_{2}$ & $2 \mathrm{mM}$ \\
\hline & HEPES & $10 \mathrm{mM}$ \\
\hline & $\mathrm{CaCl}_{2}$ & $2 \mathrm{mM}$ \\
\hline
\end{tabular}


Table 7. Voltage/Current protocols

\begin{tabular}{|c|c|}
\hline $\begin{array}{l}\text { Electrophysiological } \\
\text { parameter }\end{array}$ & Voltage protocol \\
\hline Global Current & $\begin{array}{l}\text { 1. Holding potential: }-80 \mathrm{mV} \\
\text { 2. Prepulse: }-80 \mathrm{mV}, 200 \mathrm{~ms} \\
\text { 3. Prepulse: }-60 \mathrm{mV}, 5 \mathrm{~ms} \\
\text { 4. Test Pulse: }-100 \text { to } 100 \mathrm{mV}, 250 \mathrm{~ms} \\
\text { 5. Holding potential: }-80 \mathrm{mV} \\
\text { 6. Interval: } 5 \mathrm{~s} \text { at holding potential } \\
\text { Leak subtraction: } \mathrm{P} / 10 \text {, Holding }-80 \mathrm{mV}\end{array}$ \\
\hline $\mathrm{I}_{\mathrm{KDR}}$ & $\begin{array}{l}\text { 1. Holding potential: }-80 \mathrm{mV} \\
\text { 2. Prepulse: }-20 \mathrm{mV}, 200 \mathrm{~ms} \\
\text { 3. Prepulse: }-60 \mathrm{mV}, 5 \mathrm{~ms} \\
\text { 4. Test Pulse: }-100 \text { to } 100 \mathrm{mV} \text { in } 10 \mathrm{mV} \\
\text { increments, } 250 \mathrm{~ms} \\
\text { 5. Holding potential: }-80 \mathrm{mV} \\
\text { 6. Interval: } 5 \mathrm{~s} \text { at holding potential } \\
\text { Leak subtraction: } \mathrm{P} / 10, \text { Holding }-80 \mathrm{mV}\end{array}$ \\
\hline$I_{K A}$ & Global current - I KDR \\
\hline TEA / 4-AP block of $I_{K D R}$ & $\begin{array}{l}\text { 1. Holding potential: }-80 \mathrm{mV} \\
\text { 2. Prepulse: }-20 \mathrm{mV}, 200 \mathrm{~ms} \\
\text { 3. Test Pulse: } 40 \mathrm{mV}, 250 \mathrm{~ms} \\
\text { 4. Holding potential: }-80 \mathrm{mV} \\
\text { 5. Interval: } 5 \mathrm{~s} \text { at holding potential } \\
\text { 6. Repeat } 10 \text { times for control, } 10 \text { times with TEA / } \\
\text { 4-AP, } 10 \text { times wash } \\
\text { Leak subtraction: } \mathrm{P} / 10, \text { Holding }-80 \mathrm{mV}\end{array}$ \\
\hline PTX-2 block of $I_{K A}$ & $\begin{array}{l}\text { 1. Holding potential: }-80 \mathrm{mV} \\
\text { 2. Prepulse: }-80 \mathrm{mV}, 200 \mathrm{~ms} \\
\text { 3. Test Pulse: } 0 \mathrm{mV}, 20 \mathrm{~ms} \\
\text { 4. Holding potential: }-80 \mathrm{mV} \\
\text { 5. Interval: } 10 \mathrm{~s} \text { at holding potential } \\
\text { 6. Repeat } 3 \text { times for control, } 3 \text { times with PTX-2, } 3 \\
\text { times wash } \\
\text { No leak subtraction }\end{array}$ \\
\hline TTX block of $\mathrm{I}_{\mathrm{Na}+}$ & $\begin{array}{l}\text { 1. Holding potential: }-80 \mathrm{mV} \\
\text { 2. Prepulse: }-80 \mathrm{mV}, 200 \mathrm{~ms} \\
\text { 3. Test Pulse: } 0 \mathrm{mV}, 25 \mathrm{~ms} \\
\text { 4. Holding potential: }-80 \mathrm{mV} \\
\text { 5. Interval: } 5 \mathrm{~s} \text { at holding potential } \\
\text { 6. Repeat } 5 \text { times for control, } 5 \text { times with TTX, } 5 \\
\text { times wash } \\
\text { Leak subtraction: } \mathrm{P} / 10, \text { Holding }-80 \mathrm{mV}\end{array}$ \\
\hline $\mathrm{I}_{\text {AMPA }}$ & $\begin{array}{l}\text { 1. Holding potential: }-80 \mathrm{mV}, 1 \mathrm{~s} \\
\text { 2. Test Pulse: }-80 \mathrm{mV}, \mathrm{AMPA}, 2 \mathrm{~s}\end{array}$ \\
\hline
\end{tabular}


3. Holding potential: $-80 \mathrm{mV}$, 3s

\begin{tabular}{ll}
\hline $\mathrm{I}_{\mathrm{CTZ}}$ & 1. Holding potential: $-80 \mathrm{mV}, 1 \mathrm{~s}$ \\
& 2. Test Pulse: $-80 \mathrm{mV}, \mathrm{CTZ}, 2 \mathrm{~s}$ \\
& 3. Holding potential: $-80 \mathrm{mV}, 3 \mathrm{~s}$ \\
\hline $\mathrm{I}_{\text {AMPA }}+\mathrm{CTZ}$ & 1. Holding potential: $-80 \mathrm{mV}, \mathrm{CTZ}, 4 \mathrm{~s}$ \\
& 2. Test Pulse: $-80 \mathrm{mV}$ to $80 \mathrm{mV}$ in $40 \mathrm{mV}$ steps, \\
& 3. Holding potential: $-80 \mathrm{mV}, \mathrm{CTZ}, 3 \mathrm{~s}$ \\
\hline Current Clamp & 1. Constant current to clamp at: $-80 \mathrm{mV}, 100 \mathrm{~ms}$ \\
& 2. Test Pulse: -40 to $240 \mathrm{pA}$ in $20 \mathrm{pA}$ steps, 800 \\
& 3s \\
& 3. Constant current to clamp at: $-80 \mathrm{mV}, 1 \mathrm{~s}$ \\
\hline
\end{tabular}

Table 8. Pharmacological tools and reagents for electrophysiology

\begin{tabular}{lcll}
\hline \multicolumn{1}{c}{ Reagent } & Concentration & Manufacturer & Catalog number \\
\hline \hline ( \pm )-AMPA & $150 \mu \mathrm{M}$ & Sigma & A6816 \\
Cyclothiazide & $100 \mu \mathrm{M}$ & Sigma & C9847 \\
Phrixotoxin-2 & $1 \mu \mathrm{M}$ & Alomone & $\mathrm{P}-700$ \\
TTX & $500 \mathrm{nM}$ & Sigma & T8024 \\
Tetraethylammonium chloride & $10 \mathrm{mM}$ & Sigma & 86614 \\
Lucifer Yellow $\mathrm{CH}, \mathrm{K}^{+}$salt & $1 \%$ & Invitrogen & L1177 \\
\hline
\end{tabular}

\subsubsection{Analysis of electrophysiology data}

Current Voltage relationship of $\mathrm{I}_{\mathrm{KDR}}$ : To produce the current to voltage relationship of $I_{K D R}$, the mean current from $85-95 \%$ of the pulse was plotted against the voltage used to elicit the current response.

The currents referred to as "rectifying" were those where an inward rectification occurred at positive potentials. Depending on the absence or presence of rectification, the data of the I-V relationship were fitted with the PulseFit (HEKA Elektronik) built-in Equation 1 or Equation 2, respectively. Here, the term $V$ refers to the command voltage, $V_{\text {half }}$ is the half maximal activation potential and Slope is the slope of the pseudo lineal phase of the curve. 
$V_{\text {rev }}$ is the reversal potential or equilibrium potential (defined in Equation 3), where $R$ is the universal gas constant $\left(8.314 \mathrm{~J} \cdot \mathrm{K}^{-1} \cdot \mathrm{mol}^{-1}\right), T$ is the temperature in Kelvin, $z$ is the valence of the ionic species, $F$ is the Faraday constant $\left(96485 \mathrm{C} \cdot \mathrm{mol}^{-1}\right),[X]_{\text {out }}$ and $[X]_{\text {in }}$ are the concentrations of ion $X$ in the extracellular and intracellular solutions respectively.

\section{Equation 1}

$$
f(V)=G\left(V-V_{\text {rev }}\right)\left(\frac{1}{1+e^{\frac{V_{\text {half }}-V}{\text { Slope }}}}\right)^{4}
$$

\section{Equation 2}

$$
f(V)=G\left(V-V_{\text {rev }}\right)\left(\frac{1}{1+e^{\frac{V_{\text {half }}-V}{\text { Slope }}}}\right)^{4}-\left(\frac{1}{1+e^{\frac{V_{\text {half }}-V}{\text { Slope } B}}}\right)
$$

\section{Equation 3}

$$
V_{\text {rev }}=\frac{R T}{z F} \ln \left(\frac{[X]_{\text {out }}}{[X]_{\text {in }}}\right)
$$

Current Voltage relationship of $\mathrm{I}_{\mathrm{KA}}$ : To produce the current to voltage relationship of $I_{K A}$, the peak value of the subtracted current (see Table 7.. $I_{K A}$, page 77 ) was plotted against the voltage used to elicit the current response. Then, the data were fitted using Equation 1.

Current Voltage relationship of $\mathrm{I}_{\mathrm{Na}}{ }^{+}$: The inward current trace was fitted with the built-in Hodgkin-Huxley formalism from PulseFit (HEKA Elektronik), using the following equations

\section{Equation 4}
a) $t=x-$ Delay
b) $r_{12}=\frac{\alpha_{1}}{\alpha_{1}+\alpha_{2}}$
c) $m(t)=1-e^{\frac{-t}{\tau_{m}}}$
d) $h(t)=h_{\infty}+\left(1-h_{\infty}\right)\left(r_{12} e^{\frac{-t}{\tau_{h}}}+\left(1-r_{12}\right) e^{\frac{-t}{\tau_{h 2}}}\right)$
e) $I(t)=I(0) m(x)^{m} h(x)^{h}$ 
The peak value was then plotted against the potential applied to elicit the current. The resulting I-V relationship was fitted using Equation 1.

$h_{\infty}$ : To obtain the half maximal inactivation potential, the peak current value at $100 \mathrm{mV}$ was plotted against the prepulse potential. The resulting data were fitted with Equation 5 built-in the PulseFit analysis software (HEKA Elektronik), where $V_{m}$ is the prepulse potential, $I_{\min }$ is the minimum current, $I_{\max }$ is the maximum current, $V_{\text {half }}$ is the potential of half maximal inactivation and $k$ determines the slope of the pseudolineal portion of the curve.

\section{Equation 5}

$$
f\left(V_{m}\right)=I_{\text {min }}+\frac{I_{\text {max }}-I_{\text {min }}}{1+e^{\frac{V_{m}+V_{\text {half }}}{k}}}
$$

$\mathrm{R}_{\mathrm{m}}$ : To obtain the membrane resistance, a constant current was injected to keep the cell at its resting potential of about $-80 \mathrm{mV}$ and relative current stimuli were applied. The mean voltage from $100-600 \mathrm{~ms}$ of the current pulse was plotted for each current between -40 and $0 \mathrm{pA}$. The data were then fitted with a linear equation of the form:

\section{Equation 6}

$$
V=m I+b
$$

Where $V$ is the measured voltage response, $I$ is the injected current, $b$ is the value of $V$ when no current is applied and $m$ is the slope that, by Ohm's law, corresponds to the resistance. Before the determination of $R_{m}$ electrical access was confirmed by applying a $250 \mathrm{~ms} 60 \mathrm{mV}$ pulse.

Regenerative voltage-transient: The maximum voltage was measured directly from the voltage response. The relative overshoot and the relative afterhyperpolarization (AHP) were considered to be events deviating from a stable or steady state. Since we were not able to observe more than one spike, we defined the steady state as the mean voltage response from 100 - $600 \mathrm{~ms}$ of the current stimulus. The duration of the regenerative voltage transient was calculated between the points intersecting the baseline, therefore the AHP was not considered. The maximum rate of rise and the maximum rate of fall were the maximum and the minimum values of the differential of the voltage response, respectively. 
The data were analyzed using IgorPro (Wavemetrics) with custom written macros, PulseFit (HEKA Elektronic) and Prism (GraphPad Software).

\subsection{Dye Coupling}

Primary glioma spheroids and primary hippocampal astrocytes were dissociated as described above (74 6.4.1 Cell preparation and procedure, page 74) and plated on PLL coated $10 \mathrm{~mm}$ coverslips (Menzel). After 5 days, the cells were handled similarly as for electrophysiological recordings (Section 6.4.1 Cell preparation and procedure, page 74), however the intracellular solution contained 1\% Lucifer Yellow (Invitrogen). When the whole-cell mode was achieved, a reasonable time (1-4 minutes) was given for the cells to fill with the dye and obtain a good contrast. Two images were acquired in a 10 minute interval using a Moticam 1000 digital camera (Motic) and the Motic Images Plus acquisition software (Motic). The camera was mounted on an Axiovert 100 inverted microscope (Zeiss). A $100 \mathrm{~W}$ mercury arc fluorescent lamp (Osram) was used as a light source with excitation and emission filters of $450-490 \mathrm{~nm}$ and $515-565 \mathrm{~nm}$ (Filter set \#10, Zeiss) respectively. After, the pipette was removed and the coverslip was kept for observation 30 minutes later. Concomitant with the images of the fluorescent dye, phase contrast images were also acquired.

\subsection{Western Blot}

\subsubsection{Protein extraction}

A cell pellet was obtained and washed twice with PBS. Following centrifugation at $3000 \mathrm{xg}$, the cells were lysed by resuspending in non-denaturating lysis buffer (Table 9) with protease inhibitor (Roche) and incubating for $30 \mathrm{~min}$ at room temperature. The lysate was centrifuged for $15 \mathrm{~min}$ at $14000 \mathrm{xg}$. The supernatant containing the protein was then removed and stored for further analysis. 


\subsubsection{Determination of protein content}

To determine the total protein concentration, the BCA Protein Assay Kit (Thermo Scientific) was used according to the manufacturer's instructions. The assay is based on the reduction of $\mathrm{Cu}^{2+}$ to $\mathrm{Cu}^{+}$in alkaline medium. The reaction product exhibits a strong absorbance at $562 \mathrm{~nm}$ and can therefore be detected by a colorimetric readout. Briefly, a working reagent was prepared by mixing 50 parts of BCA reagent $A$ with 1 part of $B C A$ reagent $B$, then $30 \mu \mathrm{l}$ of the sample were mixed with $200 \mu \mathrm{l}$ of the working reagent and incubated at $37^{\circ} \mathrm{C}$ for 30 minutes. The absorbance at $562 \mathrm{~nm}$ was measured with a 1420 VICTOR multi label counter (Wallac) and the concentration was calculated by calibration with a standard curve of albumin solutions ranging from 10 to $200 \mathrm{~g} / \mathrm{ml}$ (Thermo scientific).

\subsubsection{Protein gel electrophoresis}

To denature the protein, $1 \mu \mathrm{l}$ sample reducing agent (Invitrogen) and $2.5 \mu$ loading buffer (Invitrogen) were added to the protein $(10-100 \mu \mathrm{g})$ to a total volume of $10 \mu \mathrm{l}$ and were incubated at $70^{\circ} \mathrm{C}$ for $10 \mathrm{~min}$. The denatured protein and a protein ladder (NE BioLabs) as a control of the molecular weight were loaded into $3-8 \%$ or $4-12 \%$ gradient polyacrylamide gels with Tris-acetate (Invitrogen) or Bis-Tris (Invitrogen) system respectively. The gel was placed in a chamber loaded with running buffer (Table 9) and a constant voltage of $150 \mathrm{~V}$ or $200 \mathrm{~V}$ was applied for 1-2 hours to achieve separation of the proteins.

\subsubsection{Protein transfer and blotting}

Afterwards, the proteins were transferred to a nitrocellulose membrane (GE Healthcare) by placing the gel in direct contact with the membrane in the presence of transfer buffer (Table 9). The potential used for protein transfer started at $10 \mathrm{~V}$ with stepwise increments of $10 \mathrm{~V}$ every ten minutes up to a potential of $50 \mathrm{~V}$, where it 
remained for 30 minutes. The membrane was rinsed with deionized water and dried overnight at room temperature. Following rehydration with deionized water, the membrane was treated with Western Blot Signal Enhancer (Thermo Scientific) according to the manufacturer's instructions.

To avoid unspecific biding of the primary antibody, the membrane was incubated with 10\% Casein (1:1000 dilution) (Roche) in TBS-T (Table 9). Primary antibodies at their optimal dilutions (Table 11.) were applied for one to two hours at room temperature or at $4^{\circ} \mathrm{C}$ overnight. After the incubation period, the membrane was washed 5 times with deionized water and for 5 minutes with TBS-T. The membrane was then incubated with the appropriate secondary antibody (Table 11.) coupled to horseradish peroxidase (HRP) for 45 minutes at room temperature, followed by 7 wash steps with deionized water and 5 minutes with TBS-T.

Blots were developed using a chemiluminescent HRP substrate (Millipore), which takes advantage of the horseradish peroxidase enzyme to catalyze the reaction of luminol and $\mathrm{H}_{2} \mathrm{O}_{2}$, generating light. The emitted light was detected with a ChemiDoc XRS system (Bio-Rad) and the image acquisition was done with the Quantity One 1-D Analysis Software v4.6.9 (Bio-Rad). For post-acquisition processing the image analysis software FIJI was used (Schindelin, 2008).

Table 9. Buffers for Western Blot

\begin{tabular}{llc}
\hline \multicolumn{1}{c}{ Buffer } & \multicolumn{1}{c}{ Composition } & $\begin{array}{c}\text { Concentration/ Volume/ } \\
\text { Percentage }\end{array}$ \\
\hline \hline $\begin{array}{l}\text { Non-denaturing lysis } \\
\text { buffer }\end{array}$ & Triton X-100 & $1 \%$ \\
& Tris-HCl & $50 \mathrm{mM}$ \\
& $\mathrm{NaCl}$ & $300 \mathrm{mM}$ \\
& EDTA & $5 \mathrm{mM}$ \\
\hline $\begin{array}{l}\text { Running Buffer (Bis- } \\
\text { Tris) }\end{array}$ & $\begin{array}{l}\text { 20X NuPAGE MES SDS } \\
\text { buffer } \\
\text { Deionized water }\end{array}$ & $50 \mathrm{ml}$ \\
\hline $\begin{array}{l}\text { Running Buffer (Tris- } \\
\text { Acetate) }\end{array}$ & $\begin{array}{l}20 X \mathrm{Tris}^{-A c e t a t e ~ S D S} \\
\text { buffer } \\
\text { Deionized water }\end{array}$ & $950 \mathrm{ml}$ \\
\hline Transfer Buffer & $\mathrm{NaHCO}_{3}$ & $50 \mathrm{ml}$ \\
& $\mathrm{Na}_{2} \mathrm{CO}_{3}$ & $950 \mathrm{ml}$ \\
\hline
\end{tabular}




\begin{tabular}{llc} 
& SDS & $0.01 \%$ \\
& Methanol & $20 \%$ \\
\hline TBS-T & Tris & $20 \mathrm{mM}$ \\
& $\mathrm{NaCl}$ & $0.15 \mathrm{M}$ \\
& Tween 20 & $0.05 \%$ \\
\hline
\end{tabular}

Table 10. Reagents for Western Blot

\begin{tabular}{lll}
\hline \multicolumn{1}{c}{ Reagent } & \multicolumn{1}{c}{ Manufacturer } & \multicolumn{1}{c}{$\begin{array}{c}\text { Catalog } \\
\text { Number }\end{array}$} \\
\hline \hline Protease inhibitor cocktail tablets & Roche & 1169748001 \\
BCA Protein Assay Kit & Thermo Scientific & 23225 \\
NuPAGE Reducing Agent (10X) & Invitrogen & NP0009 \\
NuPAGE LDS Sample Buffer (4X) & Invitrogen & NP0007 \\
Prestained Protein Ladder, Broad Range & $\begin{array}{l}\text { New England } \\
\text { BioLabs }\end{array}$ & P7710S \\
NuPAGE Novex 4-12\% Bis-Tris Gel & Invitrogen & NP0322 \\
NuPAGE Novex 3-8\% Tris-Acetate Gel & Invitrogen & EA03785 \\
20X NuPAGE MES SDS Running Buffer & Invitrogen & NP0002 \\
20X NuPAGE Tris-Acetate SDS Running & Invitrogen & LA0041 \\
$\begin{array}{l}\text { Buffer } \\
\text { Pierce Western Blot Signal Enhancer }\end{array}$ & Thermo Scientific & 21050 \\
$\begin{array}{l}\text { Western Blocking Reagent } \\
\text { Immobilon Western Chemiluminescent HRP }\end{array}$ & Millipore & 11921673001 \\
Substrate & & WBKL S00 50 \\
\hline
\end{tabular}


Table 11. Antibodies for Western Blot.

\begin{tabular}{|c|c|c|c|c|}
\hline Antibody & $\begin{array}{l}\text { Species/ } \\
\text { Clonality }\end{array}$ & Dilution & Manufacturer & $\begin{array}{l}\text { Catalog } \\
\text { Number }\end{array}$ \\
\hline $\begin{array}{l}\text { Anti-NG2 Chondroitin } \\
\text { Sulfate Proteoglycan }\end{array}$ & $\begin{array}{l}\text { Rabbit } \\
\text { Polyclonal }\end{array}$ & $1: 500$ & Millipore & AB5320 \\
\hline Anti-GFAP & $\begin{array}{l}\text { Rabbit } \\
\text { Polyclonal }\end{array}$ & $1: 1000$ & Promega & G5601 \\
\hline Anti-Calnexin & $\begin{array}{l}\text { Rabbit } \\
\text { Polyclonal }\end{array}$ & $1: 1000$ & $\begin{array}{l}\text { Enzo Life } \\
\text { Sciences }\end{array}$ & $\begin{array}{l}\text { ADI-SPA- } \\
860\end{array}$ \\
\hline Anti-Nestin, clone $10 \mathrm{C} 2$ & $\begin{array}{l}\text { Mouse } \\
\text { Monoclonal }\end{array}$ & $1: 1000$ & Millipore & MAB5326 \\
\hline $\begin{array}{l}\text { ECL Anti-Rabbit lgG, } \\
\text { Horseradish Peroxidase- } \\
\text { Linked }\end{array}$ & $\begin{array}{l}\text { Donkey } \\
\text { Polyclonal }\end{array}$ & $1: 10000$ & GE Healthcare & NA934V \\
\hline
\end{tabular}




\section{References}

Akopian, G., Kressin, K., Derouiche, A., and Steinhäuser, C. (1996). Identified glial cells in the early postnatal mouse hippocampus display different types of $\mathrm{ca}^{2+}$ currents. Glia 17, 181-94.

Al-Mayhani, M.T.F., Grenfell, R., Narita, M., Piccirillo, S., Kenney-Herbert, E., Fawcett, J.W., Collins, V.P., Ichimura, K., and Watts, C. (2011). Ng2 expression in glioblastoma identifies an actively proliferating population with an aggressive molecular signature. Neuro-Oncology 13, 830-45.

Alcantara Llaguno, S., Chen, J., Kwon, C.-H., Jackson, E.L., Li, Y., Burns, D.K., Alvarez-Buylla, A., and Parada, L.F. (2009). Malignant astrocytomas originate from neural stem/progenitor cells in a somatic tumor suppressor mouse model. Cancer Cell $15,45-56$.

Almqvist, P.M., Mah, R., Lendahl, U., Jacobsson, B., and Hendson, G. (2002). Immunohistochemical detection of nestin in pediatric brain tumors. Journal of Histochemistry \& Cytochemistry 50, 147-58.

Bachoo, R.M., Maher, E.A., Ligon, K.L., Sharpless, N.E., Chan, S.S., You, M.J., Tang, Y., DeFrances, J., Stover, E., Weissleder, R., et al. (2002). Epidermal growth factor receptor and ink4a/arf: Convergent mechanisms governing terminal differentiation and transformation along the neural stem cell to astrocyte axis. Cancer Cell 1, 269-77.

Bailey, P., and Cushing, H. (1926). A classification of the tumors of the glioma group on a histogenetic basis with a correlated study of prognosis (Philadelphia, PA: Lippincott).

Bao, J., Reim, K., and Sakaba, T. (2010). Target-dependent feedforward inhibition mediated by short-term synaptic plasticity in the cerebellum. The Journal of Neuroscience 30, 8171-9.

Behin, A., Hoang-Xuan, K., Carpentier, A.F., and Delattre, J.-Y. (2003). Primary brain tumours in adults. The Lancet $361,323-31$.

Beier, D., Hau, P., Proescholdt, M., Lohmeier, A., Wischhusen, J., Oefner, P.J., Aigner, L., Brawanski, A., Bogdahn, U., and Beier, C.P. (2007). Cd133+ and cd133- 
glioblastoma-derived cancer stem cells show differential growth characteristics and molecular profiles. Cancer Research 67, 4010-5.

Belachew, S., Chittajallu, R., Aguirre, A.A., Yuan, X., Kirby, M., Anderson, S., and Gallo, V. (2003). Postnatal ng2 proteoglycan-expressing progenitor cells are intrinsically multipotent and generate functional neurons. The Journal of Cell Biology $161,169-86$.

Bergles, D.E., Roberts, J.D.B., Somogyi, P., and Jahr, C.E. (2000). Glutamatergic synapses on oligodendrocyte precursor cells in the hippocampus. Nature 405, 187-91.

Bordey, A., and Sontheimer, H. (1998). Electrophysiological properties of human astrocytic tumor cells in situ: Enigma of spiking glial cells. Journal of Neurophysiology 79, 2782-93.

Brackenbury, W.J., Djamgoz, M.B.A., and Isom, L.L. (2008). An emerging role for voltage-gated na+ channels in cellular migration: Regulation of central nervous system development and potentiation of invasive cancers. The Neuroscientist 14, 571-83.

Brychtova, S., Fiuraskova, M., Hlobilková, A., Brychta, T., and Hirnak, J. (2007). Nestin expression in cutaneous melanomas and melanocytic nevi. Journal of Cutaneous Pathology 34, 370-5.

Burg, M.A., Grako, K.A., and Stallcup, W.B. (1998). Expression of the ng2 proteoglycan enhances the growth and metastatic properties of melanoma cells. Journal of Cellular Physiology 177, 299-312.

Burg, M.A., Nishiyama, A., and Stallcup, W.B. (1997). A central segment of the ng2 proteoglycan is critical for the ability of glioma cells to bind and migrate toward type vi collagen. Experimental Cell Research 235, 254-64.

Chekenya, M., Rooprai, H.K., Davies, D., Levine, J.M., Butt, A.M., and Pilkington, G.J. (1999). The ng2 chondroitin sulfate proteoglycan: Role in malignant progression of human brain tumours. International Journal of Developmental Neuroscience 17, 42135.

Cheng, A., Tang, H., Cai, J., Zhu, M., Zhang, X., Rao, M., and Mattson, M.P. (2004). Gap junctional communication is required to maintain mouse cortical neural progenitor cells in a proliferative state. Developmental Biology 272, 203-16. 
Chittajallu, R., Aguirre, A., and Gallo, V. (2004). Ng2-positive cells in the mouse white and grey matter display distinct physiological properties. The Journal of Physiology $561,109-22$.

Chou, Y.-H., Khuon, S., Herrmann, H., and Goldman, R.D. (2003). Nestin promotes the phosphorylation-dependent disassembly of vimentin intermediate filaments during mitosis. Molecular Biology of the Cell 14, 1468-78.

Clarke, M.F., Dick, J.E., Dirks, P.B., Eaves, C.J., Jamieson, C.H.M., Jones, D.L., Visvader, J., Weissman, I.L., and Wahl, G.M. (2006). Cancer stem cells--perspectives on current status and future directions: Aacr workshop on cancer stem cells. Cancer Research 66, 9339-44.

Clarke, S., Shetty, A., Bradley, J., and Turner, D. (1994). Reactive astrocytes express the embryonic intermediate neurofilament nestin. Neuroreport 5, 1885-8.

Collins, A.T., Berry, P.A., Hyde, C., Stower, M.J., and Maitland, N.J. (2005). Prospective identification of tumorigenic prostate cancer stem cells. Cancer Research 65, 10946-51.

Colman, H., Zhang, L., Sulman, E.P., McDonald, J.M., Shooshtari, N.L., Rivera, A., Popoff, S., Nutt, C.L., Louis, D.N., Cairncross, J.G., et al. (2010). A multigene predictor of outcome in glioblastoma. Neuro-Oncology 12, 49-57.

Cottin, S., Gould, P.V., Cantin, L., and Caruso, M. (2011). Gap junctions in human glioblastomas: Implications for suicide gene therapy. Cancer Gene Ther 18, 674-81.

Dahlstrand, J., Collins, V.P., and Lendahl, U. (1992). Expression of the class vi intermediate filament nestin in human central nervous system tumors. Cancer Research 52, 5334-41.

Darcy, D.P., and Isaacson, J.S. (2010). Calcium-permeable ampa receptors mediate glutamatergic signaling in neural precursor cells of the postnatal olfactory bulb. Journal of Neurophysiology 103, 1431-7.

Daumas-Duport, C., Scheithauer, B., O'Fallon, J., and Kelly, P. (1988). Grading of astrocytomas: A simple and reproducible method. Cancer 62, 2152-65. 
Dawson, M.R.L., Levine, J.M., and Reynolds, R. (2000). Ng2-expressing cells in the central nervous system: Are they oligodendroglial progenitors? Journal of Neuroscience Research 61, 471-9.

Dawson, M.R.L., Polito, A., Levine, J.M., and Reynolds, R. (2003). Ng2-expressing glial progenitor cells: An abundant and widespread population of cycling cells in the adult rat cns. Molecular and Cellular Neuroscience 24, 476-88.

de Groot, J., Piao, Y., Lu, L., Fuller, G., and Yung, W. (2008). Knockdown of glur1 expression by rna interference inhibits glioma proliferation. Journal of Neuro-Oncology $88,121-33$

de Groot, J., and Sontheimer, H. (2011). Glutamate and the biology of gliomas. Glia 59, 1181-9.

DeAngelis, L.M. (2001). Brain tumors. The New England Journal of Medicine 344, 11423.

Diochot, S., Drici, M.-D., Moinier, D., Fink, M., and Lazdunski, M. (1999). Effects of phrixotoxins on the kv4 family of potassium channels and implications for the role of ito1 in cardiac electrogenesis. British Journal of Pharmacology 126, 251-63.

Ducharme, G., Newell, E.W., Pinto, C., and Schlichter, L.C. (2007). Small-conductance $\mathrm{cl}-$ channels contribute to volume regulation and phagocytosis in microglia. European Journal of Neuroscience 26, 2119-30.

Ehrmann, J., Kolář, Z., and Mokrý, J. (2005). Nestin as a diagnostic and prognostic marker: Immunohistochemical analysis of its expression in different tumours. Journal of Clinical Pathology 58, 222-3.

Eisenmann, K.M., McCarthy, J.B., Simpson, M.A., Keely, P.J., Guan, J.-L., Tachibana, K., Lim, L., Manser, E., Furcht, L.T., and lida, J. (1999). Melanoma chondroitin sulphate proteoglycan regulates cell spreading through cdc42, ack-1 and p130cas. Nat Cell Biol 1, 507-13.

Ekstrand, A.J., James, C.D., Cavenee, W.K., Seliger, B., Pettersson, R.F., and Collins, V.P. (1991). Genes for epidermal growth factor receptor, transforming growth factor $\alpha$, and epidermal growth factor and their expression in human gliomas in vivo. Cancer Research 51, 2164-72. 
Eramo, A., Lotti, F., Sette, G., Pilozzi, E., Biffoni, M., Di Virgilio, A., Conticello, C., Ruco, L., Peschle, C., and De Maria, R. (2007). Identification and expansion of the tumorigenic lung cancer stem cell population. Cell Death Differ 15, 504-14.

Feldkamp, M.M., Lau, N., and Guha, A. (1997). Signal transduction pathways and their relevance in human astrocytomas. Journal of Neuro-Oncology 35, 223-48.

Ferlay, J., Shin, H.R., Bray, F., Forman, D., Mathers, C., and Parkin, D.M. (2010). Cancer incidence and mortality worldwide: larc cancerbase no.10 [internet] (Lyon, France: International Agency for Research on Cancer).

Fitzner, D., Schneider, A., Kippert, A., Mobius, W., Willig, K.I., Hell, S.W., Bunt, G., Gaus, K., and Simons, M. (2006). Myelin basic protein-dependent plasma membrane reorganization in the formation of myelin. EMBO J 25, 5037-48.

Fox, B.D., Cheung, V.J., Patel, A.J., Suki, D., and Rao, G. (2011). Epidemiology of metastatic brain tumors. Neurosurgery clinics of North America 22, 1-6.

Frisén, J., Johansson, C.B., Török, C., Risling, M., and Lendahl, U. (1995). Rapid, widespread, and longlasting induction of nestin contributes to the generation of glial scar tissue after cns injury. The Journal of Cell Biology 131, 453-64.

Fucile, S., Miledi, R., and Eusebi, F. (2006). Effects of cyclothiazide on glur1/ampa receptors. Proceedings of the National Academy of Sciences 103, 2943-7.

Fukushi, J.-i., Inatani, M., Yamaguchi, Y., and Stallcup, W.B. (2003). Expression of ng2 proteoglycan during endochondral and intramembranous ossification. Developmental Dynamics 228, 143-8.

Furnari, F.B., Fenton, T., Bachoo, R.M., Mukasa, A., Stommel, J.M., Stegh, A., Hahn, W.C., Ligon, K.L., Louis, D.N., Brennan, C., et al. (2007). Malignant astrocytic glioma: Genetics, biology, and paths to treatment. Genes \& Development 21, 2683-710.

Galli, R., Binda, E., Orfanelli, U., Cipelletti, B., Gritti, A., De Vitis, S., Fiocco, R., Foroni, C., Dimeco, F., and Vescovi, A. (2004). Isolation and characterization of tumorigenic, stem-like neural precursors from human glioblastoma. Cancer Research 64, 7011-21.

Gallo, V., Zhou, J., McBain, C., Wright, P., Knutson, P., and Armstrong, R. (1996). Oligodendrocyte progenitor cell proliferation and lineage progression are regulated by 
glutamate receptor-mediated $k+$ channel block. The Journal of Neuroscience 16, $2659-$ 70 .

Ge, W.-P., Yang, X.-J., Zhang, Z., Wang, H.-K., Shen, W., Deng, Q.-D., and Duan, S. (2006). Long-term potentiation of neuron-glia synapses mediated by ca2+-permeable ampa receptors. Science 312, 1533-7.

Ge, W.-P., Zhou, W., Luo, Q., Jan, L.Y., and Jan, Y.N. (2009). Dividing glial cells maintain differentiated properties including complex morphology and functional synapses. Proceedings of the National Academy of Sciences 106, 328-33.

Ge, W., Martinowich, K., Wu, X., He, F., Miyamoto, A., Fan, G., Weinmaster, G., and Sun, Y.E. (2002). Notch signaling promotes astrogliogenesis via direct csl-mediated glial gene activation. Journal of Neuroscience Research 69, 848-60.

Gerstner, E.R., and Batchelor, T.T. (2010). Primary central nervous system lymphoma. Arch Neurol 67, 291-7.

Ghali, L., Wong, S.-T., Tidman, N., Quinn, A., Philpott, M.P., and Leigh, I.M. (2004). Epidermal and hair follicle progenitor cells express melanoma-associated chondroitin sulfate proteoglycan core protein. J Investig Dermatol 122, 433-42.

Globus, J.H., and Kuhlenbeck, H. (1942). Tumors of the striatothalamic and related regios. Their probable source of origin and more common forms. Arch Pathol 34, 674734.

Globus, J.H., and Kuhlenbeck, H. (1944). The subependymal plate (matrix) and its relationship to brain tumors of the ependymal type. J Neuropath Exp Neurol 3, 1-35.

Gritti, A., Parati, E., Cova, L., Frolichsthal, P., Galli, R., Wanke, E., Faravelli, L., Morassutti, D., Roisen, F., Nickel, D., et al. (1996). Multipotential stem cells from the adult mouse brain proliferate and self-renew in response to basic fibroblast growth factor. The Journal of Neuroscience 16, 1091-100.

Gutman, G.A., Chandy, K.G., Grissmer, S., Lazdunski, M., McKinnon, D., Pardo, L.A., Robertson, G.A., Rudy, B., Sanguinetti, M.C., Stuhmer, W., et al. (2005). International union of pharmacology. Liii. Nomenclature and molecular relationships of voltage-gated potassium channels. Pharmacological Reviews 57, 473-508. 
Hamill, O.P., Marty, A., Neher, E., Sakmann, B., and Sigworth, F.J. (1981). Improved patch-clamp techniques for high-resolution current recording from cells and cell-free membrane patches Pflügers Archiv European Journal of Physiology 391, 85-100.

Hemmati, H.D., Nakano, I., Lazareff, J.A., Masterman-Smith, M., Geschwind, D.H., Bronner-Fraser, M., and Kornblum, H.I. (2003). Cancerous stem cells can arise from pediatric brain tumors. Proceedings of the National Academy of Sciences 100, 1517883.

Hermann, P.C., Huber, S.L., Herrler, T., Aicher, A., Ellwart, J.W., Guba, M., Bruns, C.J., and Heeschen, C. (2007). Distinct populations of cancer stem cells determine tumor growth and metastatic activity in human pancreatic cancer. Cell - Stem Cell 1, 313-23.

Hill, R.P. (2006). Identifying cancer stem cells in solid tumors: Case not proven. Cancer Research 66, 1891-6.

Holland, E.C., Celestino, J., Dai, C., Schaefer, L., Sawaya, R.E., and Fuller, G.N. (2000). Combined activation of ras and akt in neural progenitors induces glioblstoma formation in mice. Nat Genet 25, 55-7.

Hopewell, J.W. (1975). The subependymal plate and the genesis of gliomas. The Journal of Pathology 117, 101-3.

Horner, P.J., Thallmair, M., and Gage, F.H. (2002). Defining the ng2-expressing cell of the adult cns. Journal of Neurocytology 31, $469 \mathrm{ppl}=-80$.

Huse, J.T., and Holland, E.C. (2009). Genetically engineered mouse models of brain cancer and the promise of preclinical testing. Brain pathology (Zurich, Switzerland) 19, $132-43$.

Huse, J.T., and Holland, E.C. (2010). Targeting brain cancer: Advances in the molecular pathology of malignant glioma and medulloblastoma. Nat Rev Cancer 10, 319-31.

Ignatova, T.N., Kukekov, V.G., Laywell, E.D., Suslov, O.N., Vrionis, F.D., and Steindler, D.A. (2002). Human cortical glial tumors contain neural stem-like cells expressing astroglial and neuronal markers in vitro. Glia 39, 193-206. 
Ishiuchi, S., Tsuzuki, K., Yoshida, Y., Yamada, N., Hagimura, N., Okado, H., Miwa, A., Kurihara, H., Nakazato, Y., Tamura, M., et al. (2002). Blockage of ca2+-permeable ampa receptors suppresses migration and induces apoptosis in human glioblastoma cells. Nat Med 8, 971-8.

Ishiwata, T., Matsuda, Y., and Naito, Z. (2011). Nestin in gastrointestinal and other cancers: Effects on cells and tumor angiogenesis. World Journal of Gastroenterology 17, 409-18.

Jäderstad, J., Jäderstad, L.M., Li, J., Chintawar, S., Salto, C., Pandolfo, M., Ourednik, V., Teng, Y.D., Sidman, R.L., Arenas, E., et al. (2010). Communication via gap junctions underlies early functional and beneficial interactions between grafted neural stem cells and the host. Proceedings of the National Academy of Sciences 107, 51849.

Jimeno, A., Feldmann, G., Suárez-Gauthier, A., Rasheed, Z., Solomon, A., Zou, G.-M., Rubio-Viqueira, B., García-García, E., López-Ríos, F., Matsui, W., et al. (2009). A direct pancreatic cancer xenograft model as a platform for cancer stem cell therapeutic development. Molecular Cancer Therapeutics 8, 310-4.

Joshi, A., Parsons, D., Velculescu, V., and Riggins, G. (2011). Sodium ion channel mutations in glioblastoma patients correlate with shorter survival. Molecular Cancer 10, 17.

Kapoor, N., Bartoszewski, R., Qadri, Y.J., Bebok, Z., Bubien, J.K., Fuller, C.M., and Benos, D.J. (2009). Knockdown of asic1 and epithelial sodium channel subunits inhibits glioblastoma whole cell current and cell migration. Journal of Biological Chemistry 284, 24526-41.

Káradóttir, R., Hamilton, N.B., Bakiri, Y., and Attwell, D. (2008). Spiking and nonspiking classes of oligodendrocyte precursor glia in cns white matter. Nat Neurosci 11, 450-6.

Karram, K., Chatterjee, N., and Trotter, J. (2005). Ng2-expressing cells in the nervous system: Role of the proteoglycan in migration and glial-neuron interaction. Journal of Anatomy 207, 735-44.

Kern, S.E., and Shibata, D. (2007). The fuzzy math of solid tumor stem cells: A perspective. Cancer Research 67, 8985-8. 
Kernohan, J.W., Mabon, R.F., Svien, H.J., and Adson, A.W. (1949). A simplified classification of the gliomas. Mayo Clin Proc. 24, 71-5.

Kim, T.S., Halliday, A.L., Hedley-Whyte, E.T., and Convery, K. (1991). Correlates of survival and the daumas-duport grading system for astrocytomas. Journal of Neurosurgery $74,27-37$.

Koch-Institut, R., and Deutschland, G.d.e.K.i. (2010). Krebs in deutschland 2005 2006. Häufigkeiten und trends. .

Komitova, M., Serwanski, D.R., Richard Lu, Q., and Nishiyama, A. (2011). Ng2 cells are not a major source of reactive astrocytes after neocortical stab wound injury. Glia 59, 800-9.

Komitova, M., Zhu, X., Serwanski, D.R., and Nishiyama, A. (2009). Ng2 cells are distinct from neurogenic cells in the postnatal mouse subventricular zone. The Journal of Comparative Neurology 512, 702-16.

Kraus, J.A., Lamszus, K., Glesmann, N., Beck, M., Wolter, M., Sabel, M., Krex, D., Klockgether, T., Reifenberger, G., and Schlegel, U. (2001). Molecular genetic alterations in glioblastomas with oligodendroglial component. Acta Neuropathologica $101,311-20$.

Kukley, M., Nishiyama, A., and Dietrich, D. (2010). The fate of synaptic input to ng2 glial cells: Neurons specifically downregulate transmitter release onto differentiating oligodendroglial cells. The Journal of Neuroscience 30, 8320-31.

Lai, B., Mao, X.O., Xie, L., Chang, S.-Y., Xiong, Z.-G., Jin, K., and Greenberg, D.A. (2010). Electrophysiological properties of subventricular zone cells in adult mouse brain. Brain Research 1340, 96-105.

Lantos, P.L., and Cox, D.J. (1976). The origin of experimental brain tumors: A sequential study. Experientia 32, 1467-8.

Legg, J., Jensen, U.B., Broad, S., Leigh, I., and Watt, F.M. (2003). Role of melanoma chondroitin sulphate proteoglycan in patterning stem cells in human interfollicular epidermis. Development 130, 6049-63. 
Lendahl, U., Zimmerman, L.B., and McKay, R.D.G. (1990). Cns stem cells express a new class of intermediate filament protein. Cell 60, 585-95.

Li, H., Cherukuri, P., Li, N., Cowling, V., Spinella, M., Cole, M., Godwin, A.K., Wells, W., and DiRenzo, J. (2007). Nestin is expressed in the basal/myoepithelial layer of the mammary gland and is a selective marker of basal epithelial breast tumors. Cancer Research 67, 501-10.

Lin, R.C.S., Matesic, D.F., Marvin, M., McKay, R.D.G., and Brüstle, O. (1995). Reexpression of the intermediate filament nestin in reactive astrocytes. Neurobiology of Disease 2, 79-85.

Lin, S.-C., and Bergles, D.E. (2002). Physiological characteristics of ng2-expressing glial cells. Journal of Neurocytology $31,537-49$.

Lin, S.-c., and Bergles, D.E. (2004). Synaptic signaling between gabaergic interneurons and oligodendrocyte precursor cells in the hippocampus. Nat Neurosci 7, 24-32.

Lindberg, N., Kastemar, M., Olofsson, T., Smits, A., and Uhrbom, L. (2009). Oligodendrocyte progenitor cells can act as cell of origin for experimental glioma. Oncogene 28, 2266-75.

Liu, C., Sage, J.C., Miller, M.R., Verhaak, Roel G.W., Hippenmeyer, S., Vogel, H., Foreman, O., Bronson, R.T., Nishiyama, A., Luo, L., et al. (2011). Mosaic analysis with double markers reveals tumor cell of origin in glioma. Cell 146, 209-21.

Liu, X., Chang, Y., Reinhart, P.H., and Sontheimer, H. (2002). Cloning and characterization of glioma bk, a novel bk channel isoform highly expressed in human glioma cells. The Journal of Neuroscience 22, 1840-9.

Llinas, R., and Sugimori, M. (1980). Electrophysiological properties of in vitro purkinje cell somata in mammalian cerebellar slices. The Journal of Physiology 305, 171-95.

Louis, D., Ohgaki, H., Wiestler, O., Cavenee, W., Burger, P., Jouvet, A., Scheithauer, B., and Kleihues, P. (2007a). The 2007 who classification of tumours of the central nervous system. Acta Neuropathologica 114, 97-109. 
Louis, D.N., Ohgaki, H., Wiestler, O.D., and Cavenee, W.K. (2007b). Who classification of tumours of the central nervous system (Lyon: IARC).

Louis, S.A., Rietze, R.L., Deleyrolle, L., Wagey, R.E., Thomas, T.E., Eaves, A.C., and Reynolds, B.A. (2008). Enumeration of neural stem and progenitor cells in the neural colony-forming cell assay. Stem Cells 26, 988-96.

Lu, W.J., Lan, F., He, Q., Lee, A., Tang, C.Z., Dong, L., Lan, B., Ma, X., Wu, J.C., and Shen, L. (2011). Inducible expression of stem cell associated intermediate filament nestin reveals an important role in glioblastoma carcinogenesis. International Journal of Cancer 128, 343-51.

Makagiansar, I.T., Williams, S., Dahlin-Huppe, K., Fukushi, J.-i., Mustelin, T., and Stallcup, W.B. (2004). Phosphorylation of ng2 proteoglycan by protein kinase c- $\alpha$ regulates polarized membrane distribution and cell motility. Journal of Biological Chemistry 279, 55262-70.

Mayer, M., Bhakoo, K., and Noble, M. (1994). Ciliary neurotrophic factor and leukemia inhibitory factor promote the generation, maturation and survival of oligodendrocytes in vitro. Development 120, 143-53.

McDougal, D.H., Hermann, G.E., and Rogers, R.C. (2011). Vagal afferent stimulation activates astrocytes in the nucleus of the solitary tract via ampa receptors: Evidence of an atypical neural-glial interaction in the brainstem. The Journal of Neuroscience 31 , 14037-45.

Mueller, J., Reyes-Haro, D., Pivneva, T., Nolte, C., Schaette, R., Luebke, J., and Kettenmann, H. (2009). The principal neurons of the medial nucleus of the trapezoid body and ng2+ glial cells receive coordinated excitatory synaptic input. The Journal of General Physiology 134, 115-27.

Muth-Köhne, E., Terhag, J., Pahl, S., Werner, M., Joshi, I., and Hollmann, M. (2010). Functional excitatory gabaa receptors precede ionotropic glutamate receptors in radial glia-like neural stem cells. Molecular and Cellular Neuroscience 43, 209-21.

Namba, T., Mochizuki, H., Suzuki, R., Onodera, M., Yamaguchi, M., Namiki, H., Shioda, S., and Seki, T. (2011). Time-lapse imaging reveals symmetric neurogenic cell 
division of gfap-expressing progenitors for expansion of postnatal dentate granule neurons. PLoS ONE 6, e25303.

Newell, E.W., and Schlichter, L.C. (2005). Integration of $\mathrm{k}+$ and $\mathrm{cl}-$ currents regulate steady-state and dynamic membrane potentials in cultured rat microglia. The Journal of Physiology 567, 869-90.

Nishiyama, A., Chang, A., and Trapp, B.D. (1999). Ng2+ glial cells: A novel glial cell population in the adult brain. Journal of neuropathology and experimental neurology 58, 1113-24.

Nishiyama, A., Lin, X.H., Giese, N., Heldin, C.H., and Stallcup, W.B. (1996). Colocalization of $\mathrm{ng} 2$ proteoglycan and pdgf $\alpha$-receptor on $02 \mathrm{a}$ progenitor cells in the developing rat brain. Journal of Neuroscience Research 43, 299-314.

Nishiyama, A., Watanabe, M., Yang, Z., and Bu, J. (2002). Identity, distribution, and development of polydendrocytes: Ng2-expressing glial cells. Journal of Neurocytology $31,437 \mathrm{ppl}=-55$.

Ogden, A.T., Waziri, A.E., Lochhead, R.A., Fusco, D., Lopez, K., Ellis, J.A., Kang, J., Assanah, M., McKhann, G.M., Sisti, M.B., et al. (2008). Identification of a2b5+cd133tumor-initiating cells in adult human gliomas. Neurosurgery 62, 505-14.

Oh, D., and Prayson, R.A. (1999). Evaluation of epithelial and keratin markers in glioblastoma multiforme. Archives of Pathology \& Laboratory Medicine 123, 917-20.

Oki, K., Kaneko, N., Kanki, H., Imai, T., Suzuki, N., Sawamoto, K., and Okano, H. (2010). Musashi1 as a marker of reactive astrocytes after transient focal brain ischemia. Neuroscience Research 66, 390-5.

Onkal, R., and Djamgoz, M.B.A. (2009). Molecular pharmacology of voltage-gated sodium channel expression in metastatic disease: Clinical potential of neonatal nav1.5 in breast cancer. European Journal of Pharmacology 625, 206-19.

Ozerdem, U., and Stallcup, W.B. (2004). Pathological angiogenesis is reduced by targeting pericytes via the ng2 proteoglycan. Angiogenesis 7, 269 - 76.

Packer, R.J., Gajjar, A., Vezina, G., Rorke-Adams, L., Burger, P.C., Robertson, P.L., Bayer, L., LaFond, D., Donahue, B.R., Marymont, M.H., et al. (2006). Phase iii study of 
craniospinal radiation therapy followed by adjuvant chemotherapy for newly diagnosed average-risk medulloblastoma. Journal of Clinical Oncology 24, 4202-8.

Pannasch, U., Färber, K., Nolte, C., Blonski, M., Yan Chiu, S., Messing, A., and Kettenmann, H. (2006). The potassium channels kv1.5 and kv1.3 modulate distinct functions of microglia. Molecular and Cellular Neuroscience 33, 401-11.

Pardo, L.A., Contreras-Jurado, C., Zientkowska, M., Alves, F., and Stühmer, W. (2005). Role of voltage-gated potassium channels in cancer. Journal of Membrane Biology 205, 115-24.

Pardo, L.A., del Camino, D., Sánchez, A., Alvez, F., Brüggemann, A., Beckh, S., and Stühmer, W. (1999). Oncogenic potential of eag k+ channels. The EMBO Journal 18, 5540-7.

Parkerson, K.A., and Sontheimer, H. (2003). Contribution of chloride channels to volume regulation of cortical astrocytes. American Journal of Physiology- Cell Physiology 284, C1460-7.

Patchell, R.A. (2003). The management of brain metastases. Cancer Treatment Reviews 29, 533-40.

Patt, S., Labrakakis, C., Bernstein, M., Weydt, P., Cervós-Navarro, J., Nisch, G., and Kettenmann, H. (1996). Neuron-like physiological properties of cells from human oligodendroglial tumors. Neuroscience 71, 601-11.

Paukert, M., and Bergles, D.E. (2006). Synaptic communication between neurons and ng2+ cells. Current Opinion in Neurobiology 16, 515-21.

Persson, A.I., Petritsch, C., Swartling, F.J., Itsara, M., Sim, F.J., Auvergne, R., Goldenberg, D.D., Vandenberg, S.R., Nguyen, K.N., Yakovenko, S., et al. (2010). Nonstem cell origin for oligodendroglioma. Cancer Cell 18, 669-82.

Peters, A. (2004). A fourth type of neuroglial cell in the adult central nervous system. Journal of Neurocytology 33, 345-57.

Pollack, I.F. (1994). Brain tumors in children. New England Journal of Medicine 331, 1500-7. 
Pollack, I.F., and Jakacki, R.I. (2011). Childhood brain tumors: Epidemiology, current management and future directions. Nat Rev Neurol 7, 495-506.

Rettig, J., Heinemann, S.H., Wunder, F., Lorra, C., Parcej, D.N., Oliver Dolly, J., and Pongs, O. (1994). Inactivation properties of voltage-gated $\mathrm{k}+$ channels altered by presence of [beta]-subunit. Nature 369, 289-94.

Reya, T., Morrison, S.J., Clarke, M.F., and Weissman, I.L. (2001). Stem cells, cancer, and cancer stem cells. Nature 414, 105-11.

Reynolds, B.A., and Rietze, R.L. (2005). Neural stem cells and neurospheres- reevaluating the relationship. Nature Methods 2, 333-6.

Reynolds, B.A., and Weiss, S. (1992). Generation of neurons and astrocytes from isolated cells of the adult mammalian central nervous system. Science $255,1707-10$.

Richardson, G.D., Robson, C.N., Lang, S.H., Neal, D.E., Maitland, N.J., and Collins, A.T. (2004). Cd133, a novel marker for human prostatic epithelial stem cells. Journal of Cell Science 117, 3539-45.

Rountree, C.B., Ding, W., He, L., and Stiles, B. (2008). Expansion of cd133 expressing liver cancer stem cells in liver specific pten deleted mice. Stem Cells In press, stemcells.2008-0332.

Roy, M.L., Saal, D., Perney, T., Sontheimer, H., Waxman, S.G., and Kaczmarek, L.K. (1996). Manipulation of the delayed rectifier kv1.5 potassium channel in glial cells by antisense oligodeoxynucleotides. Glia 18, 177-84.

Rushing, E.J., Sandberg, G.D., and Horkayne-Szakaly, I. (2010). High-grade astrocytomas show increased nestin and wilms's tumor gene (wt1) protein expression. International Journal of Surgical Pathology 18, 255-9.

Salvati, M., Formichella, A., D'Elia, A., Brogna, C., Frati, A., Giangaspero, F., Delfini, R., and Santoro, A. (2009). Cerebral glioblastoma with oligodendrogliomal component: Analysis of 36 cases. Journal of Neuro-Oncology 94, 129-34.

Sanai, N., Alvarez-Buylla, A., and Berger, M.S. (2005). Neural stem cells and the origin of gliomas. The New England Journal of Medicine 353, 811-22. 
Sanai, N., Chang, S., and Berger, M.S. (2011). Low-grade gliomas in adults. Journal of Neurosurgery 115, 948-65.

Schaarschmidt, G., Wegner, F., Schwarz, S.C., Schmidt, H., and Schwarz, J. (2009). Characterization of voltage-gated potassium channels in human neural progenitor cells. PLoS ONE 4, e6168.

Schindelin, J. (2008). Fiji is just imagej (batteries included).

Schmidt, K., Eulitz, D., Veh, R.d.W., Kettenmann, H., and Kirchhoff, F. (1999). Heterogeneous expression of voltage-gated potassium channels of the shaker family (kv1) in oligodendrocyte progenitors. Brain Research 843, 145-60.

Schools, G.P., Zhou, M., and Kimelberg, H.K. (2006). Development of gap junctions in hippocampal astrocytes: Evidence that whole cell electrophysiological phenotype is an intrinsic property of the individual cell. Journal of Neurophysiology 96, 1383-92.

Schwab, A. (2001). lon channels and transporters on the move. Physiology 16, 29-33.

Seaberg, R.M., and van der Kooy, D. (2002). Adult rodent neurogenic regions: The ventricular subependyma contains neural stem cells, but the dentate gyrus contains restricted progenitors. The Journal of Neuroscience 22, 1784-93.

Seifert, G., and Steinhäuser, C. (2001). Ionotropic glutamate receptors in astrocytes. In Progress in brain research, B. Castellano Lopez, M.N.-S., ed. (Elsevier), pp. 287-99.

Shoshan, Y., Nishiyama, A., Chang, A., Mörk, S., Barnett, G.H., Cowell, J.K., Trapp, B.D., and Staugaitis, S.M. (1999). Expression of oligodendrocyte progenitor cell antigens by gliomas: Implications for the histogenesis of brain tumors. Proceedings of the National Academy of Sciences 96, 10361-6.

Simons, M., Krämer, E.-M., Thiele, C., Stoffel, W., and Trotter, J. (2000). Assembly of myelin by association of proteolipid protein with cholesterol- and galactosylceramiderich membrane domains. The Journal of Cell Biology 151, 143-54.

Singh, S.K., Clarke, I.D., Terasaki, M., Bonn, V.E., Hawkins, C., Squire, J., and Dirks, P.B. (2003). Identification of a cancer stem cell in human brain tumors. Cancer Research 63, 5821-8. 
Singh, S.K., Hawkins, C., Clarke, I.D., Squire, J.A., Bayani, J., Hide, T., Henkelman, R.M., Cusimano, M.D., and Dirks, P.B. (2004). Identification of human brain tumour initiating cells. Nature 432, 396-401.

Sivasankaran, B., Degen, M., Ghaffari, A., Hegi, M.E., Hamou, M.-F., lonescu, M.-C.S., Zweifel, C., Tolnay, M., Wasner, M., Mergenthaler, S., et al. (2009). Tenascin-c is a novel rbpjk-induced target gene for notch signaling in gliomas. Cancer Research 69, 458-65.

Sontheimer, H. (2008). An unexpected role for ion channels in brain tumor metastasis. Experimental Biology and Medicine 233, 779-91.

Sontheimer, H., Black, J.A., Ransom, B.R., and Waxman, S.G. (1992). Ion channels in spinal cord astrocytes in vitro. I. Transient expression of high levels of na+ and k+ channels. Journal of Neurophysiology 68, 985-1000.

Sontheimer, H., and Kettenmann, H. (1988). Heterogeneity of potassium currents in cultured oligodendrocytes. Glia 1, 415-20.

Stacey Nee, M., and Harald, S. (2000). Changes in ion channel expression accompany cell cycle progression of spinal cord astrocytes. Glia 30, 39-48.

Stallcup, W.B., and Beasley, L. (1987). Bipotential glial precursor cells of the optic nerve express the ng2 proteoglycan. Journal of Neuroscience 7, 2737-44.

Stallcup, W.B., and Huang, F.-J. (2008). A role for the ng2 proteoglycan in glioma progression. Cell Adh Migr. 2, 192-201.

Stupp, R., Mason, W.P., van den Bent, M.J., Weller, M., Fisher, B., Taphoorn, M.J.B., Belanger, K., Brandes, A.A., Marosi, C., Bogdahn, U., et al. (2005). Radiotherapy plus concomitant and adjuvant temozolomide for glioblastoma. The New England Journal of Medicine 352, 987-96.

Sugawara, K.-i., Kurihara, H., Negishi, M., Saito, N., Nakazato, Y., Sasaki, T., and Takeuchi, T. (2002). Nestin as a marker for proliferative endothelium in gliomas. Lab Invest 82, 345-51.

Svendsen, A., Verhoeff, J., Immervoll, H., Brøgger, J., Kmiecik, J., Poli, A., Netland, I., Prestegarden, L., Planagumà, J., Torsvik, A., et al. (2011). Expression of the progenitor 
marker ng2/cspg4 predicts poor survival and resistance to ionising radiation in glioblastoma. Acta Neuropathologica 122, 495-510.

Tamagno, I., and Schiffer, D. (2006). Nestin expression in reactive astrocytes of human pathology. Journal of Neuro-Oncology 80, 227-33.

Tammaro, P., Smirnov, S.V., and Moran, O. (2005). Effects of intracellular magnesium on kv1.5 and kv2.1 potassium channels. European Biophysics Journal 34, 42-51.

Tanner, D.C., Cherry, J.D., and Mayer-Pröschel, M. (2011). Oligodendrocyte progenitors reversibly exit the cell cycle and give rise to astrocytes in response to interferon-y. The Journal of Neuroscience 31, 6235-46.

Tascos, N., Parr, J., and Gonatas, N. (1982). Immunocytochemical study of the glial fibrillary acidic protein in human neoplasms of the central nervous system. Human Pathology 13, 454-8.

Toyama, T., Lee, V.M., Rorke, L.B., Marvin, M., McKay, R.D., and Trojanowski, J.Q. (1992). Nestin expression in embryonic human neuroepithelium and in human neuroepithelial tumor cells. Lab Invest 66, 303-13.

Tripathi, R.B., Clarke, L.E., Burzomato, V., Kessaris, N., Anderson, P.N., Attwell, D., and Richardson, W.D. (2011). Dorsally and ventrally derived oligodendrocytes have similar electrical properties but myelinate preferred tracts. The Journal of Neuroscience $31,6809-19$.

Trotter, J., Karram, K., and Nishiyama, A. (2010). Ng2 cells: Properties, progeny and origin. Brain Research Reviews 63, 72-82.

Tsujimura, T., Makiishi-Shimobayashi, C., Lundkvist, J., Lendahl, U., Nakasho, K., Sugihara, A., Iwasaki, T., Mano, M., Yamada, N., Yamashita, K., et al. (2001). Expression of the intermediate filament nestin in gastrointestinal stromal tumors and interstitial cells of cajal. The American journal of pathology 158, 817-23.

Uchida, K., Mukai, M., Okano, H., and Kawase, T. (2004). Possible oncogenicity of subventricular zone neural stem cells: Case report. Neurosurgery 55, 977-8 
Velasco, M., Dahl, D., Roessmann, U., and Gambetti, P. (1980). Immunohistochemical localization of glial fibrillary acidic protein in human glial neoplasms. Cancer 45, 48494.

Vescovi, A.L., Galli, R., and Reynolds, B.A. (2006). Brain tumor stem cells. Nat Rev Cancer 6, 425.

Vick, N.A., Lin, M.-J., and Bigner, D.D. (1977). The role of the subependymal plate in glial tumorigenesis. Acta Neuropathologica 40, 63-71.

Visvader, J.E. (2011). Cells of origin in cancer. Nature 469, 314-22.

von Deimling, A., Louis, D.N., von Ammon, K., Petersen, I., Hoell, T., Chung, R.Y., Martuza, R.L., Schoenfeld, D.A., Yaşargil, M.G., Wiestler, O.D., et al. (1992). Association of epidermal growth factor receptor gene amplification with loss of chromosome 10 in human glioblastoma multiforme. Journal of Neurosurgery 77, 295301.

Wan, F., Herold-Mende, C., Campos, B., Centner, F.-S., Dictus, C., Becker, N., Devens, F., Mogler, C., Felsberg, J., Grabe, N., et al. (2011). Association of stem cellrelated markers and survival in astrocytic gliomas. Biomarkers 16, 136-43.

Wang, D.D., Krueger, D.D., and Bordey, A. (2003). Biophysical properties and ionic signature of neuronal progenitors of the postnatal subventricular zone in situ. Journal of Neurophysiology 90, 2291-302.

Wang, J., Sakariassen, P.Ø., Tsinkalovsky, O., Immervoll, H., Ove, S., Svendsen, B.A., Prestegarden, L., Røsland, G., Thorsen, F., Stuhr, L., et al. (2007). Cd133 negative glioma cells form tumors in nude rats and give rise to cd133 positive cells. Cancer Cell Biology 122, 761-8.

Wang, J., Svendsen, A., Kmiecik, J., Immervoll, H., Skaftnesmo, K.O., Planagumà, J., Reed, R.K., Bjerkvig, R., Miletic, H., Enger, P.Ø., et al. (2011). Targeting the ng2/cspg4 proteoglycan retards tumour growth and angiogenesis in preclinical models of $\mathrm{gbm}$ and melanoma. PLoS ONE 6, e23062.

Wang, Y., Yang, J., Zheng, H., Tomasek, G.J., Zhang, P., McKeever, P.E., Lee, E.Y.H.P., and Zhu, Y. (2009). Expression of mutant p53 proteins implicates a lineage 
relationship between neural stem cells and malignant astrocytic glioma in a murine model. Cancer Cell 15, 514-26.

Wasseff, S.K., and Scherer, S.S. (2011). Cx32 and cx47 mediate oligodendrocyte:Astrocyte and oligodendrocyte:Oligodendrocyte gap junction coupling. Neurobiology of Disease 42, 506-13.

Wei, L.-C., Shi, M., Cao, R., Chen, L.-W., and Chan, Y.-S. (2008). Nestin small interfering rna (sirna) reduces cell growth in cultured astrocytoma cells. Brain Research 1196, 103-12.

Whyment, A.D., Coderre, E., Wilson, J.M.M., Renaud, L.P., O'Hare, E., and Spanswick, D. (2011). Electrophysiological, pharmacological and molecular profile of the transient outward rectifying conductance in rat sympathetic preganglionic neurons in vitro. Neuroscience 178, 68-81.

Wilhelmsson, U., Eliasson, C., Bjerkvig, R., and Pekny, M. (2003). Loss of gfap expression in high-grade astrocytomas does not contribute to tumor development or progression. Oncogene 22, 3407-11.

Wisoff, J.H., Sanford, R.A., Heier, L.A., Sposto, R., Burger, P.C., Yates, A.J., Holmes, E.J., and Kun, L.E. (2011). Primary neurosurgery for pediatric low-grade gliomas: A prospective multi-institutional study from the children's oncology group. Neurosurgery $68,1548-55$

Wu, Y., Liu, Y., Levine, E.M., and Rao, M.S. (2003). Hes1 but not hes5 regulates an astrocyte versus oligodendrocyte fate choice in glial restricted precursors. Developmental Dynamics 226, 675-89.

Yamada, H., Takano, T., Ito, Y., Matsuzuka, F., Miya, A., Kobayashi, K., Yoshida, H., Watanabe, M., Iwatani, Y., and Miyauchi, A. (2009). Expression of nestin mrna is a differentiation marker in thyroid tumors. Cancer letters 280, 61-4.

Ying, M., Wang, S., Sang, Y., Sun, P., Lal, B., Goodwin, C.R., Guerrero-Cazares, H., Quinones-Hinojosa, A., Laterra, J., and Xia, S. (2011). Regulation of glioblastoma stem cells by retinoic acid: Role for notch pathway inhibition. Oncogene 30, 3454-67. 
Yu, S.-C., Xiao, H.-L., Jiang, X.-F., Wang, Q.-L., Li, Y., Yang, X.-J., Ping, Y.-F., Duan, J.J., Jiang, J.-Y., Ye, X.-Z., et al. (2012). Connexin 43 reverses malignant phenotypes of glioma stem cells by modulating e-cadherin. Stem Cells 30, 108-20.

Yuan, X., Curtin, J., Xiong, Y., Liu, G., Waschsmann-Hogiu, S., Farkas, D.L., Black, K.L., and Yu, J.S. (2004). Isolation of cancer stem cells from adult glioblastoma multiforme. Oncogene 23, 9392-400.

Zhou, M., Schools, G.P., and Kimelberg, H.K. (2006). Development of glast(+) astrocytes and $\mathrm{ng} 2(+)$ glia in rat hippocampus ca1: Mature astrocytes are electrophysiologically passive. Journal of Neurophysiology 95, 134-43.

Zhu, X., Bergles, D.E., and Nishiyama, A. (2008). Ng2 cells generate both oligodendrocytes and gray matter astrocytes. Development 135, 145-57.

Zhu, X., Hill, R.A., Dietrich, D., Komitova, M., Suzuki, R., and Nishiyama, A. (2011). Age-dependent fate and lineage restriction of single ng2 cells. Development $138,745-$ 53.

Ziskin, J.L., Nishiyama, A., Rubio, M., Fukaya, M., and Bergles, D.E. (2007). Vesicular release of glutamate from unmyelinated axons in white matter. Nat Neurosci 10, 32130. 


\section{Appendix}

\subsection{Index of Figures}

Figure 1. NG2 and nestin protein expression in BTICs. Western blot using anti-NG2 specific antibodies shows the presence of a band at $\sim 280 \mathrm{kDa}$ in 5 out of $7 \mathrm{BTIC}$ lines tested. Mouse total brain protein was used as a positive control and mouse liver and the NG2 negative mouse melanoma cell lines were used as negative controls. A band at $\sim 240 \mathrm{kDa}$ was detected using an anti-nestin antibody in all BTICs. An antibody against calnexin $(\sim 90 \mathrm{kDa})$ was used as a loading control. Note a higher relative intensity of the NG2 band in \#10 and \#1034.

Figure 2. Membrane expression of NG2 In all BTIC lines, the amount of labeled cells was above $80 \%$ (red), as evidenced by the increase of fluorescence intensity above unlabeled controls (black). No shift in the mean fluorescence intensity was observed in B16 cells (lower right pane). The horizontal line shows an arbitrary gate to define percentage of positive cells above background fluorescence. $A U=$ Arbitrary Units.

Figure 3. BTICs co-express NG2 and PDGFRa. Representative images of cells labeled for NG (red) and PDGFRa (green). Note the peripheral localization of NG2 with a markedly uneven expression in some processes (left column). Scale bars $=10 \mu \mathrm{m} .19$

Figure 4. BTICs co-express nestin and NG2. Representative cells from each line labeled with specific anti-NG2 (green) and anti-nestin (red) antibodies. NG2 signal has a pattern compatible with a membrane staining showing enhancement in cellular processes. Nestin has an intracellular localization. An exemplary line \#1034, is shown in an enlarged display (top row) to better appreciate the structural details. TO-PRO-3 (TP3) was used as a nuclear marker (blue). Scale bars $=20 \mu \mathrm{m}$.

Figure 5. GFAP ${ }^{+}$cells express NG2. NG2 signal (green) is observed in the majority of \#1034 cells (right, middle panel), whereas GFAP (red) is expressed in a subpopulation of cells (right, top panel). In $\mathrm{GFAP}^{+} / \mathrm{NG}^{+}$cells (left panel), the expression of the GFAP seems to be confined to the intracellular compartment, while 
the NG2 signal is more abundant in the periphery. Nuclei were counterstained with TOPRO-3 (blue). Scale bars $=20 \mu \mathrm{m}$

Figure 6. $\mathrm{GFAP}^{+}$cells express nestin. $\mathrm{GFAP}^{+}$cells (red) from \#10 (top row) and \#1034 (bottom row) co-expressed the NSC-marker nestin (green). All GFAP-cells were also nestin ${ }^{+}$. Nuclei were counterstained with TO-PRO-3 (blue). Scale bars $=20 \mu \mathrm{m} . ~ .22$

Figure 7. Differentiation potential of BTICs A. Representative confocal image of \#1034, showing $\mathrm{GFAP}^{+}$cells (red) after 5 days in neurobasal medium (NB, left panel) or NB supplemented with $10 \%$ FCS (FCS, right panel). B. The increase in the GFAP ${ }^{+}$ population was also observed when the medium was supplemented with T3, CNTF or Forskolin (FORS). No NeuN or MBP was detected in any of the conditions. 23

Figure 8. Differentiation of mouse OPCs. After 5 days in the presence of T3, mouse OPCs express MBP and reduce the number of $\mathrm{NG}^{+}$cells (middle upper row). No differences are observed in the number of GFAP or NeuN expressing cells (lowermost row). Scale bars $=50 \mu \mathrm{m}$ 25

Figure 9. Intermediate membrane resistance of BTICs. A. Representative voltage response to a stepwise current injection in $\# 10(n=8)$. The red line represents the best linear fit to the data. The dotted line represents $95 \%$ confidence intervals. B. Slope of the curve (as in A) for all cell lines tested. Asterisks represent zeros after the decimal point in the value of $p$ and are only displayed for values where $p<0.05$. Error bars in $B$ represent standard error of the mean (s.e.m.)

Figure 10. Transient inward currents in BTICs. A. Current response of a representative \#1095 cell (upper panel) to variable voltage steps from a holding potential of $-80 \mathrm{mV}$ (lower panel). The current has fast activating and fast inactivating components and reaches steady-state towards the end of the pulse. Note the presence of a fast transient current in the first few milliseconds of the voltage pulse (upper panel, inset). B. Inward current elicited in response to a depolarization to $0 \mathrm{mV}$, from a holding potential of $-60 \mathrm{mV}$ (lower panel). C. Current density values of the inward current of individual cells in all cell lines tested. Red lines represent the mean. 28

Figure 11. Voltage dependence of transient inward currents A. Current - Voltage (I$\mathrm{V})$ relationship of the transient inward current exhibits a similar behavior in all BTIC lines. B. No significant differences between lines were observed in half maximal activation or reversal potential (C.). Error bars represent standard error of the mean. 29 
Figure 12. Transient inward currents are sensitive to TTX. A. Current response of a \#1095 cell to a voltage stimulus of $0 \mathrm{mV}$ from a holding potential of $-80 \mathrm{mV}$ (bottom panel). The control response (uppermost panel) can be blocked by applying $500 \mathrm{nM}$ TTX to the bath solution (middle upper panel) and can be reverted by removal of the toxin (middle lower panel). To better illustrate the effect of TTX on the sodium current, a cell with low outward current density was used. B. TTX blocked above $95 \%$ of the current in all cell lines tested. Error bars represent standard error of the mean.

Figure 13. Expression pattern of voltage-gated sodium channels in BTICs. A. Immunostaining using an antibody against a common epitope of voltage-gated sodium channels (Pan-Na, green) revealed a signal cluster adjacent to cell nuclei (blue) and in some lines it could be observed as a clear membrane staining (\#10 and \#1063). The cells were identified by staining the nuclei with TO-PRO3 (TP3, blue). Scale bars $=50$ $\mu \mathrm{M}$. B. Two methods, electrophysiology (EP) and immunocytochemistry (ICC) were used to determine the percentage of positive cells. A discrepancy between the two methods was observed in lines \#1095 and \#1051, probably due to the different sensitivity of both techniques. The asterisks represent a $p$ value $<0.05$. Error bars represent standard error of the mean 31

Figure 14. Outward regenerative voltage transients. A. Voltage response to a stepwise current injection protocol shown in $B$. Note the appearance of a single, broad voltage transient at the beginning of the pulse in response to larger current injection. 32

Figure 15. Biophysical parameters of regenerative voltage transients $A$. Representative voltage trace from a \#1034 cell, showing a schematic representation of the reference points used to measure different biophysical parameters. The mean values for absolute regenerative transient peak $(B)$, relative overshoot $(C)$, relative afterhyperpolarization (D) and transient width $(E)$, are represented for each cell line. Error bars represent standard error of the mean.

Figure 16. Speed of the regenerative voltage transient. A. Representative regenerative voltage transient of a $\# 10$ cell (left panel) and its respective differential ( $B$ left panel). The regenerative transient is much slower than mouse granule cell neurons ( $A$ and $B$, right panel). Note the large difference in the scale bars. C. Speed of the regenerative transient represented in terms of its differential as maximum rate of rise (MRR) and maximum rate of fall (MRF). No significant differences were observed between lines. The MRR and MRF of neurons were $>20$ fold larger than that of BTICs. 
Asterisks represent $p$ values $<0.05$. Error bars represents standard error of the mean.

Figure 17. Sodium and potassium channel density and transient generation. The sodium and potassium channel density was compared in cells that exhibited transients and cells that did not, for \#10 (upper left panel), \#1063 (upper right panel), \#1095 (lower left panel) and \#1051 (lower right panel). Significance was calculated using unpaired t-test. The asterisks represent zeros after the decimal point for $p$ value $<0.05$. n.s. $=$ non-significant. Error bars represent standard error of the mean. 37

Figure 18. Regenerative voltage transients are sensitive to TTX. Representative voltage transient in a \#1095 cell (black) was abolished by the application of 500nM TTX (red).

Figure 19. $I_{K D R}$ is blocked by TEA. A. Representative current response to a voltage pulse to $40 \mathrm{mV}$ (lower panel), before and after the application of $10 \mathrm{mM}$ TEA. B. The current was blocked to about $70 \%$ in all cell lines. Error bars represent standard error of the mean.

Figure 20. $I_{K D R}$ density. A. Representative current response of a \#10 cell (upper panel) to variable voltage stimuli (lower panel). Note that the current towards the end of the pulse is larger by depolarization to $40 \mathrm{mV}$ than to $100 \mathrm{mV}$ (arrows). B. I $\mathrm{KDR}_{\text {density }}$ at $40 \mathrm{mV}$ of individual cells, for all cell lines tested. Red lines represent the mean value.

Figure 21. Voltage dependence of $I_{K D R}$. A. I-V relationship of $I_{K D R}$, notice the rectification at $\sim 40 \mathrm{mV}$ and a similar behavior in all cell lines. No differences were observed in half maximal activation potential ( $\mathrm{B}$, upper panel) or half maximal block potential (B, lower panel). Error bars represent standard error of the mean.

Figure 22. Kv1.5 expression in BTICs. A specific anti Kv1.5 antibody (red) produced a staining in the cell periphery in all cell lines tested. Nuclei were labeled with TO-PRO3 Scale bars $=20 \mu \mathrm{m}$.

Figure 23. Rectification of $\mathrm{I}_{\mathrm{KDR}}$. A. I-V relationships of rectifying (open circles) and non-rectifying (solid circles) \#1095 cells. B. The majority of the cells in all groups had rectification. C. Significant differences were found in the current density at $40 \mathrm{mV}$ in \#1063 and \#1095 between cells with (white) and without (black) rectification. D. 
Normalized I-V relationship of \#10 cells in the presence (solid circles) or absence (open circles) of intracellular magnesium. Solid lines represent a fit to the data. Error bars represent standard errors of the mean and are in some cases obscured by the markers. Asterisks represent $p$ value $<0.05$.

Figure 24. Peak current density and decay of $I_{K A} A$. Representative current responses of a \#1095 cell to its corresponding voltage protocols (B). A transient outward current can be isolated by subtracting $I_{K D R}(A$, middle panel) from the mixed current (A, left panel). C. Peak current density of individual cells at $100 \mathrm{mV}$. Red lines represent mean value. D. No significant differences were found in the inactivation time constants of $\mathrm{I}_{\mathrm{KA}}$. Error bars represent standard error of the mean.

Figure 25. Voltage dependent activation and time to peak current in $\mathrm{I}_{\mathrm{KA}}$. A. Similar I$V$ relationships of isolated $I_{K A}$ were observed in all cell lines tested. Solid lines represent a fit to the data. The half maximum activation potential ( $\mathrm{B}$, upper panel) and the time to peak current (B, lower panel) showed no significant differences. Error bars represent standard error of the mean 44

Figure 26-27. Voltage dependent inactivation $(\boldsymbol{h} \infty)$ of $\mathrm{I}_{\mathrm{KA}}$. A. Representative current trace of a \#1095 cell upon stimulation to $100 \mathrm{mV}$ after variable voltage pre-pulses (B). C. Peak current to pre-pulse voltage relationship with similar half inactivation potential for all lines (D). Error bars represent standard error of the mean.

Figure 28. Cyclothiazide (CTZ) potentiates AMPA currents in BTICs. A. An inward current was observed when AMPA $(150 \mu \mathrm{M})$ was applied to the bath solution. B. The AMPA current was potentiated by application of CTZ. C. Normalized mean current showing a significant increase (up to 20 fold) in the AMPA mediated current by CTZ. The effect was observed in all cell lines tested. Asterisks represent zeroes after the decimal point for $p$ values $<0.05$. Error bars represent standard error of the mean. .... 46

Figure 29. BTICs express GluR1 and have a linear $\mathrm{I}_{\mathrm{AMPA}}-\mathrm{V}$ relationship. A. AMPA elicited inward or outward currents depending on the holding potential. B. The normalized $I_{A M P A}$ exhibited a linear I-V relationship. Error bars represent standard errors of the mean C. Immunostaining of GluR1 (green) showing a punctate signal in all cells. Note that neuronal cultures from primary hippocampus (lowermost panel, right) have a heterogeneous staining. Nuclei were stained with TOPRO-3 (blue). Scale bars $=20$ $\mu \mathrm{m}$. 
Figure 30. No dye coupling in BTICs. Representative \#1051 cell showing no dyecoupling with neighboring cells after injection with lucifer yellow in a 10 minute time span (upper row). In mouse astrocytes (lower row), a fluorescent signal was detected in near-by cells (arrow heads) besides the injected one (arrow) after the same time period. 48 


\subsection{Index of Tables}

Table 1. Classification of astrocytic tumors and their correspondent WHO grading. Adapted from the 2007 WHO Classification of Tumours of the Central Nervous System

(Louis et al., 2007b) 3

Table 2. Cell culture supplements, growth factors and reagents ......................... 68

Table 3. Cell lines, culture media and supplements .....................................6 69

Table 4. Reagents for immunocytochemistry ................................................. 72

Table 5. Antibodies for immunocytochemistry ................................................ 72

Table 6. Solutions for electrophysiological recordings .................................... 76

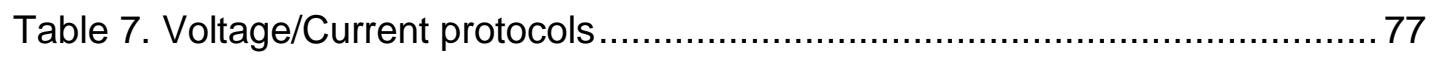

Table 8. Pharmacological tools and reagents for electrophysiology ….................. 78

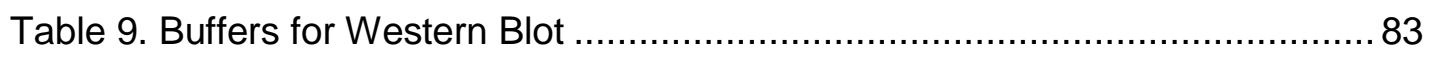

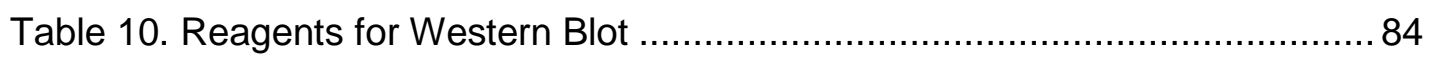

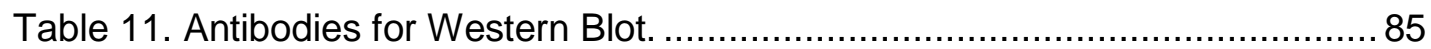




\section{Acknowledgements}

I would like to thank Prof. Dr. Walter Stühmer for the opportunity to conduct my $\mathrm{PhD}$ thesis in his laboratory, for exciting discussion about scientific and non-scientific subjects and for being not only a great boss, but a great person. My most sincere gratitude to Prof. Dr. Luis Pardo for his supervision, inspiration, guidance and discussion, but also for being a role model scientist, a mentor and a friend.

To our collaborators Dr. Ella Kim, Prof. Dr. Alf Giese and Christoph Schmidt-Salue many appreciations for the excellent team work.

I would like to thank the members of my thesis committee Prof. Dr. Tobias Moser and Dr. Till Marquardt for always finding time to assist to the meetings and for helping to shape my project. Thanks also to the members of the extended thesis committee Prof. Dr. Mikael Simons, Prof. Dr. Karsten Hanisch and Prof. Dr. Michael Hörner for accepting so willingly to participate in the last, but one of the most important steps of the PhD. To Prof. Hörner together with Sandra Drube I also want to thank for all the help provided in the frame of the IMPRS Neuroscience Program; they made of the whole integration experience a very soft process!

I am grateful to the GGNB and the IMPRS Programs for believing in me and allowing me to carry my post-graduate studies in Göttingen. Without this platform I couldn't have fulfilled my dream of becoming a scientist. Thanks for providing opportunity to so many people.

I would also like to thank my co-workers and friends at the Department of Molecular Biology of Neuronal Signals and other departments of the Max-Planck Institute of experimental Medicine. The scientific and personal quality in this institute made my time here an unforgettable experience.

It wouldn't have been possible to successfully complete my studies here without the support of my family. Thank you all. Sünke, who went together with me through this process and became my wife, I love you. To my father Hugo and my grandfather Tilo for inspiring me and being the model of the person I want to become. To my mother Marta for loving me from the distance. To my brother Bernal, my sisters Alejandra and Adriana, my nieces and nephews: Mariana, Alejandro, José Andrés and Fiorela, thanks for making home a magical place. Finally thanks to my second mom and dad: Gisela and Uwe, for giving me a second home and a second family. 


\section{Curriculum Vitae}

\section{Alonso Barrantes-Freer, M.D.}

Department of Molecular Biology of Neuronal Signals AG Oncophysiology

Max-Planck Institute of experimental Medcine

Hermann-Rein-Straße 3

37075 Göttingen

Tel: +49 (0) $5513899-635$

Fax: +49 (0) $5513899-644$

Email: barrantes@em.mpg.de

Personal Information

Birth date / place

Citizenship

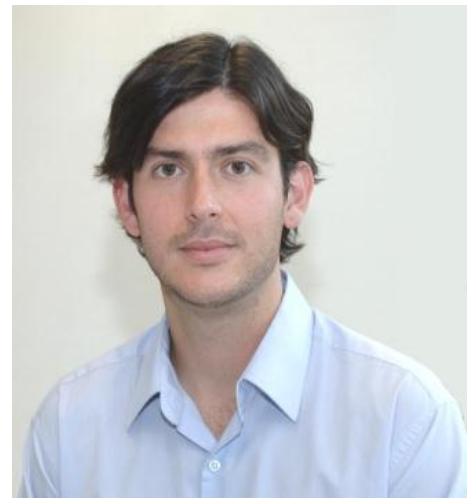

May $15^{\text {th }} 1981$ San José, Costa Rica

Costarican

\section{Education}

PhD student

10/08 - Present

Max-Planck Institute of experimental Medicine

Department of Molecular Biology of Neuronal Signals / AG Oncophysiology

International Max-Planck Research School (IMPRS)

Neuroscience, Göttingen

MSc. Student

$09 / 07-10 / 08$

International Max-Planck Research School (IMPRS)

Neuroscience, Göttingen. Grade 1,33

Colegiatura (Medical licence Costa Rica)

03/07

Colegio de Médicos y Cirujanos de Costa Rica

Doctor y Licenciatura en Medicina y Cirugía (M.D)

02/07

Universidad de Costa Rica. Final grade: 86 / 100

Bachillerato en Ciencias Médicas (BSc.)

09/04

Universidad de Costa Rica

Bachillerato en Educación Media (High School Diploma)

Colegio Bilingüe Saint Paul, Costa Rica.

Bachiller con Excelencia. Final grade 91,96 / 100 


\section{Scientific Activities}

Phd Project: Electrophysiological identification of

10/08 - Present

cellular subpopulatios in human Glioblastoma

Supervisors: Prof. Dr. Walter Stühmer / Prof. Dr. Luis Pardo

Max Planck Institute of experimental Medicine, Göttingen

Laboratory rotation: Iidentification of regulatory elements

$05 / 08-06 / 08$

In fast and slow motrneurons

European Neuroscience Institute, Göttingen

Dr. Till Marquardt

Laboratory rotation: Subcellular localization and electrophysiological

$03 / 08-04 / 08$

Properties of the "split" ion channel Eag1-Venus

Max Planck Institute of experimental Medicine, Göttingen

Prof. Dr. Luis Pardo

Laboratory rotation: Role of Pejvakin in the auditory System

$01 / 08-03 / 08$

„InnenOhrLabor" Universitätsklinikum Göttingen

Prof. Dr. T. Moser

Research assistant in Programa de Investigación en Neurociencia

$01 / 07-07 / 07$

(Neuroscience Research Program)

Universidad de Costa Rica, Costa Rica

Research assistant in Programa Nacional de Tamizaje Neonatal

y Alto Riesgo. (Center for genetic and metabolic diseases)

Hospital Nacional de Niños, Costa Rica

Research assistant: Epidemiology of neurodegenerative

$05 / 02-01 / 04$

Diseases (Parkinson and Alzheimer).

Universidad de Costa Rica, Costa Rica

Practical Medical Experience

Medic. Ambulant Medical Service (EBAIS)

$4 / 07$

In the Chirripó-Cabécar Aboriginal Territory

Grano de Oro, Turrialba, Costa Rica.

Practical Year (Internado)

National admission Test for the practical year

10/06

(Place 23 of 450 )

Pediatrics

Hospital Nacional de Niños

01/06-03/06 
Internal medicine

Social medicne

Surgery

Gynecology and Obstetrics
Hospital Calderón Guardia

03/06-05/06

Chirripó-Cabécar Indianergebiet

Hospital San Juan de Dios

Hospital San Juan de Dios
$06 / 06-08 / 06$

$08 / 06-10 / 06$

$10 / 06-12 / 06$

\section{Teaching Experience}

Tutorials

WS $09 / 10$ und 10/11 SoSe 10/11

„Principles of Electrophysiology“

IMPRS Neuroscience, Göttingen

Supervision of Laboratory Rotations

WS $09 / 10$ und 10/11 SoSe 10/11

IMPRS Neuroscience, Göttingen

Lecturer : Tropical medicine

05/08

Universidad Veritas, Costa Rica

\section{Stipends}

GGNB Excellence Stipend

05/09 - Present

PhD Stipend from the the Max- Planck-Society

$10 / 08-05 / 09$

Stipend of the Excellence Foundation for the Promotion

09/07-07/08

of the Max-Planck Society

Beca de Internado CENDEISSS (Stipend for the practical clinical year) $\quad$ 01/06 - 12/06

Beca de Estímulo Universidad de Costa Rica

$03 / 99-12 / 06$

University stipend for good performance in the university admission test

Grade: 725 / 800

\section{Publications}

Mortensen LS, Sakaba T, Schmidt H, Barrantes-Freer A, Ufartes R, Eilers J, Stühmer W, Pardo LA. Loss of Eag1 causes increased $\mathrm{Ca} 2+$ influx into the presynaptic terminal. 2012, in preparation

Barrantes-Freer A., Kim E., Bielanska J., Giese A., Mortensen S., Stühmer W, Pardo LA. Functional properties of the plasma membrane of human glioma initiating cells. In preparation. 2012

Kim E., Richter C., Barrantes-Freer A., Prüfer J., Schmitz-Salue C., Valbuena P., Rippl M., Gunawan B., Rave-Fränk M., Schulz-Schaeffer W., Giese A.. Novel insights into the biology of stem-like brain tumor initiating cells derived from glioma cell lines. Submitted. 201s

Barrantes-Freer et al. Embarazo y aborto en adolescente. Med. leg. Costa Rica v.20 n.1 mar.2003 